\title{
CANCER-RELATED FATIGUE: THE ROLE OF DEMOGRAPHIC AND MEDICAL \\ FACTORS, SYMPTOM SEVERITY, ILLNESS PERCEPTIONS, AND COPING \\ STRATEGIES IN TESTING LEVENTHAL'S COMMON SENSE MODEL IN OVARIAN \\ CANCER PATIENTS
}

by

Crystal Hare, BSc.

Bachelor of Arts, University of Calgary, 2015

Bachelor of Science, University of Lethbridge, 2010

\author{
A thesis \\ presented to Ryerson University \\ in partial fulfillment of the \\ requirements for the degree of \\ Master of Arts \\ in the program of Psychology
}

Toronto, Ontario, Canada, 2017

(C) Crystal Hare, 2017 


\section{AUTHOR'S DECLARATION FOR ELECTRONIC SUBMISSION OF A THESIS}

I hereby declare that I am the sole author of this thesis. This is a true copy of the thesis, including any required final revisions, as accepted by my examiners.

I authorize Ryerson University to lend this thesis to other institutions or individuals for the purpose of scholarly research.

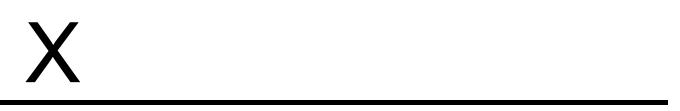

I further authorize Ryerson University to reproduce this thesis by photocopying or by other means, in total or in part, at the request of other institutions or individuals for the purpose of scholarly research. I understand that my thesis may be made electronically available to the public.

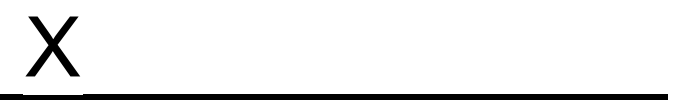




\title{
Cancer-Related Fatigue: The Role of Demographic and Medical Factors, Symptom Severity, Illness Perceptions, and Coping Strategies in Testing Leventhal's Common Sense Model in Ovarian Cancer Patients
}

\author{
Crystal Hare \\ Master of Arts \\ Psychology \\ Ryerson University
}

2017

\begin{abstract}
Cancer-related fatigue (CRF) is the most common symptom among cancer patients. Up to $58 \%$ of ovarian cancer $(\mathrm{OC})$ patients report debilitating fatigue. Yet, the risks for developing CRF remain poorly understood. The way patients' perceive and cope with their symptoms may help to understand CRF. Leventhal's Common Sense Model of Illness Perceptions was used to evaluate the effects of patients' cancer-related perceptions on fatigue, using positive and negative coping strategies as mediators. OC patients $(N=283)$ completed self-report questionnaires. Results revealed that younger age, being unemployed, and greater anxiety, pain, nausea, and sleep dissatisfaction were associated with worse fatigue. Additionally, two illness perceptions, greater illness identity and consequences, were associated with worse fatigue. Indirect effect analyses revealed personal and treatment control to have an indirect effect on fatigue through positive coping. Implications for the CRF literature and relevance to OC patients are discussed.
\end{abstract}




\section{Acknowledgements}

First, and foremost I would like to thank Dr. Tae Hart for their support, guidance, patience, and continuous encouragement over the last two years. I could not ask for a better mentor to help me navigate this academic journey. Your unwavering support, especially when I've made mistakes, has encouraged me to not be afraid to work toward what ever goals inspire me. I would also like to thank Dr. Colleen Carney for all the research and learning opportunities I have received through my work with the Sleep and Depression Lab. Tae and Colleen, you have both been instrumental to my academic, research, and clinical success thus far, and I am very much looking forward to continuing to learn from you in the future. I would also like to thank Dr. Trevor Hart for taking the time to share his expertise and insights. Thank you for all the time and work you have all invested in this project.

Thank you to the Psychosocial Medicine Lab_Cassie and Lindsey_for your guidance in everything from course selection, statistical analyses, to selecting the best practicum placement. Also a big thanks to the Sleep and Depression Lab, which has been a great environment for learning the protocols and processes required to conduct a research trial.

I would like to also thank my family. My mom and my sisters have been a constant source of emotional support while I went through the steep learning curve that is the first year of a Master's degree in Clinical Psychology. My extended family here in Toronto became my surrogate mom, dad, sister and brother the moment I arrived. Finally, I would like to thank Andrew. Thank you for all the gourmet meals you have cooked when I was too busy to worry about eating healthy, and for reminding me to have fun, even when fun didn't fit in my schedule. You keep me healthy and happy. 


\section{Table of Contents}

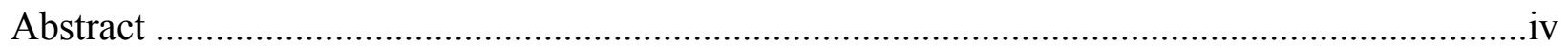

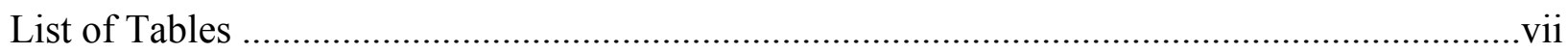

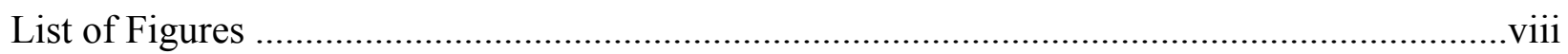

Cancer-Related Fatigue (CRF) ...................................................................................

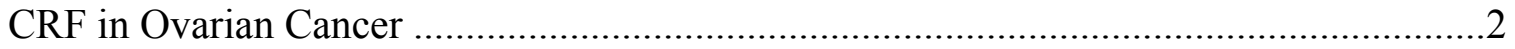

Underlying Mechanisms of CRF .........................................................

Leventhal's Common Sense Model (CSM) of Illness Perceptions .........................................10

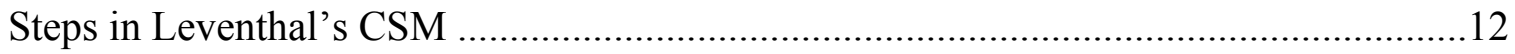

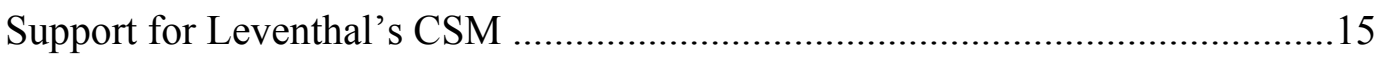

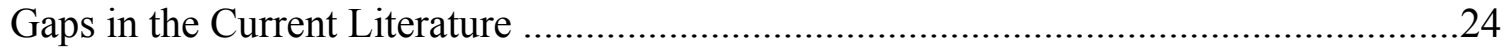

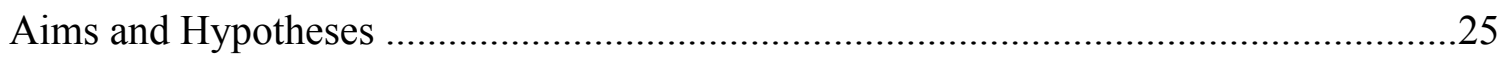

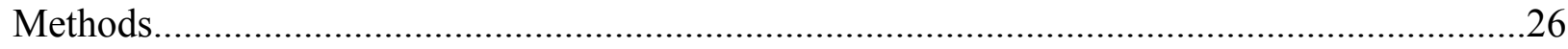

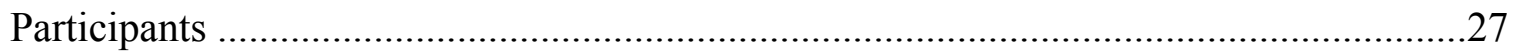

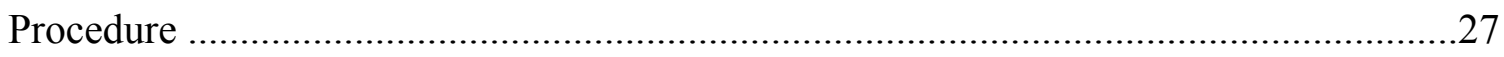

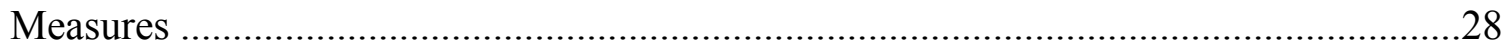

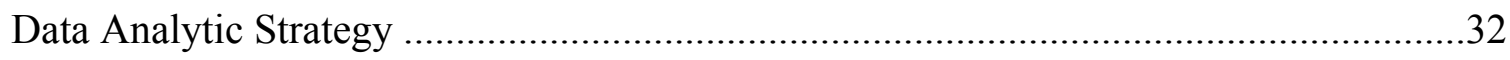

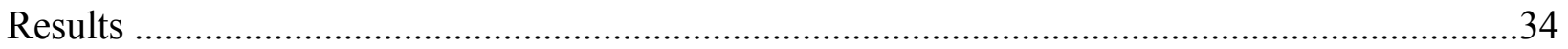

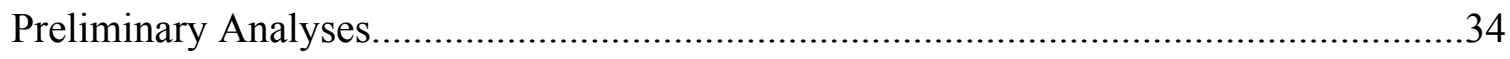

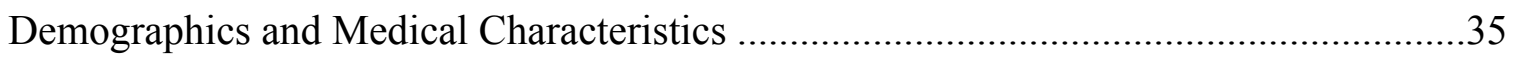

Descriptive Information on Key Variables ….....................................................

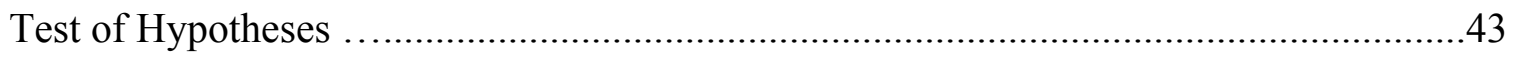

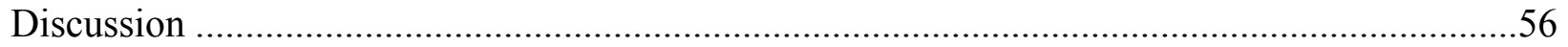


Sample Description

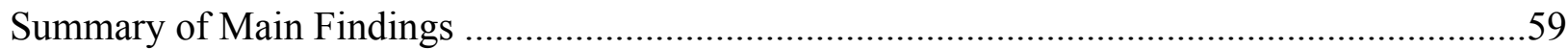

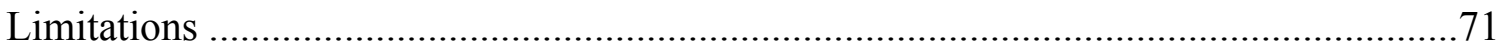

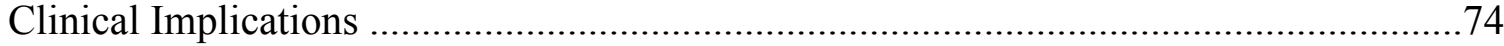

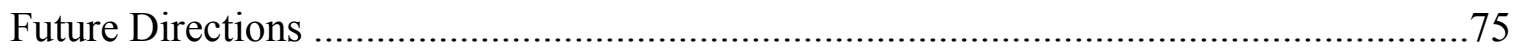

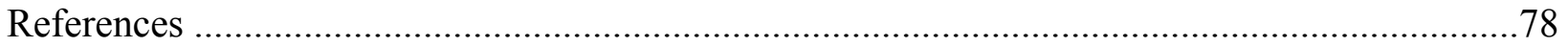




\section{List of Tables}

Table 1: Illness perceptions according to Leventhal's Common Sense Model with examples from the Illness Perception Questionnaire-Revised ....................................................14

Table 2: Positive and negative coping strategies, with description and example items from The Brief COPE Short-Form ........................................................................... 16-17

Table 3: Questionnaires assessing each step in Leventhal's Common Sense Model ..................28

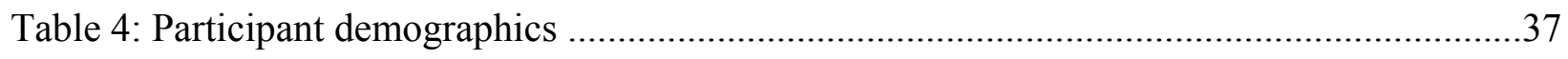

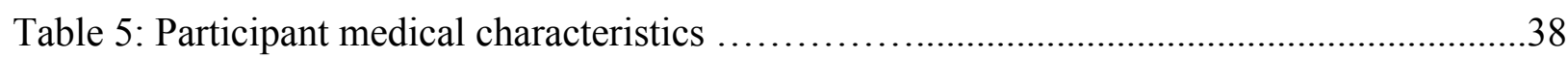

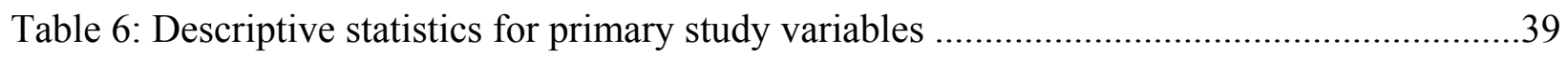

Table 7: Factor loadings for exploratory factor analysis with varimax rotation of Brief-COPE

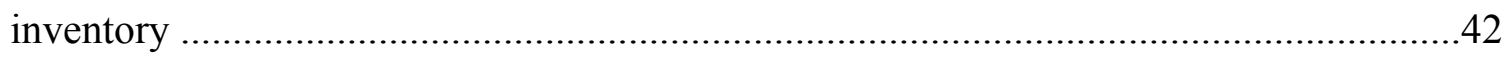

Table 8: Associations of demographic, medical, and symptom variables with fatigue................45

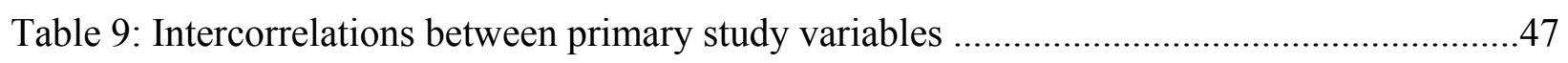

Table 10: Summary of linear regression analysis for variables predicting fatigue severity..........48

Table 11: Bootstrapping analyses examining the indirect effect of positive and negative coping strategies on the relationship between illness perceptions and fatigue severity ..........49-51 


\section{List of Figures}

Figure 1: Leventhal's Common Sense Model ......................................................................11

Figure 2: Leventhal's Common Sense Model applied to fatigue ............................................12

Figure 3: Indirect effects of coping strategies on the relationship between personal control and

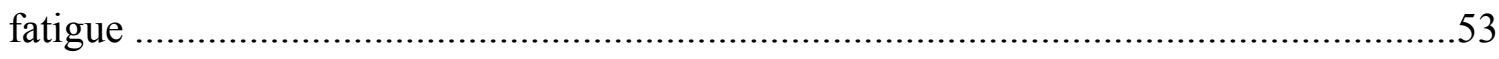

Figure 4: Indirect effects of coping strategies on the relationship between treatment control and

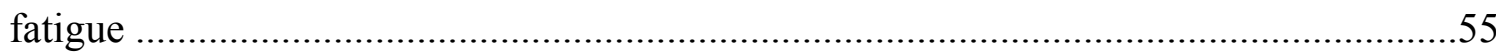


Fatigue is a common physical and/or cognitive complaint experienced by the general population. Physical fatigue is often perceived as a sense of physical tiredness, weakness, or exhaustion, with greater effort being required to accomplish a task, resulting in reduced activity (Hofman, Ryan, Figueroa-Moseley, Jean-Pierre, \& Morrow, 2007). In comparison, mental fatigue is often described as a reduced capacity to maintain attention or concentration, which can disrupt learning, short-term memory, and result in reduced motivation to complete cognitive tasks (Ryan et al., 2007). Fatigue within the general population is attributed to a number of factors, including work-related stress (Bültmann, Kant, Schröer, \& Kasl, 2002), cognitive or physical over-exertion (e.g., prolonged periods of concentration or physical labour) or physical health issues (e.g., anemia or immune system activation in response to infection; Appels \& Mulder, 1989; Trojan et al., 2007). However, increased periods of regenerative activities (e.g., rest or sleep) are typically adequate to ameliorate fatigue within the general population.

\section{Cancer-Related Fatigue (CRF)}

The clinical features of fatigue specific to the cancer experience, termed cancer-related fatigue $(\mathrm{CRF})$, overlap with the features of fatigue described within the general population, including diminished physical performance or effort with increased periods of inactivity, difficulty concentrating and reduced memory capacity, with reduced ability to complete day-today tasks (Horneber, Fischer, Dimeo, Rüffer, \& Weis, 2012). However, CRF is different from fatigue experienced by the general population, in that it is not alleviated by periods of rest or regeneration (Ancoli-Israel, Moore, \& Jones, 2001; Piper \& Cella, 2010). CRF often results in feelings of helplessness, higher distress, as well as anxiety and depressed mood; negatively impacting work, social relationships, mood, sleep-wake cycles and daily activities (Andrykowski, Donovan, Laronga, \& Jacobsen, 2010; Bower, Lamkin, \& Manuscript, 2012; 
Brown, Barsevick, Newhall, \& Manuscript, 2008; Horneber et al., 2012; Prue, Rankin, Allen, Gracey, \& Cramp, 2006; Weis, 2011). CRF has been found at all stages of the cancer diagnosis and treatment trajectory, being reported by approximately $40 \%$ of patients diagnosed with cancer (Horneber et al., 2012), and up to $90 \%$ of patients undergoing chemotherapy or radiation treatment (Bardwell \& Ancoli-Israel, 2008; Hofman et al., 2007; Seo, Oh, \& Seo, 2010). It typically appears in a cyclical pattern during each round of chemotherapy or radiation therapy, followed by a gradual decline after treatment has completed (Dhruva et al., 2010). Yet, CRF can also persist for months or years following the completion of treatment in up to one-third of cancer patients (Minton, Alexander, \& Stone, 2012), making it the most common and problematic symptom among long-term cancer survivors (Bower, Ganz, \& Aziz, 2005), resulting in the greatest interference in quality of life (Fagundas et al., 2011).

\section{CRF in Ovarian Cancer}

An estimated 22,440 women in the United States (Cancer Statistics Review, 2017), and 2,800 women in Canada (Canadian Cancer Society, 2017), will be diagnosed with ovarian cancer in 2017, with 70\% being diagnosed with advanced stage cancer (Stage III or IV; Anderson \& Hacker, 2008). Yet, little research has examined fatigue among ovarian cancer patients, despite evidence to suggest this group may be at greater risk for developing CRF compared to other cancer populations (Anderson \& Hacker, 2008; Holzner et al., 2003; Payne, 2002). Fatigue is reported as a significant and debilitating side effect in $24-58 \%$ of ovarian cancer patients (Cella et al., 2003; Goff et al., 2004; Holzner et al., 2003), with up to $37 \%$ of patients experiencing significant fatigue and negative impacts lasting far beyond the completion of treatment (Holzner et al., 2003). 
Underlying mechanisms of CRF. Although CRF is one of the most prevalent symptoms in cancer patients and survivors, the mechanisms underlying this chronic and debilitating condition are still poorly understood. The causal mechanisms underlying the onset, maintenance, and severity of CRF may be associated with the cancer itself (e.g., presence and metastasis of the tumour), or cancer treatments (e.g., chemotherapy, radiation therapy, hormonal therapy, surgical removal of tumour); both of which increase patient susceptibility to a number of conditions linked with fatigue, including physiological distress (e.g., pain, nausea, vomiting), neutropenia (lack of sufficient neutrophils in the blood, leading to increased susceptibility to contagion), anemia, infection, and malnourishment (Mitchell, 2010). These predisposing factors appear to be mediated or moderated by a number of underlying bidirectional factors, including: Genetic predisposition (Barsevick, Frost, Zwinderman, Hall, \& Halyard, 2010; Bower, Ganz, Irwin, Arevalo, \& Cole, 2011; Ryan et al., 2007); comorbid physiological disorders, such as anxiety and depression (Brown \& Kroenke, 2009; Carpenter, 2009; Minton et al., 2012); behavioural or environmental factors, including daily exercise routine and ambient light exposure (Ancoli-Israel et al., 2012; Barsevick et al., 2013; Hrushesky et al., 2009; Neikrug et al., 2012); and underlying physiological factors, including upregulation of inflammatory cytokines, disturbance of the hypothalamic-pituitary-adrenal (HPA) axis with associated dysregulation of diurnal cortisol and melatonin secretion, and disruption in the circadian sleep-wake cycle (Bower et al., 2011, 2012; Eismann, Lush, \& Sephton, 2010; Hrushesky et al., 2009; Ishida et al., 2005; Miller, AncoliIsrael, Bower, Capuron, \& Irwin, 2008; Saligan \& Kim, 2012; Sephton \& Spiegel, 2003; Son, Chung, \& Kim, 2011).

Although these underlying factors appear to impact all cancer patients to varying extents, there is evidence to indicate that ovarian cancer patients may be at increased risk for developing 
and experiencing more significant fatigue due to a number of disease and treatment-related factors specific to this cancer population.

Cancer and treatment related factors. Potentially the most important factor related to heightened susceptibility and severity of fatigue in ovarian cancer patients is related to the fact that on average, 70 to $80 \%$ of patients are not diagnosed until the cancer has progressed to a more advanced stage (III or IV; Anderson \& Hacker, 2008). Although a number of studies have reported no association between fatigue and the size (Hann et al., 1997; Hann, Jacobsen, Martin, Azzarello, \& Greenberg, 1998), or stage of the tumour (Andrykowski, Curran, \& Lightner, 1998; Hann et al., 1997; Hann et al., 1998; Knobel et al., 2000; Loge, Abrahamsen, Ekeberg, \& Kaasa, 2000; Okuyama et al., 2000, 2001), more advanced stages of cancer often require more intense or combined treatment regimens, which are correlated with greater fatigue severity, maintenance and disruption to daily life (Sura, Murphy, \& Gonzales, 2006). This is particularly relevant to patients with ovarian cancer, as they often require a combination of surgical cytoreduction (i.e., surgical removal of the tumour) prior to receiving a combination of intravenous (IV) and intraperitoneal (IP) chemotherapy, which involves administering chemotherapeutic agents directly into the abdominal cavity via a catheter (Armstrong et al., 2006; Jaaback, Johnson, \& Lawrie, 2016; Rothenberg et al., 2003). In addition, the post-surgical period is typically associated with a number of treatment-related side-effects commonly correlated with fatigue, including pain, nausea, and vomiting. The association between chemotherapy and fatigue has been well documented within other cancer populations (Blesch et al., 1991; Danaher et al., 2006; Hacker \& Ferrans, 2003; Jacobsen et al., 1999), with both single-agent therapy and combination chemotherapy being associated with increased fatigue (Escobar et al., 2004; Hussain et al., 2003; Markman et al., 2003). 
To date, three studies have examined the association between chemotherapy and fatigue in ovarian cancer patients (Carlsson, Strang, \& Bjurström, 2000; Lutgendorf et al., 2000). The first study by Carlsson et al. (2000) showed that gynaecological cancer patients previously treated with chemotherapy ( $N=235,24 \%$ of which had ovarian cancer), endorsed greater fatigue than those not treated with chemotherapy. Comparable results were found by Lutgendorf et al., (2000) when examining fatigue outcomes in gynaecological cancer patients $(N=48 ; 70.9 \%$ of which had ovarian cancer) undergoing treatment regimens of varying intensity. Patients treated with more intensive chemotherapy reported more fatigue, and less vigour, compared with less intensively treated patients. In addition, the use of IP chemotherapy may result in intensified fatigue due to insertion-related side-effects, including abdominal pain and catheter-related infection (Almadrones, 2007). Indeed, women who develop catheter infections often experience abdominal pain and distension, fever, and reduced physical activity, all of which may contribute to fatigue. In addition, patients treated with combination therapy have been found to experience significantly greater fatigue, over a longer duration, compared to the monotherapy group (IV only; Armstrong et al., 2006), indicating this more strenuous treatment approach often prescribed for ovarian cancer patients may be driving worse fatigue outcomes.

Finally, while the majority of studies to date have reported no association between time since diagnosis and fatigue in cancer patients (Broeckel, Jacobsen, Horton, Balducci, \& Lyman, 1998; Hann et al., 1997; Hann et al., 1998; Knobel et al., 2000), a single study examining fatigue in haematological cancer patients found that individuals who had been more recently diagnosed reported greater fatigue severity (So, Dodgson, \& Tai, 2003), making this a potential medical variable of interest in ovarian cancer patients. 
Pain. A number of studies have demonstrated a positive relationship between pain and fatigue in cancer patients (Badr, Basen-Engquist, Taylor, \& De Moor, 2006; Bower et al., 2000; Jacobsen et al., 1999). Ovarian cancer patients are at greater risk, compared to other cancer populations, for pain development and pain management problems due to a myriad of reasons, including post-cytoreductive surgical pain, IP catheter pain (due to insertion, dislodgment or infection), and abdominal pain (due to cramping and distension resulting from catheter insertion and site-specific chemotherapy). Importantly, it appears that abdominal pain scores increase as chemotherapy dosage increases (Markman et al., 1992), and when combined IV and IP chemotherapy is used, compared to IV treatment alone (Armstrong et al., 2006). This may be of particular importance to advanced stage ovarian cancer patients, as they are often treated with higher doses of chemotherapy in addition to combined treatment protocols (IV and IP chemotherapy; Anderson \& Hacker, 2008). However, to date, the association between pain and fatigue in ovarian cancer patients has yet to be examined, making this an important future research avenue.

Nausea and vomiting. Both nausea and vomiting have been significantly correlated with fatigue in cancer patients undergoing radiotherapy (Jereczek-Fossa, Marsiglia, \& Orecchia, 2002) and chemotherapy (Knobf, 1986; Stone, Richards, A’Hern, \& Hardy, 2001). Nausea, similar to pain, increases if combined use of IV and IP chemotherapy, or higher doses of chemotherapy are employed (Armstrong et al., 2006; Rothenberg et al., 2003), making this another potentially relevant, yet unexplored, variable associated with fatigue in ovarian cancer patients.

Psychological distress. Depression and anxiety have been strongly associated with fatigue in other cancer populations (Bower et al., 2006; Holzner et al., 2003; Tchekmedyian, 
Kallich, McDermott, Fayers, \& Erder, 2003). A meta-analysis by Prue et al. (2006), examining both physiological and psychological factors associated with fatigue, found 14 studies demonstrating higher scores of anxiety and depression were significantly associated with greater fatigue severity. Another study by Seo et al. (2010) examined the relationship between anxiety and depression and fatigue severity in a sample of 110 cancer patients, using physical distress (pain, nausea/vomiting, lack of appetite) as a mediator. The authors found that while psychological distress did not have a significant direct effect on fatigue, it had a significant total effect on fatigue, indicating physical distress significantly mediated the relationship between psychological distress (anxiety and depression) and fatigue. These results suggest that while psychological distress may not directly affect fatigue in cancer patients, it can increase fatigue severity if patients are experiencing physical distress.

To date, only one study has examined the difference between fatigued and non-fatigued ovarian cancer survivors $(N=98 ;+6$ months since completion of treatment) with depression and anxiety; finding significantly higher depression $(d=.93, p<.001)$ and anxiety $(d=1.14, p<$ .001) scores in individuals who met criteria for significant fatigue (as determined by a score of 12 or more out of a possible score of 20 on the General Fatigue subscale of the Multidimensional Fatigue Inventory, which has been validated for use in cancer patients; Smets, Garssen, Bonke, $\&$ de Haes, 1995), compared to those who did not (Holzner et al., 2003). However, the linear relationship between depressive and anxious symptomology with fatigue severity in ovarian cancer patients has yet to be examined. Importantly, this patient population typically is not diagnosed until the disease has progressed to a later stage, which can result in high anxiety (Bodurka-Bevers et al., 2000; Kornblith et al., 1995; Portenoy et al., 1994), and depression 
(Brown \& Kroenke, 2009; Ryan et al., 2007), potentially making this patient population at greater risk for experiencing fatigue.

Sleep disturbance. In addition, sleep disturbances are common among cancer patients (Derogatis et al., 1979; Stiefel, Kornblith, \& Holland, 1990), and have been associated with greater CRF severity and duration in cancer patients before, during, and immediately after cancer treatment (Anderson et al., 2003; Berger \& Higginbotham, 2000; Danaher et al., 2006; Given, Given, Azzouz, \& Stommel, 2001; Lee, 2001), and in long-term cancer survivors (Bower et al., 2000; Clevenger et al., 2012). Indeed, strong correlations between fatigue and various sleep parameters have been noted in a number of different cancer populations, including poor perceived sleep quality, or difficulty initiating or maintaining sleep, multiple nighttime awakenings, early morning awakenings, and restless sleep (Ancoli-Israel et al., 2006; Anderson et al., 2003; Andrykowski et al., 2010; Berger, 1998; Berger \& Farr, 1999; Bower et al., 2000b; Broeckel et al., 1998; Geoff et al., 2004; Redeker, Lev, \& Ruggiero, 2000; Roscoe et al., 2007; Roscoe et al., 2002; Servaes, Verhagen, \& Bleijenberg, 2002).

To date, two studies examining sleep disturbances in ovarian cancer have found a significant association between more sleep disruption and greater fatigue severity (Clevenger et al., 2012; Sandadi et al., 2011). A number of factors unique to ovarian cancer patients, such as abdominal distension and pain commonly associated with IP chemotherapy, may precipitate or exacerbate sleep disturbances, thereby contributing to both the development and severity of fatigue (Can, Durna, \& Aydiner, 2004; Clevenger et al., 2012; Geinitz et al., 2004; Haghighat, Akbari, Holakouei, Rahimi, \& Montazeri, 2003; Jacobsen et al., 1999; Jacobsen, Andrykowski, \& Thors, 2004; Donovan et al., 2004; Sandadi et al., 2011; Shun et al., 2005; Smets et al., 1998; Stone, Hardy, Huddart, A’Hern, \& Richards, 2000; Wratten et al., 2004). 
Demographic factors. In addition to disease and treatment-related factors, a number of demographic variables, including age, gender, ethnicity, marital or relationship status, having children, annual income, employment status, and education level achieved have been examined as potential risk factors for fatigue in cancer patients. One comprehensive review by Prue et al., (2006) on the prevalence and pattern of CRF in the general cancer population noted a number of conflicting results within the literature. The majority of studies failed to find a relationship between age (Can et al., 2004; Geinitz et al., 2004; Haghighat et al., 2003; Jacobsen et al., 1999, 2004; Donovan et al., 2004; Shun et al., 2005; Smets et al., 1998; Stone et al., 2000; Wratten et al., 2004), ethnicity (Hann et al., 1999; Jacobsen et al., 2004; Shun et al., 2005), marital status (Can et al., 2004; Haghighat et al., 2003; Hann et al., 1999; Jacobsen et al., 2004; Respini, Jacobsen, Thors, Tralongo, \& Balducci, 2003), education (Can et al., 2004; Haghighat et al., 2003; Hann et al., 1999; Respini et al., 2003; Smets et al., 1998), employment status (Can et al., 2004; Hann et al., 1999), annual income (Can et al., 2004; Hann et al., 1999; Jacobsen et al., 2004) and fatigue. However, one study demonstrated a positive association between younger age and greater fatigue (de Jong, Candel, Schouten, Abu-Saad, \& Courtens, 2005), one study by Carlson et al., (2004) found significantly greater fatigue in minority populations (e.g., African American, Asian, and Hispanic patients) compared to patients of European descent, and two studies found an association between lower education and fatigue (Jacobsen et al., 2004; Shun et al., 2005). Finally, two studies reported individuals who were married or in long-term relationships endorsed lower ratings of fatigue (de Jong, Candel, Schouten, Abu-Saad, \& Courtens, 2004; de Jong et al., 2005), one study noted a positive association between having children and fatigue (Dhruva et al., 2010), while one other study failed to find an association (de 
Jong et al., 2004). Importantly, the relationship between these demographic variables and fatigue specifically in ovarian cancer patients has yet to be examined.

\section{Leventhal's Common Sense Model of Illness Perceptions}

To date, the majority of studies examining psychological factors associated with CRF have solely examined the relationship between depression or anxiety with fatigue, without delving into patient perceptions specific to their cancer experience that may be driving fatigue (Ahlberg et al., 2004; Anderson \& Hacker, 2008; Holzner et al., 2003; Tchekmedyian et al., 2003; Visser \& Smets, 1998). Research suggests that the ways in which women perceive or understand their cancer experience (Andersen, Woods, \& Copeland, 1997; Costanzo, Lutgendorf, Bradley, Rose, \& Anderson, 2005; Stewart, Duff, Wong, Melancon, \& Cheung, 2001), and employ coping strategies to manage their symptoms (Costanzo, Lutgendorf, Rothrock, \& Anderson, 2006; Lutgendorf et al., 2002), can influence a number of health-related outcomes (Costanzo et al., 2006; Lutgendorf et al., 2002; Stanton, Danoff-burg, \& Huggins, 2002; Thompson \& Shear, 1998). Leventhal's Common Sense Model (CSM) of Illness Perceptions may provide a novel framework to examine CRF (Leventhal, Meyer, \& Nerenz, 1980). According to this model, patients' perceptions regarding their cancer experience can impact how they cope with their diagnosis and accompanying symptoms, which in turn can mediate health outcomes-including fatigue. Leventhal's CSM can be broken down into three steps: (1) Illness perceptions, (2) coping behaviours, and (3) health related outcomes. Refer to Figure 1 for a complete detailed description of the stages in the model. 
Step 1

illness perceptions
Step 2

coping strategies
Step 3

health-related

outcomes

Personal controllability - high

Treatment controllability - high

Illness identity - low

Chronicity - low

Cyclicality - low

Consequences - low

Coherence - high

Personal controllability - low

Treatment controllability - low

Illness identity - high

Chronicity - high

Cyclicality - high

Consequences - high

Coherence - low

Figure 1. Leventhal's Common Sense Model. Illness perceptions predict selection of certain coping strategies, which in turn impact health-related outcomes.

Applying this model to CRF, when individuals are confronted with a diagnosis of cancer, their cognitive and emotional processing systems work in tandem to develop interpretations of their cancer experience (i.e., illness perceptions), which in turn will determine which types of coping strategies the individual will employ to cope with their cancer experience. The selection of coping strategies will in turn mediate the relationship between the patients' cancer-related illness perceptions and fatigue severity outcomes. A full description of the steps and the components of this model are explained in the following sections. Refer to Figure 2 for a complete detailed description of the stages in the model with fatigue as the outcome of interest. 
Step 1

illness perceptions
Step 2

coping strategies
Step 3

health-related

outcomes

Personal controllability - high

Treatment controllability - high

Illness identity - low

Chronicity - low

Cyclicality - low

Consequences - low

Coherence - high

Personal controllability - low

Treatment controllability - low

Illness identity - high

Chronicity - high

Cyclicality - high

Consequences - high

Coherence - low

Figure 2. Leventhal's Common Sense Model applied to fatigue. Illness perceptions predict coping strategies, which in turn impact fatigue severity.

Steps in Leventhal's Common Sense Model (CSM). Step One in Leventhal's CSM refers to illness perceptions, which pertain to an individual's subjective beliefs about their cancer experience. Illness perceptions can be broken down into seven categories related to an illness threat such as cancer, including objective features and symptoms associated with the cancer diagnosis, and subjective personal beliefs about the nature and implications of those objective features or symptoms (Table 1). These include: (1) Illness identity, which refers to the type and total number of symptoms patients' attribute to their cancer experience; (2) chronicity, which refers to patients' beliefs about the anticipated duration of their cancer (e.g., whether patients' believe their cancer will be long-term or easily treatable), and (3) cyclicality, which refers to anticipated recurrence of the cancer (e.g., whether patients' anticipate periods of remission and 
relapse); (4) consequences, which refers to patients' views concerning any costs to lifestyle or goals attributable to their cancer (e.g., loss of employment or reduced social activities); (5) personal controllability, which refers to patients' perceptions about their own self-efficacy to manage their cancer (e.g., whether the patients' actions or behaviours will impact the cancer experience or related symptoms); (6) treatment controllability, which refers to how treatable, via medical or therapeutic interventions, patients perceive the their cancer and associated symptoms to be (e.g., whether the underlying cause of the cancer is treatable or not, or if the symptoms associated with the cancer are manageable with medications or psychosocial interventions); and finally, (6) illness coherence, which refers to the patients' comprehension of their cancer experience (e.g., how well they understand their diagnosis and related symptoms). Importantly, prior analyses of these illness perceptions show them to be correlated, but not to a magnitude that indicates conceptual overlap (Chen, Tsai, \& Lee, 2008; Giannousi, Manaras, Georgoulias, \& Samonis, 2010; Hagger, \& Orbell, 2003; Moss-Morris et al., 2002).

Step Two in Leventhal's CSM describes the relationship between illness perceptions and selection of coping behaviours, with certain illness perceptions eliciting or suppressing specific coping behaviours. Within the literature, the following coping strategies are considered to be positive or adaptive: Problem-focused or approach-based (e.g., altering or modifying stressors associated with the cancer experience), acceptance-based (e.g., accepting the cancer experience without judgment or attachment), reappraisal-based (e.g., self-reflection, examination and modification of emotional reactions to the cancer experience), seeking emotional or instrumental support, and spiritual/religious involvement (Dempster, Howell, \& McCorry, 2015; Hagger \& Orbell, 2003). 
Table 1

Illness Perceptions According to Leventhal's Common Sense Model with Examples From the Illness Perception Questionnaire-Revised

\begin{tabular}{|c|c|c|}
\hline $\begin{array}{c}\text { Illness } \\
\text { perceptions }\end{array}$ & Description & Example \\
\hline $\begin{array}{l}\text { Personal } \\
\text { control }\end{array}$ & $\begin{array}{l}\text { Perceptions pertaining to the patients' } \\
\text { own self-efficacy to manage } \\
\text { symptoms associated with the illness } \\
\text { experience }\end{array}$ & $\begin{array}{l}\text { "There is a lot I can do to control } \\
\text { my symptoms" } \\
\text { "My actions have no effect on the } \\
\text { outcomes of my illness" }\end{array}$ \\
\hline $\begin{array}{l}\text { Treatment } \\
\text { control }\end{array}$ & $\begin{array}{l}\text { Whether the illness experience is } \\
\text { perceived to be treatable/manageable } \\
\text { with medications or other therapeutic } \\
\text { interventions }\end{array}$ & $\begin{array}{l}\text { "My treatment can control my } \\
\text { condition" } \\
\text { "There is nothing which can help } \\
\text { my illness" }\end{array}$ \\
\hline Identity & $\begin{array}{l}\text { The type and number of symptoms } \\
\text { associated with the illness experience } \\
\text { Options include pain, sore nausea, } \\
\text { fatigue, headaches, loss of strength, } \\
\text { etc. }\end{array}$ & $\begin{array}{l}\text { "I have experienced the following } \\
\text { symptoms since my illness" } \\
\text { "These symptoms are related to my } \\
\text { illness" }\end{array}$ \\
\hline Chronicity & $\begin{array}{l}\text { The expected duration of the illness } \\
\text { experience }\end{array}$ & $\begin{array}{l}\text { "My illness will last a short time" } \\
\text { "I expect to have this illness for the } \\
\text { rest of my life" }\end{array}$ \\
\hline Cyclicality & $\begin{array}{l}\text { Whether the illness experience is } \\
\text { expected to go through periods of } \\
\text { remission and relapse }\end{array}$ & $\begin{array}{l}\text { "My symptoms come and go in } \\
\text { cycles" } \\
\text { "My illness is very unpredictable" }\end{array}$ \\
\hline Consequences & $\begin{array}{l}\text { Perceptions pertaining to any gains or } \\
\text { losses to lifestyle or goals attributed to } \\
\text { the illness experience }\end{array}$ & $\begin{array}{l}\text { "My illness is a serious condition" } \\
\text { "My illness has major } \\
\text { consequences on my life" }\end{array}$ \\
\hline $\begin{array}{l}\text { Illness } \\
\text { coherence }\end{array}$ & $\begin{array}{l}\text { How well the patient understand their } \\
\text { illness experience and related } \\
\text { symptoms }\end{array}$ & $\begin{array}{l}\text { "I have a clear picture or } \\
\text { understanding of my condition" } \\
\text { "My illness is a mystery to me" }\end{array}$ \\
\hline
\end{tabular}

In contrast, negative coping strategies include avoidance, disengagement and denialbased coping strategies (Stanton, Danoff-Burg, \& Huggins, 2002; Van Elderen et al., 1999), and self-blame or negative emotional expression (e.g., venting, expressing anger, sadness, or 
hopelessness about one's cancer and associated symptoms; Hagger \& Orbell, 2003). For a full list of positive and negative coping strategies, see Table 2.

Step Three in Leventhal's CSM predicts that selection of certain coping strategies will in turn influence health-related outcomes, including the onset, severity and duration of symptoms associated with the cancer experience. Thus, coping responses mediate the relationship between illness perceptions and health-related outcomes, such that positive coping strategies enhance positive health-related outcomes (Holland \& Holahan, 2003; Harcourt, Rumsey, \& Ambler, 1999; Osowiecki \& Compas, 1998), while negative coping strategies result in poorer healthrelated outcomes (Hack \& Degner, 2004; McCaul et al., 1999; Stanton et al., 2002). Applying this to fatigue in cancer patients, it is hypothesized that coping strategies will mediate the relationship between illness perceptions and the severity of CRF.

Support for Leventhal's Common Sense Model: A review of the literature. A metaanalysis of 45 studies by Hagger and Orbell (2003) examined the relationship between seven illness perceptions (illness identity, consequences, personal and treatment control, chronicity, cyclicality, and illness coherence), seven types of coping strategies (avoidance/denial, cognitive reappraisal, emotional expression, social support seeking, general and specific problem-focused coping, and number of doctor's visits), and six potential health-related outcomes (psychological distress, psychological well-being, physical functioning, role and social functioning, vitality, and symptom severity) across a diverse set of patient populations (e.g., HIV, diabetes, cancer, rheumatoid arthritis). The authors reported all results using averaged intercorrelation coefficients $\left(r_{\mathrm{c}}\right)$ corrected for sampling and measurement error within each study. 
Table 2

Positive and Negative Coping Strategies, with Description and Example Items from The Brief COPE Short-Form

\begin{tabular}{|c|c|c|}
\hline Positive coping & Description & Examples \\
\hline $\begin{array}{l}\text { Cognitive-avoidance (end-stage } \\
\text { cancer or during treatment) }\end{array}$ & $\begin{array}{l}\text { Effort to ignore/not think about } \\
\text { illness/symptoms (e.g., denial) }\end{array}$ & $\begin{array}{l}\text { "I've been refusing to believe that it has happened" } \\
\text { "I've been saying to myself, this isn't real" }\end{array}$ \\
\hline $\begin{array}{l}\text { Behavioural-avoidance (end- } \\
\text { stage cancer or during } \\
\text { treatment) }\end{array}$ & $\begin{array}{l}\text { Behavioural efforts to avoid thinking } \\
\text { about/experiencing the } \\
\text { illness/symptoms (e.g., distraction) }\end{array}$ & $\begin{array}{l}\text { "I've been doing something to think about it less, } \\
\text { such as going to the movies, watching TV, reading, } \\
\text { daydreaming, sleeping, or shopping" }\end{array}$ \\
\hline Praying & $\begin{array}{l}\text { Belief that an external power is } \\
\text { responsible for the outcome of the } \\
\text { illness/symptoms (e.g., low self- } \\
\text { efficacy) }\end{array}$ & "I've been praying or meditating" \\
\hline $\begin{array}{l}\text { Problem-focused or } \\
\text { approach-based }\end{array}$ & $\begin{array}{l}\text { Changing on modifying stressors } \\
\text { associated with the cancer experience }\end{array}$ & $\begin{array}{l}\text { "I've been taking action to try to make the situation } \\
\text { better" } \\
\text { "I've been concentrating my efforts on doing } \\
\text { something about the situation I'm in" }\end{array}$ \\
\hline Social support seeking & $\begin{array}{l}\text { Seeking social support to help with } \\
\text { physical, psychological repercussions } \\
\text { of illness/symptoms }\end{array}$ & $\begin{array}{l}\text { "I've been getting emotional support from others" } \\
\text { "I've been trying to get advice or help from other } \\
\text { people about what to do" }\end{array}$ \\
\hline Cognitive-reappraisal & $\begin{array}{l}\text { Self-reflection, examination and } \\
\text { alteration of emotional responses to } \\
\text { the cancer experience }\end{array}$ & $\begin{array}{l}\text { "I've been trying to see it in a different light, to make } \\
\text { it seem more positive" } \\
\text { "I've been looking for something good in what is } \\
\text { happening" }\end{array}$ \\
\hline
\end{tabular}


Table 2 Continued

Acceptance-based

Accepting the cancer experience without judgment or attachment
"I've been learning to live with it"

"I've been accepting the reality of the fact that it has happened"

\begin{tabular}{lll}
\hline \multicolumn{1}{c}{ Negative coping } & \multicolumn{1}{c}{ Description } & \multicolumn{1}{c}{ Examples } \\
\hline $\begin{array}{l}\text { Cognitive-avoidance (during } \\
\text { recovery/remission, after } \\
\text { treatment) }\end{array}$ & $\begin{array}{l}\text { Psychological efforts to avoid or } \\
\text { distance oneself from the } \\
\text { illness/disease (e.g., ignoring } \\
\text { symptoms) }\end{array}$ & $\begin{array}{l}\text { "I've been refusing to believe that it has happened" } \\
\text { "I've been saying to myself, this isn't real" }\end{array}$ \\
$\begin{array}{l}\text { Behavioural-avoidance or } \\
\text { disengagement } \\
\text { (during recovery/remission, } \\
\text { after treatment) }\end{array}$ & $\begin{array}{l}\text { Behavioural efforts to avoid } \\
\text { thinking/experiencing the } \\
\text { illness/symptoms (e.g., distraction) }\end{array}$ & $\begin{array}{l}\text { "I've been using alcohol or other drugs to help me get } \\
\text { through it" } \\
\text { "I've been turning to work or other activities to take } \\
\text { my mind off things" } \\
\text { "I've been giving up trying to deal with it" }\end{array}$ \\
$\begin{array}{l}\text { Emotional expression or self- } \\
\text { blame }\end{array}$ & $\begin{array}{l}\text { Venting, expressing anger, sadness, } \\
\text { hopelessness, or self-blame }\end{array}$ & $\begin{array}{l}\text { "I've been expressing my negative feelings" } \\
\text { "I've been saying things to let my unpleasant feelings } \\
\text { escape" }\end{array}$
\end{tabular}

Note: Coping strategies listed under "positive" and "negative" are based on exploratory factor analysis conducted as recommended by Bellizzi and Blank (2006). 
Relationship between illness perceptions and coping strategies. In support of the hypothesized relationship between illness perceptions and coping strategies, Hagger and Orbell (2003) found that greater perceptions of personal or treatment controllability (e.g., endorsement of personal and treatment self-efficacy related to managing their illness/disease) were significantly positively correlated with the following positive coping strategies: General problem-focused $\left(r_{\mathrm{c}}=.27, p<.05\right)$, and specific problem-focused $\left(r_{\mathrm{c}}=.12, p<0.05\right)$, cognitive reappraisal $\left(r_{\mathrm{c}}=.20, p<.05\right)$, and social support seeking $\left(r_{\mathrm{c}}=.08, p<.05\right)$. In comparison, patients who endorsed greater consequences associated with their illness/disease selected significantly greater negative coping strategies, including avoidance/denial $\left(r_{\mathrm{c}}=.23, p<.05\right)$ and emotional expression $\left(r_{\mathrm{c}}=.21, p<.05\right)$. In addition, the illness perception of timeline (e.g., acute, chronic or cyclical) was significantly positively correlated with the positive coping strategy of cognitive reappraisal $\left(r_{\mathrm{c}}=.14, p<.05\right)$ when the patient believed their illness/disease to be acute, and negative avoidance/denial type coping strategies $\left(r_{\mathrm{c}}=.12, p<.05\right)$ when they perceived their illness/disease to be chronic or cyclical in nature.

Overall, these results indicate that patients who perceive their illness/disease to be severe or highly symptomatic, chronic or cyclical in nature, with significant consequences on their daily life, tend to select negative coping strategies. In contrast, patients that perceive their illness/disease to be treatable (e.g., surgery, chemotherapy), acute, and believe their own personal behaviours/actions can impact their illness and related health outcomes, tend to select positive coping strategies to deal with their illness/disease experience.

Relationship between illness perceptions and health-related outcomes. In support of the hypothesized relationship between illness perceptions and health-related outcomes, Hagger and Orbell (2003) found that patients who endorsed greater illness/disease-related consequences and 
a chronic or cyclical timeline, demonstrated significantly worse psychosocial outcomes, including poorer well-being, role functioning (e.g., employment or familial functioning), social functioning, and vitality $\left(r_{\mathrm{c}}=-.67\right.$ to $\left.-.11, p<.05\right)$. Greater patient endorsement of more severe illness/disease-related consequences $\left(r_{\mathrm{c}}=-.18, p<.05\right)$ was also significantly associated with worse physical functioning (e.g., physical activity, mobility, and self-care), providing further support for the relationship between greater endorsement of negative illness perceptions and worse health-related outcomes. Finally, greater patient endorsement of treatment and personal control over the illness/disease was significantly positively associated with better psychological well-being $\left(r_{\mathrm{c}}=.21, p<.05\right)$, higher social functioning $\left(r_{\mathrm{c}}=.13, p<.05\right)$, and more vitality $\left(r_{\mathrm{c}}=\right.$ $.24, p<.05)$. Additionally, greater patient endorsement of personal and treatment control over their illness/disease were both also significantly associated with less psychological distress $\left(r_{\mathrm{c}}=\right.$ $.17, p<.05)$ and lower disease severity $\left(r_{\mathrm{c}}=-.17, p<.05\right)$.

The association between illness perceptions and fatigue has been examined in a number of disease models, including chronic fatigue syndrome, rheumatoid arthritis, vasculitis, and epilepsy (Edwards, Suresh, Lynch, Clarkson, \& Stanley, 2001; Grayson et al., 2013; Heijmans, 1998; Rizou, De Gucht, Papavasiliou, \& Maes, 2016; Treharne et al., 2008; Trojan et al., 2007). Two cross-sectional studies examined the relationship of illness perceptions with fatigue severity, above and beyond demographic characteristics and disease duration, in patients diagnosed with chronic fatigue syndrome (Edwards et al., 2001; Heijmans, 1998). Both studies found greater endorsement of illness identity and negative consequences attributed to the disease experience to be significantly associated with greater fatigue (Edwards et al., 2001; Heijmans, 1998). Another cross-sectional study examining fatigue outcomes in patients diagnosed with vasculitis $(N=692)$ found all illness perceptions, excluding chronicity, predicted fatigue severity 
above and beyond demographic variables (e.g., age, gender, relationship status), illness duration, and severity of physical symptoms associated with vasculitis (e.g., organ damage). With the addition of the illness perceptions to the model accounting for an additional $18 \%$ of variance in fatigue above and beyond demographic and disease related factors (Grayson et al., 2013). Another study examining fatigue severity in MS patients $(N=53)$, did not use a measure of illness perceptions according to Leventhal's CSM; however, the authors did assess patients' perceptions of self-efficacy (analogous to the illness perception of personal control) in association with a number of different fatigue measures. Perceived self-efficacy to cope with or manage MS-related symptoms was found to be significantly associated $(p<.05)$ with general fatigue $(r=.52)$, physical fatigue severity $(r=.52)$, and mental fatigue $(r=.38$; Trojan et al., 2007). Finally, one study examined fatigue outcomes using a longitudinal design over a one-year period in individuals with rheumatoid arthritis (Treharne et al., 2008). The authors found a significant association between greater endorsement of perceived consequences $(\beta=.28, p<.05)$ at baseline with greater fatigue at the one-year follow-up time point, indicating this specific illness perception may predict worse fatigue over time (Treharne et al., 2008).

Only three studies have examined the impact of illness perceptions on fatigue outcomes in cancer patients (Ahlberg, Ekman, \& Gaston-Johansson, 2005a; Hoffman et al., 2009; Paddison et al., 2009). One study by Hoffman et al. (2009) examined the relationship between cancerrelated fatigue severity and perceived self-efficacy to manage fatigue (i.e., the illness perception personal control) in a sample of cancer patients (e.g., breast, lung, colon cancer; $N=298$ ). The authors reported, a significant negative correlation between perceived self-efficacy and fatigue severity $(r=-.39, p<.01)$, indicating that the less patients' believed they were able to control or manage their disease and associated symptoms, the greater their fatigue. 
Ahlberg et al. (2005a) used a prospective longitudinal design to examine the relationship between fatigue, the illness perception of sense of coherence, and psychological distress (anxiety and depression), during, and after radiation therapy in a sample of uterine cancer patients $(N=$ 60). Greater sense of coherence at baseline was associated with less fatigue $(r=-.49, p<.001)$, but was not found to be significantly associated with fatigue at either of the follow-up time points (3-weeks into treatment, and 5- to 6-weeks from baseline when treatment was completed). Only depression was found to be a significant predictor of fatigue over the follow-up time points, explaining $44 \%$ of the variance in fatigue.

In a third study by Paddison et al. (2009), the prospective impact of pre-surgical fatiguerelated illness expectation on post-surgical fatigue outcomes was examined in a sample of colorectal cancer patients $(N=51)$. Pre-surgical expectations that fatigue would be nonproblematic (e.g., the illness perception consequences) were found to predict greater fatigue severity $(p<.05)$ and longer duration of fatigue $(p<.001)$ at two months post-surgery, suggesting that unrealistic expectations related to fatigue severity or duration may promote worse fatigue outcomes.

Overall, a general pattern of findings emerged from these studies. After controlling for physical symptoms and disease duration, worse fatigue was associated with greater endorsement of the following illness perceptions: Negative consequences associated with their symptoms, and perceptions that the disease is chronic or cyclical in nature, and difficult to control (Edwards et al., 2001; Grayson et al., 2013; Heijmans, 1998; Rizou et al., 2016; Treharne et al., 2008; Trojan et al., 2007).

Relationship between coping strategies and fatigue outcomes. One cross-sectional study by Heijmans (1998), focusing on individuals with chronic fatigue syndrome (CFS; $N=98)$, also 
examined the relationship between coping and fatigue outcomes. Of the five different coping strategies examined (behavioural-avoidant, cognitive-avoidant, emotional venting, problemfocused, and social support seeking), only greater cognitive-avoidance (e.g., psychological efforts to escape or detach oneself from the illness experience) was significantly associated with fatigue severity $(p<.001)$.

Coping as a mediator between illness perceptions and health-related outcomes. Another meta-analysis by Dempster et al. (2015) also examined selection of coping strategies as a mediator in the relationship between illness perceptions and health-related outcomes. A total of 13 out of the 26 studies included in the meta-analysis examined coping strategies as a mediator. Only four of these studies found coping to significantly mediate the relationship between illness perceptions and psychosocial and health-related outcomes (e.g., physical performance, anxiety, depression, and quality of life; Evans \& Norman, 2009; Gray, 2007; Knibb \& Horton, 2008; Rutter \& Rutter, 2002). Notably, only negative coping strategies were found to mediate the relationship between illness perception and health-related outcomes, including cognitive denial or avoidance-based strategies, behavioural avoidance strategies (e.g., disengagement), and emotional expression (e.g., venting). In fact, the studies that failed to find a significant indirect effect between illness perceptions and health-related outcomes, with coping included in the model as a mediator, only examined positive coping strategies as potential mediators Dempster et al. (2015).

To date, only one study has examined coping as a mediator in fatigue outcomes, using a sample of rheumatoid arthritis patients $(N=114$; Treharne et al., 2008). Treharne and colleagues examined fatigue severity using a $10 \mathrm{~cm}$ visual analogue scale at baseline and then again 12 months later, finding approximately half of the sample (54\%) showed an increase in fatigue over 
this period, while the other half (51\%) showed a comparable decrease in fatigue scores. Baseline fatigue scores explained $13 \%$ of the variance in fatigue at the one-year follow-up time point, $(p<$ .001 ), while coping strategies (hoping and praying) did not explain any additional variance in fatigue ( $p=.72$ ). However, this study has two major limitations, which may have prevented it from revealing a relationship between coping and fatigue. First, fatigue was only assessed using a unipolar scale with "no fatigue" at one pole, and "unbearable fatigue" at the opposite pole. This measure did not assess for the nature (e.g., physical or mental dimensions) of fatigue or the prior timeline of the fatigue experience (e.g., how fatigued the respondent has felt in the past week, month, or 6 months), or fatigue-related distress. Second, the only coping strategies assessed in this model were "hoping" and "praying." However, hoping/praying can be considered both a positive and negative coping strategy, as it may be a form of acceptance-based coping, or an avoidance-based/helplessness form of coping.

Overall, these results appear to indicate that negative coping strategies may be preferentially driving the relationship between illness perceptions and health-related outcomes. However, these meta-analyses did not assess fatigue as an outcome of interest, making these findings not necessarily generalizable to CRF. The relationship between illness perceptions, coping strategies, and fatigue may prove different than other health-related outcomes previously explored in the extant literature. Indeed, to date, only two studies have examined the relationship between coping and fatigue. The first study, which examined the direct relationship between positive and negative coping strategies and fatigue in a sample of CFS patients, reported only negative avoidance-based coping to significantly predict worse fatigue (Heijmans, 1998); while the second study, which examined the coping strategy of "hoping and praying" as a proposed mediator in the relationship between illness perceptions and fatigue in a sample of patients with 
rheumatoid arthritis, reported no significant indirect effect (Treharne et al., 2008). However, the underlying physiological mechanisms, proposed causal factors, and experiential quality and manifestation of fatigue in patients with CFS and rheumatoid arthritis are different from the fatigue found in cancer patients. Ultimately the way illness perceptions and coping strategies interact and relate to fatigue in these diverse medical populations may be differentially affected by their unique disease-related factors, and thus further research is necessary to adequately understand this relationship in the context of CRF.

\section{Gaps in the Current Literature}

To date, a number of gaps in the extant literature have been revealed: First, little is known about the predictors of fatigue in ovarian cancer, such as specific demographic (e.g., age, education, relationship status) or medical factors (e.g., cancer stage, type of anti-cancer treatment used) or the severity and types of symptoms (e.g., pain, nausea, anxiety) that could identify patients most at risk for CRF. Although Leventhal's CSM has been applied to a number of medical populations to assess fatigue severity (e.g., MS, rheumatoid arthritis), to date only three studies have applied the Leventhal's CSM in limited form to cancer patients experiencing fatigue (e.g., exploring the relationship between illness perceptions and fatigue, without examining the role of coping as a mediator, or only examining a few illness perceptions in relation to fatigue, using only a single coping strategy as a mediator; Ahlberg, Ekman, \& Gaston-Johansson, 2005a; Hoffman et al., 2009; Paddison et al., 2009). In addition, Leventhal's CSM have yet to be employed using fatigue as the outcome of interest in ovarian cancer patients. Specifically, the role of coping as a mediator in the relationship between illness perceptions and CRF has yet to be examined. 
By addressing these gaps in the literature, this study will not only provide valuable insight into which demographic, medical, and symptom-related factors are associated with fatigue in ovarian cancer patients, but may also provide insight into a potential psychological correlate of CRF-illness perceptions — while elucidating a potential mechanism driving this relationship — selection of coping strategies. Moreover, health care providers can use this information to better understand which cognitive and behavioural factors may be used to identify patients at increased risk for CRF, thereby providing treatment targets for to reduce fatigue in this patient population.

\section{Aims and Hypotheses}

Aim 1. To examine the association between illness perceptions and cancer-related fatigue severity, above and beyond relevant demographic (e.g., age), medical (e.g., chemotherapy), and symptom severity (e.g., pain, nausea) factors, as delineated by Leventhal's Common Sense Model (Leventhal et al., 1980) in an ovarian cancer sample.

Hypothesis 1. Based on prior research, it is predicted that the following six demographic variables will be associated with greater fatigue severity in ovarian cancer patients: Younger age, being non-Caucasian, being unmarried, being unemployed, having a lower income and a lower level of education. For the medical and symptom severity variables, it is predicted that the following eight variables will be associated with greater fatigue severity: Later stages of ovarian cancer (III or IV), shorter time since diagnosis, currently undergoing treatment, undergoing combined treatment (compared to monotherapy), endorsing greater pain, anxiety, nausea, and sleep dissatisfaction.

Hypothesis 2. After controlling for significant covariates (as determined in Hypothesis 1), it is predicted that endorsement of the following illness perceptions will be associated with 
greater fatigue severity: 1) greater illness identity (e.g., endorsement of symptoms, which are attributed to the cancer diagnosis), 2) higher chronicity or 3) greater cyclical timeline (e.g., belief that the cancer is a relapsing or chronic condition), 4) greater negative consequences associated with cancer diagnosis (e.g., greater endorsement of negative outcomes associated with cancer and its related symptoms), 5) lower perceived personal control (e.g., lower self-efficacy to manage symptoms associated with cancer experience), 6) lower perceived treatment control (e.g., lower perceptions that cancer and related symptoms are treatable/manageable with medications or other therapeutic interventions), and 7) less coherence or understanding of cancer diagnosis and disease process (e.g., the patient does not understand what has contributed to the initiation, maintenance, and progression of the cancer).

Aim 2. To examine the extent to which selection of positive and negative coping strategies mediate the relationship between illness perceptions and fatigue severity, as delineated by Leventhal's Common Sense Model (Leventhal et al., 1980).

Hypothesis 3. It is predicted that the relationship between negative illness perceptions (e.g., illness identity, consequences, chronicity, and cyclicality) and greater fatigue severity will be mediated by selection of greater negative coping strategies, and less positive coping strategies, while greater endorsement of positive illness perceptions (e.g., personal and treatment controllability, and coherence) will be associated with reduced fatigue severity, which will be mediated by greater use of positive coping and less use of negative coping strategies. 


\section{Methods}

This is a secondary analysis of a data set originally collected to assess fear of cancer recurrence in a sample of ovarian cancer patients recruited from Princess Margaret Hospital. Data were collected between September 2014 and August 2016.

\section{Participants}

Participants were ovarian cancer patients recruited from the medical oncology, radiation and surgical oncology clinics at PMH in Toronto, Ontario. Patient medical records were screened for eligibility, which was confirmed via the medical staff in clinic.

To be eligible, all participants had to meet the following criteria: 1) Have a diagnosis of invasive ovarian cancer at any stage; 2) be proficient in English (i.e., ability to read and speak); 3) be 18 years or older; 4) be capable of providing informed consent. In addition, patients who were diagnosed with a noninvasive tumor were excluded.

\section{Procedure}

Once medical staff confirmed eligibility, a physician or other member of the patient's circle of care would receive permission from the patient to be approached by research staff after their appointment. A research staff member then provided a brief introduction to the study, and if able, obtained verbal consent. If the participant was interested but unable to provide consent in the clinic, research staff contacted the patient at a later date and obtained verbal consent over the phone.

Patients recruited in clinic were provided with an information brochure and a copy of the written consent form for their own personal records, while patients who verbally consented over the phone received these documents via email or posted mail. In addition, research staff used a script when verbally describing the overview of the study, procedure, and expected time 
commitment to potential participants. Patients were encouraged to ask questions or request clarification when needed.

Once written consent was received, each participant was assigned a study ID to ensure confidentiality. Participants were given the option to complete an online or paper-copy version of the questionnaire. For the online questionnaire, participants were emailed their study ID number and a website address that linked them to the online questionnaires. Participants were able to save their survey and complete it at a later time or date, or stop participating at any time during the survey by selecting the "opt-out" option, in addition to the option to skip questions they did not wish to complete. Participants who did not have access to the internet or who did not wish to complete the survey online were mailed a hard-copy version of the questionnaires with their assigned study ID number, with a pre-paid return envelope. Upon completion of the baseline assessment survey, participants were mailed a \$20 gift card as a token of appreciation.

\section{Measures}

Table 3 provides an overview of the three components of Leventhal's Common Sense Model and the associated measures that were used to capture each step of the model. The questionnaires are outlined in sequence with the phase of the model they are designed to operationalize, starting with the questionnaire designed to capture illness perceptions, followed by the questionnaire assessing coping strategies, and ending with the questionnaire designed to capture fatigue severity. Demographic and illness-related factors were collected via self-report questionnaires. 
Table 3

Questionnaires Assessing Each Step in Leventhal's Common Sense Model

\begin{tabular}{ll}
\hline \multicolumn{1}{c}{ Steps in Leventhal's CSM } & \multicolumn{1}{c}{ Measures } \\
\hline Step 1: Illness perceptions & Illness Perceptions Questionnaire-Revised (IPQ-R) \\
Step 2: Coping strategies & The Brief COPE Short-Form (Brief COPE) \\
Step 3: Fatigue outcomes & The Functional Assessment of Chronic Illness \\
& Therapy Fatigue Scale (FACIT-F) \\
\hline
\end{tabular}

\section{Predictor measures.}

The Illness Perception Questionnaire-Revised (IPQ-R; Moss-Morris et al., 2002) is a 38-item scale used to assess the illness perceptions in Leventhal's CSM Model (Leventhal, Leventhal, \& Contrada, 1998): Illness identity, consequences, chronicity, cyclicality, personal control, treatment control (curability), and illness coherence. The scale assesses for each of these seven illness perceptions, with each item rated on a five-point Likert scale ranging from 1 (strongly disagree), to 5 (strongly agree), with higher scores indicating greater endorsement of that particular illness perception. Table 1 provides a complete list of illness perceptions assessed in the IPQ-R, with a description of each sub-scale, and example questions for each domain. The IPQ-R has previously been used to assess illness perceptions in patients with various forms of cancer including breast, skin, head and neck, and ovarian cancer (Donovan, Hartenbach, \& Method, 2005; Giannousi et al., 2010; Millar, Purushotham, McLatchie, George, \& Murray, 2005; Scharloo et al., 2005), and has demonstrated strong construct and test-retest validity, as well as good internal reliability with with Cronbach's alpha coefficients ranging from .70 to .89 (Hagger \& Orbell, 2005). 


\section{Mediator measure.}

The Brief COPE Short-Form (Brief COPE-SF; Carver, Scheier, \& Weintraub, 1989) is a 28-item multidimensional coping inventory, consisting of 14 scales, which are each comprised of two items, designed to tap into separate coping strategies (e.g., "positive reframing" and "selfdistraction”). Response options for each question range from 0 (I haven't been doing this at all) to 3 (I've been doing this a lot), with higher scores indicating more frequent use of a particular coping strategy. Refer to Table 2 for a full list of coping strategies, with example questions, provided in the Brief-COPE-SF. This scale has previously been used with colorectal, lung or prostate cancer populations, and each scale has demonstrated strong discriminant and test-retest validity (Carver, 1997), as well as good internal reliability, with Cronbach's alphas ranging from .78 to .94 on the individual subscales (Grande, Arnott, Brundle, \& Pilling, 2014).

\section{Primary outcome measure.}

The Functional Assessment of Chronic Illness Therapy Fatigue Scale (FACIT-F; Cella et al., 2005), is a 13-item scale that assesses both feelings of fatigue (e.g., "I feel weak all over") and consequences of fatigue common in individuals with chronic illness (e.g., "I have trouble finishing things because I am so tired"), and has been validated for use with cancer populations (Webster, Cella, \& Yost, 2003). Questions are rated on a 5-point Likert scale from 0 (not at all) to 4 (very much), with lower scores indicating greater fatigue severity. A validation study using patients with cancer, stroke and HIV found the FACIT-F to have very good construct and testretest validity, as well as strong internal reliability, with Cronbach's alphas greater than .90 (Butt et al., 2013).

Covariates. All demographic and medical variables examined as potential covariates were gathered from patient medical records or self-report questionnaires. Demographic variables 
included the following items: Age, ethnicity, relationships status, number of children, level of education (e.g., high school, undergraduate degree or diploma, graduate degree), employment status, and annual income bracket. Medical variables captured via chart review included the following items: Time since diagnosis, cancer stage, and whether the patient was currently receiving treatment, and type of treatment (e.g., chemotherapy, radiation therapy, surgery, or a combination of two or all three). The remainder of the medical covariates, including pain, anxiety, nausea, and sleep dissatisfaction, were captured via self-report questionnaires described below.

The Brief Pain Inventory (BPI; Cleeland \& Ryan, 1994), 4-item severity subscale was used to assess for pain severity (e.g., "circle the number that described your pain at its worst in the last 24 hours"). Questions are answered on a scale from 0 (no pain) to 10 (pain as bad as you can imagine). The questionnaire has demonstrated good construct and test-retest validity, as well as strong internal reliability, with Cronbach's alphas ranging from .80 to .87 for the four pain severity items (Cleeland \& Ryan, 1991).

State-Trait Anxiety Inventory—State Subscale (STAI-S; (Spielberger, 1983) was used to assess for patient endorsement of current anxiety symptoms. This 20 -item scale evaluates the intensity of the patients' current feelings of anxiety (e.g., "I feel strained"). Questions are answered on a 4-point Likert scale from 1 (not at all) to 4 (very much so), with higher scores indicating greater anxiety. The STAI is one of the most widely researched and used measures to assess for general anxiety. While there is evidence to indicate that the trait subscale of this measure may be tapping into general negative affect (Balsamo et al., 2013), the state subscale appears to not suffer from this issue in construct validity, and a validation study using a large 
non-clinical sample $(N=1173)$ found the STAI to have very good internal reliability, with a Cronbach's alpha of .87 (Knight, Waalmanning, \& Spears, 1983).

Functional Assessment of Cancer Therapy-Ovarian (FACT-O; Basen-Engquist et al., 2001) was used to assess for both nausea and sleep dissatisfaction. The FACT-O has demonstrated adequate construct and test-retest validity (Basen-Engquist et al., 2001).

Nausea was assessed with a single item from the Physical Well-being Subscale: "I have nausea." This item was rated on a 5-point Likert scale from 0 (not at all) to 4 (very much), with higher scores indicating more nausea.

Sleep Dissatisfaction was assessed with a single item from the Functional Well-being Subscale: "I am sleeping well." This item was rated on a 5-point Likert scale from 0 (not at all) to 4 (very much), with higher scores indicating better sleep, or a lack of sleep difficulties. To assess for dissatisfaction with sleep, this item was reverse coded so that higher scores indicated greater sleep dissatisfaction.

\section{Data Analysis}

Hypothesis 1. To determine what demographic, medical variables, and types of symptoms were significantly associated with fatigue severity, a series of bivariate correlations were conducted when examining continuous variables (e.g., pain severity), and factorial ANOVAs were conducted when examining variables with three or more categories (e.g., ethnicity, annual income bracket, cancer stage, treatment type). All categorical demographic or medical variables that revealed significant between group differences were followed up with the Scheffe post-hoc test to determine which groups differed significantly from each other. The between group differences were then used to reduce the multi-categorical variables to dichotomous variables based on the post-hoc tests (e.g., full- and part-time employment were 
combined to created an "employed" category, and retired, on disability, and unemployed were combined to create an "unemployed" category). Finally, independent samples t-tests were then conducted to examine the relationship between dichotomized variables and fatigue (e.g., whether there were significant differences in fatigue severity between those who were currently undergoing treatment compared to those who were not).

Hypothesis 2. To examine the extent to which illness perceptions were associated with fatigue severity, a linear regression was conducted using fatigue severity as the outcome of interest. All demographic and medical variables revealed as significant predictors of fatigue in hypothesis one were included in step one of the model. Then the seven illness perception variables were entered as predictors in step two of the model: Illness identity, personal controllability, treatment controllability, chronicity, cyclicality, consequences, and illness coherence.

Hypothesis 3. Seven separate mediation analyses using the illness perceptions as the predictor variable were conducted using the PROCESS Macro version 2.15 for SPSS (Hayes, 2012). Bias corrected confidence intervals (Bca CI) were created using 10,000 re-samples with replacement, which were used to assess the direct, indirect, and total effect of illness perceptions on severity of fatigue, using negative and positive coping strategies as mediators. All demographic, medical and symptom severity variables elucidated as important predictors of fatigue in hypothesis one were controlled for in all analyses. Bias corrected confidence intervals were employed as they are designed to convert samples that are non-normally distributed, by estimating and correcting for skew and kurtosis in the sample. It should be noted that lower scores on the FACIT-F scale indicate greater fatigue. Thus, a negative relationship between illness perceptions or coping strategies and fatigue is indicative of greater fatigue severity. 
According to a mediational framework, the path from the predictor variables to the mediators (path $a$ ), the mediators to the outcome variable (path $b$ ), the predictor variables to the outcome variable (path $c$ ), and the same path after taking into consideration the mediators (path $c^{\prime}$ ), provide both the direct effect (the relationship between illness perceptions and fatigue, controlling for coping strategies), the indirect effect (the effect of illness perceptions on fatigue through coping strategies), and the total effect (the combined effect of the direct and indirect effect on fatigue). Refer to Figure 2 for the complete mediation model showing all seven illness perceptions, positive and negative coping strategies, and fatigue.

Power analysis. A power calculation, using the program Power and Precision (Borenstein, 2000), was conducted to ascertain the minimum number of participants required for sufficient power to detect a medium effect. We calculated the power for 283 participants (i.e., the number of patients in the dataset) using the most comprehensive model to be tested, which included a total of 14 variables: Seven covariates (age, employment status, current chemotherapy, pain, anxiety, nausea, and sleep dissatisfaction), seven predictors (illness perceptions), and two mediators (negative and positive coping strategies, for a minimum total $R^{2}$ $=.30$. Using these parameters, power was at $1.00(\alpha=.05)$, confirming that the sample was adequately powered for our analyses. 


\section{Results}

\section{Preliminary Data Analyses}

Prior to conducting the main analyses, data were screened for outliers and assumptions of normality and linearity were tested. According to the recommendation that the skewness statistic be divided by its standard error and the resulting $\mathrm{z}$-score should fall between $\pm 2.58(p<.01$;

Field, 2009), the screening revealed the following variables had non-normal distributions: Patient age, time since diagnosis, illness perceptions of timeline, consequences, treatment control and illness coherence, pain severity, fatigue severity, and positive and negative coping strategies.

Each of these variables was transformed using square-root and logarithmic transformations. However, the transformations were only effective at reducing skewness on the following variables: Pain severity, and selection of positive and negative coping strategies. As the transformed variables did not change the results, the untransformed data were used in all subsequent analyses.

\section{Participant Demographics and Medical Characteristics}

A total of 283 individuals were included in the present study. Table 4 displays the demographics of the sample at baseline. Participants were on average 58 years old, with the majority being Caucasian (77\%), and highly educated with $60.3 \%$ of patients reporting at least a college or university level education. In terms of employment, $38.5 \%$ were working full or parttime, while $33.8 \%$ were retired, and $20.3 \%$ were on disability. For average annual income, $43.8 \%$ reported earning up to $\$ 40,000$, while the remainder reported annual earning above this income amount. For relationship or marital status, the majority of participants, $68.9 \%$ reported they were married or in a long-term relationship, and $63.6 \%$ reported they had one or more children. 
Medical characteristics are displayed in Table 5 . The majority of patients, $69.4 \%$, were diagnosed with Stage III or IV ovarian cancer. On average, patients were 3.6 years since diagnosis, with $14.5 \%$ currently completing their initial treatment, $39.4 \%$ were currently experiencing a disease recurrence after their primary treatment, and 32.6\% had completed their primary treatment and were disease free. Almost half (49.5\%) of patients were currently undergoing treatment, with $6.3 \%$ having received surgery only, $22.7 \%$ receiving chemotherapy alone, $17.6 \%$ receiving both surgery and chemotherapy, $2.9 \%$ receiving a combination of all three treatments, while the rest (50.5\%) were not receiving treatment at the time of this study.

\section{Descriptive Information on Key Variables}

The number of items comprising each measure, the means, standard deviations, score ranges found within the present sample, and internal consistency values (Cronbach's alpha) for all key study variables (demographic, medical, and symptom types, illness perceptions, coping strategies, and fatigue) are displayed in Table 6.

Illness perceptions. The reliability coefficients (Cronbach's alpha) and mean summed scores are shown for each illness perception subscale, below:

Illness identity. This subscale of the IPQ-R demonstrated good reliability with a Cronbach's alpha coefficient of .81 , and a summed mean score of $6.18(S D=11.53)$ with a range of 0-14 (out of a total possible range of 0-14), indicating that participants, endorsed experiencing 6 out of a total 14 possible symptoms, which they attributed to their cancer experience.

Chronicity. This subscale of the IPQ-R demonstrated strong reliability with a Cronbach's alpha coefficient of .92 , and a summed mean score on of $20.37(S D=7.32)$ with a range of 6-24 (out of a total possible range of 5-25), indicating that participants reported, on average, very high endorsement of the perception that their cancer diagnosis is chronic in nature. 
Table 4

Participant Demographics $(\mathrm{N}=283)$

\begin{tabular}{|c|c|c|c|}
\hline Variable & $n$ & Mean (SD) & Range \\
\hline \multirow[t]{2}{*}{ Age, years } & 283 & $58(11.26)$ & $21-85$ \\
\hline & $n$ & \multicolumn{2}{|c|}{ Frequency (\%) } \\
\hline \multicolumn{4}{|l|}{ Education } \\
\hline$\leq$ High school degree & 42 & 15.1 & \\
\hline Some college & 69 & 24.7 & \\
\hline College/university & 114 & 40.9 & \\
\hline Graduate school & 54 & 19.4 & \\
\hline \multicolumn{4}{|l|}{ Ethnicity } \\
\hline Caucasian & 214 & 77.0 & \\
\hline Asian & 35 & 12.6 & \\
\hline African American & 12 & 4.3 & \\
\hline Hispanic & 5 & 1.8 & \\
\hline Other (mixed race) & 12 & 4.3 & \\
\hline \multicolumn{4}{|l|}{ Employment status } \\
\hline Working full-time & 78 & 27.8 & \\
\hline Working part-time & 30 & 10.7 & \\
\hline Disability & 57 & 20.3 & \\
\hline Retired & 95 & 33.8 & \\
\hline Not employed & 21 & 7.5 & \\
\hline \multicolumn{4}{|l|}{ Relationship status } \\
\hline Married/long-term partnership & 193 & 68.9 & \\
\hline Separated/divorced & 35 & 12.5 & \\
\hline Widowed & 14 & 5.0 & \\
\hline Single & 35 & 11.8 & \\
\hline Other (dating for undisclosed time) & 5 & 1.8 & \\
\hline \multicolumn{4}{|l|}{ Children } \\
\hline One or more children & 180 & 63.6 & \\
\hline No children & 103 & 36.4 & \\
\hline \multicolumn{4}{|l|}{ Average annual income } \\
\hline $0-40,000$ & 116 & 43.8 & \\
\hline $40-75,000$ & 74 & 27.9 & \\
\hline$+75,000$ & 75 & 28.3 & \\
\hline
\end{tabular}

Note. $N$ : sample size; $S D$ : standard deviation. 
Table 5

Participant Medical Characteristics ( $\mathrm{N}=283)$

\begin{tabular}{|c|c|c|c|}
\hline Variable & $N$ & Mean (SD) & Range \\
\hline \multirow[t]{2}{*}{ Time since diagnosis, in years } & 283 & $3.57(3.51)$ & $.01-19.68$ \\
\hline & $N$ & & Frequency $(\%)$ \\
\hline \multicolumn{4}{|l|}{ Cancer stage } \\
\hline Stage 1 & 63 & & 22.4 \\
\hline Stage 2 & 23 & & 8.2 \\
\hline Stage 3 & 162 & & 57.7 \\
\hline Stage 4 & 33 & & 11.7 \\
\hline \multicolumn{4}{|l|}{ Currently undergoing treatment } \\
\hline Yes & 133 & & 49.5 \\
\hline No & 150 & & 50.5 \\
\hline \multicolumn{4}{|l|}{ Point in cancer treatment } \\
\hline Recurrence of disease, on treatment & 111 & & 39.4 \\
\hline Post primary treatment, disease free & 92 & & 32.6 \\
\hline Completing primary treatment & 41 & & 14.5 \\
\hline Past recurrence, now disease free & 17 & & 6.0 \\
\hline Recurrence of disease, no treatment & 12 & & 4.3 \\
\hline $\begin{array}{l}\text { Post primary treatment, diseased } \\
\text { (surveillance, maintenance, follow-up) }\end{array}$ & 9 & & 3.2 \\
\hline \multicolumn{4}{|l|}{ Types of treatment at current time } \\
\hline Surgery only & 17 & & 6.3 \\
\hline Chemotherapy only & 62 & & 22.7 \\
\hline Surgery and chemotherapy & 48 & & 17.6 \\
\hline Surgery, radiation and chemotherapy & 8 & & 2.9 \\
\hline Not currently receiving treatment & 138 & & 50.5 \\
\hline
\end{tabular}

Note. $N$ : sample size; $S D$ : standard deviation. 
Table 6

Descriptive Statistics for Primary Study Variables

\begin{tabular}{lrrrrr}
\hline \multicolumn{1}{c}{ Variable } & $\begin{array}{r}\text { Total } \\
\text { items }\end{array}$ & $n$ & Mean $(S D)$ & Range & $\begin{array}{c}\text { Internal } \\
\text { consistency }(\alpha)\end{array}$ \\
\hline Illness perceptions & & & & & \\
$\quad$ Personal control & 6 & 284 & $20.14(4.83)$ & $6-30$ & .85 \\
$\quad$ Treatment control & 5 & 255 & $18.63(3.59)$ & $5-25$ & .71 \\
$\quad$ Illness identity & 14 & 283 & $6.18(3.30)$ & $0-14$ & .81 \\
$\quad$ Chronicity & 6 & 259 & $20.37(7.32)$ & $6-24$ & .92 \\
$\quad$ Cyclicality & 4 & 281 & $11.24(3.57)$ & $4-20$ & .77 \\
$\quad$ Consequences & 6 & 283 & $22.63(4.75)$ & $6-30$ & .80 \\
$\quad$ Illness coherence & 5 & 223 & $19.31(4.49)$ & $5-25$ & .88 \\
Coping strategy & & & & & \\
$\quad$ Positive & 12 & 286 & $2.80(.63)$ & $1-4$ & .85 \\
$\quad$ Negative & 8 & 287 & $1.46(.44)$ & $1-4$ & .71 \\
Fatigue severity & 13 & 275 & $35.81(11.53)$ & $5-52$ & .95 \\
Pain severity & 4 & 259 & $1.66(2.02)$ & $0-9$ & .94 \\
Anxiety severity & 20 & 274 & $37.71(13.46)$ & $20-79$ & .96 \\
Nausea & 1 & 272 & $.53(.90)$ & $0-4$ & $\mathrm{n} / \mathrm{a}$ \\
Sleep dissatisfaction & 1 & 273 & $1.74(1.25)$ & $0-4$ & $\mathrm{n} / \mathrm{a}$ \\
\hline
\end{tabular}

Note. $N$ : sample size; $S D$ : standard deviation.

Cyclicality. This subscale of the IPQ-R demonstrated adequate reliability with a Cronbach's alpha coefficient of .77, and a summed mean score of $11.2(S D=3.57)$ with a range of 4-20 (out of a total possible range of 4-20), indicating that participants reported, on average, moderate endorsement of the perception that their cancer diagnosis is cyclical in nature.

Consequences. This subscale of the IPQ-R demonstrated good reliability with a Cronbach's alpha coefficient of .80 , and a summed mean score of $22.63(S D=4.75)$ with a range of 6-30 (out of a total possible range of 6-30), indicating that participants reported, on average, high endorsement of that their cancer diagnosis has significant negative consequences in their daily life. 
Personal control. This subscale of the IPQ-R demonstrated good reliability with a Cronbach's alpha coefficient of .85 , and a summed mean score of $20.14(S D=4.83)$ with a range of 6-30 (out of a total possible range of 6-30), indicating that participants reported, on average, moderately high endorsement of the perception that they had personal control over their cancer diagnosis.

Treatment control. This subscale of the IPQ-R demonstrated adequate reliability with a Cronbach's alpha coefficient of .71, and a summed mean score of $18.63(S D=3.59)$ with a range of 5-25 (out of a possible range of 5-25), indicating participants reported, on average, moderately high endorsement that their medical care will be effective in treating their cancer diagnosis.

Illness coherence. This subscale of the IPQ-R demonstrated strong reliability with a Cronbach's alpha coefficient of .88 , and a summed mean score of $19.31(S D=4.49)$ with a range of 5-25 (out of a possible range of 5-25), indicating that participants reported, on average, moderately high to high endorsement that they understand their cancer diagnosis and symptoms.

Coping. Based on recommendations by the instrument developer of the Brief-COPE (Carver, 1997), an exploratory factor analysis (EFA) was conducted. First, the scree plot was examined to determine the number of factors to extract (Cattell, 1966). A two-factor solution was revealed, using the number of points to the left of the site of inflection (e.g., the "elbow") on the screen plot graph. This form of factor extraction, via the scree plot, has been shown to provide a reliable criterion for factor selection in samples with over 200 participants (Stevens, 2009). Next, the EFA was re-run using a forced principal factors extraction set to a two-factor solution with varimax rotation, to determine which questions from the Brief-COPE-SF mapped onto the two extracted factors. The varimax rotation ensures items are loaded in an orthogonal design to either one of the two possible factor loadings. In line with the protocol outlined by (Comrey \& Lee, 
1992), a minimum of .40 was used as the threshold for determining items eligible for loading onto a factor, in accordance with a minimum sample size requirement of $N=200$. Refer to Table 7 for a complete list of items comprising each of the two revealed factors, with factor loadings.

Twelve items loaded onto factor one, with an eigenvalue of 5.47, and a Cronbach's alpha coefficient of .85, indicating good internal reliability. This factor included items from the following subscales of the Brief-COPE: Self-distraction, active coping, use of emotional support, use of instrumental support, positive reframing, and planning. Based on the predominantly positive goal-oriented coping strategies belonging to these subscales this factor was labeled "Positive Coping." The summed mean score for the Positive Coping scale was 2.80 $(S D=.63)$ with a range of 1-4 (out of a total possible range of 1-4), which reflects that participants reported, on average, moderate to high endorsement of positive coping strategies.

Eight items loaded onto factor two, with an eigenvalue of 3.01, and a Cronbach's alpha coefficient of .71, indicating adequate reliability. These items included questions from the following subscales of the Brief-COPE: Denial, behavioural disengagement, self-blame, and non-acceptance. Based on the predominantly negative and avoidant coping strategies belonging to these subscales Factor 2 was labeled "Negative Coping." The summed mean score for the Negative Coping subscale was $1.46(S D=.44)$ with a range of 1-3.25 (out of a total possible range of 1-4), which reflects that participants reported, on average, low to moderate selection of negative coping strategies. 
Table 7

Factor Loadings for Exploratory Factor Analysis With Varimax Rotation of Brief-COPE Inventory

\begin{tabular}{|c|c|c|}
\hline Items & Factor one & Factor two \\
\hline $\begin{array}{l}\text { 1. I have been turning to work or other activities to take my mind off } \\
\text { things. }\end{array}$ & .43 & .11 \\
\hline $\begin{array}{l}\text { 2. I've been concentrating my efforts on doing something about the } \\
\text { situation I'm in. }\end{array}$ & .61 & -.07 \\
\hline 3. I've been saying to myself "this isn't real." & .23 & .60 \\
\hline 4. I've been using alcohol or other drugs to make myself feel better. & -.02 & .13 \\
\hline 5. I've been getting emotional support from others. & 63 & -.14 \\
\hline 6. I've been giving up trying to deal with it. & -.08 & .59 \\
\hline 7. I've been taking action to try to make the situation better. & .66 & -.12 \\
\hline 8. I've been refusing to believe that it has happened. & .25 & .51 \\
\hline 9. I've been saying things to let my unpleasant feelings escape. & .38 & .24 \\
\hline 10. I've been getting help and advice from other people. & .70 & -.06 \\
\hline 11. I've been using alcohol or other drugs to help me get through it. & .02 & .28 \\
\hline $\begin{array}{l}\text { 12. I've been trying to see it in a different light, to make it seem more } \\
\text { positive. }\end{array}$ & .59 & -.12 \\
\hline 13. I've been criticizing myself. & .14 & .60 \\
\hline 14. I've been trying to come up with a strategy about what to do. & .68 & .04 \\
\hline 15. I've been getting comfort and understanding from someone. & .67 & -.12 \\
\hline 16. I've been giving up the attempt to cope. & .01 & .47 \\
\hline 17. I've been looking for something good in what is happening. & .55 & -.14 \\
\hline 18. I've been making jokes about it. & .28 & -.29 \\
\hline $\begin{array}{l}\text { 19. I've been doing something to think about it less, such as going to } \\
\text { movies, watching TV, reading }\end{array}$ & .47 & .19 \\
\hline $\begin{array}{l}\text { 20. I've been accepting the reality of the fact that it has happened } \\
\text { (reverse coded) }\end{array}$ & -.34 & .47 \\
\hline 21. I've been expressing my negative feelings. & .37 & .15 \\
\hline 22. I've been trying to find comfort in my religion or spiritual beliefs. & .34 & .18 \\
\hline 23. I've been getting advice or help from people about what to do. & .64 & .11 \\
\hline 24. I've been learning to live with it (reverse coded) & -.31 & .52 \\
\hline 25. I've been thinking hard about what steps to take. & .62 & .09 \\
\hline 26. I've been blaming myself for things that happened. & .12 & .67 \\
\hline 27. I've been praying or meditating. & .34 & .15 \\
\hline 28. I've been making fun of the situation. & .27 & -.20 \\
\hline
\end{tabular}

Note. Factor loadings $>.40$ are in boldface, and represent the specific items loading on to each factor. 
Fatigue. The FACIT demonstrated excellent reliability with a Cronbach's alpha coefficient of .95. The summed mean score was $35.81(S D=11.53)$ with a range of 5-52 (out of a total possible range of $0-52$ ). The mean score reflects that participants reported, on average, clinically significant fatigue, as any score below 42 is considered a clinical cut-off for CRF. As a reminder, lower scores on this scale indicate worse fatigue.

Pain. The severity subscale of the BPI demonstrated excellent reliability with a Cronbach's alpha coefficient of .94. The summed mean score was $1.66(S D=2.02)$ with a range of 0-9 (out of a total possible range of 0-9). The mean score reflects that participants reported, on average, low pain.

Anxiety. The STAI-S demonstrated excellent reliability with a Cronbach's alpha coefficient of .96. The summed total score was $37.71(S D=13.46)$ with a range of 20-79 (out of a total possible range of 20-80). The summed score reflects that participants reported, on average, moderate anxiety.

Nausea. This single item of the FACT-O Physical Well-being subscale had a mean score of $.53(S D=.90)$ with a range of 0-4 (out of a total possible range of $0-4)$. The mean score reflects that participants reported, on average, a low amount of nausea.

Sleep dissatisfaction. This single item of the FACT-O Functional Well-being subscale had a mean score of $1.74(S D=1.25)$ with a range of $0-4$ (out of a total possible range of $0-4$ ). The mean score reflects that participants reported, on average, a moderate amount of dissatisfaction with their sleep. 


\section{Test of Hypotheses}

\section{Hypothesis 1. Examining demographic, medical factors, and types of symptoms}

associated with fatigue. To determine what demographic, medical variables, and types of symptoms were significantly associated with fatigue severity, a series of bivariate correlations were conducted with the following continuous variables: Age, time since diagnosis, pain, anxiety, nausea, sleep dissatisfaction and fatigue severity. Younger age $(r=.14)$, greater anxiety $(r=-.43)$, more nausea $(r=-.49)$, more sleep dissatisfaction $(r=-.40)$, and worse pain $(r=-.45)$ were all found to be significantly correlated with fatigue severity $(p<.01)$. A factorial ANOVA was then conducted to examine the following demographic or medical variables with three or more categories: Level of education, ethnicity, employment, relationship status, annual income, cancer stage, as well as current treatment types. Only employment was found to show significant between group differences with fatigue, $F(4,224)=5.15, p=.001$. A Scheffe post-hoc test revealed that those who were unemployed (e.g., unemployed, on disability or retired) had significantly greater fatigue than those who were working full or part time $(p<.001)$. Based on these results, individuals who were full or part-time employed were incorporated into a single category, and individuals who were unemployed, retired or on disability were incorporated in the other category. Next, independent samples t-tests were conducted to examine the relationship between the following dichotomized variables and fatigue: Whether the participant had children $($ yes $=1$, no $=0)$, were employed (yes $=1$, no $=0)$, or currently undergoing treatment (yes $=1$, no $=1$ ). Only employment status reveled a significant difference in fatigue severity, with unemployed individuals endorsing higher fatigue $(M=34.40, S D=11.23)$ compared to employed $(M=37.90, S D=11.73), t(271)=2.46, p=.015$. Table 8 shows the relationships between all variables with fatigue severity. 
Table 8

Associations of Demographic, Medical, and Symptom Variables with Fatigue

\begin{tabular}{lc}
\hline Variable & $r, F$, or $t$ \\
\hline Age & $.14 *_{\mathrm{a}}$ \\
Ethnicity & $.66 \mathrm{~b}$ \\
Education & $-.45 \mathrm{~b}$ \\
Relationship status & $.91 \mathrm{~b}$ \\
Children & $.15 \mathrm{c}$ \\
Employment status & $2.46^{*} \mathrm{c}$ \\
Annual income & $1.04 \mathrm{~b}$ \\
Time since diagnosis & $.09 \mathrm{a}$ \\
Stage of cancer & $1.92 \mathrm{~b}$ \\
Current treatment & $.52 \mathrm{c}$ \\
Treatment type & $1.72 \mathrm{~b}$ \\
Pain severity & $-.45^{*}{ }_{\mathrm{a}}$ \\
Anxiety severity & $-.43 * *_{\mathrm{a}}$ \\
Nausea & $-.49 * *_{\mathrm{a}}$ \\
Sleep dissatisfaction & $-.40 * *_{\mathrm{a}}$ \\
\hline
\end{tabular}

Note. $a=$ Pearson correlations were used to assess the relationship between fatigue and continuous variables. $b=$ Factorial ANOVAs were used to test for significant differences between groups on fatigue severity in categorical variables. $c=$ Independent samples t-tests were used to assess for differences in fatigue severity between groups in dichotomous variables. $* p<.05, * * p<.01$.

Education, relationship status, having children, income, time since diagnosis, cancer stage, currently undergoing treatment, and treatment type were not significantly associated with fatigue. However, younger age, $r=.14, p=.021$, being unemployed, $t(271)=2.46, p=.015$, and endorsing greater pain, $r=-.45, p<.001$, anxiety, $r=-.43, p<.001$, nausea, $r=-.49, p<.001$ and sleep dissatisfaction, $r=-.40, p<.001$, were all significantly correlated with fatigue, and thus included as covariates in all subsequent analyses. 


\section{Hypothesis 2. The association of illness perceptions with fatigue severity. Prior to}

conducting regression analyses, multicollinearity was assessed through a correlation matrix with all variables of interest included in the model. Most variables were weakly to moderately correlated between the illness perceptions of treatment control and chronicity. Refer to Table 9 for a complete correlation matrix.

It was predicted that after controlling for age, employment status, pain severity, nausea, sleep dissatisfaction, and anxiety, greater endorsement of the following illness perceptions would be associated with greater fatigue severity: 1) Illness identity (e.g., number of symptoms attributed to cancer diagnosis), 2) chronicity or 3) cyclicality, and 4) negative consequences associated with cancer diagnosis (e.g., greater endorsement of negative outcomes associated with cancer and its related symptoms). Lower endorsement of the following illness perceptions was expected be associated with greater fatigue severity: 5) personal controllablity (e.g., lower selfefficacy to manage symptoms associated with cancer experience), 6) treatment controllability (e.g., lower perceptions that cancer and related symptoms are treatable/manageable with medications or other therapeutic interventions), and 7) illness coherence (e.g., the patient does not understand what has contributed to the initiation, maintenance, and progression of the cancer). 
Table 9

Intercorrelations Between Primary Study Variables

\begin{tabular}{|c|c|c|c|c|c|c|c|c|c|c|}
\hline & 1. & 2. & 3. & 4. & 5. & 6. & 7. & 8. & 9. & 10. \\
\hline 1. Personal control & 1.00 & & & & & & & & & \\
\hline 2. Treatment control & $.47 * *$ & 1.00 & & & & & & & & \\
\hline 3. Illness identity & $-.18^{*}$ & -.09 & 1.00 & & & & & & & \\
\hline 4. Chronicity & $-.34 * *$ & $-.49 * *$ & $.25^{* *}$ & 1.00 & & & & & & \\
\hline 5. Cyclicality & .02 & $-.18 * *$ & $.33 * *$ & $.21^{* *}$ & 1.00 & & & & & \\
\hline 6. Consequences & -.09 & $-.15 *$ & $.43 * *$ & $.38 * *$ & $.27 * *$ & 1.00 & & & & \\
\hline 7. Illness coherence & .07 & .13 & -.02 & .03 & $-.30 * *$ & -.07 & 1.00 & & & \\
\hline 8. Positive coping & $-.28 * *$ & $-.28 * *$ & .13 & .10 & -.01 & $-.18 * *$ & -.03 & 1.00 & & \\
\hline 9. Negative coping & -.08 & -.12 & .09 & -.01 & $.14^{*}$ & $.18 * *$ & $-.37 * *$ & .01 & 1.00 & \\
\hline 10. Fatigue severity & .03 & .07 & $-.45 * *$ & $-.14 *$ & $-.31 * *$ & $-.40 * *$ & $.17 * *$ & $-.16^{*}$ & $-.17 * *$ & 1.00 \\
\hline
\end{tabular}


As shown in Table 10, a two-step hierarchical multiple regression analysis was conducted. All significant findings are reported using standardized beta weights $(\beta)$. Lower scores indicated greater fatigue. Step One of the regression, which included the covariates, accounted for $47 \%$ of the variance in fatigue severity, $R^{2}=.47, F(6,105)=15.46, p<.001$. Being unemployed, $\beta=.15, p=.046$, greater pain severity, $\beta=-.32, p<.001$, endorsing greater nausea, $\beta=-.32, p<.001$, and more anxiety, $\beta=-.27, p=.001$, all predicted greater fatigue.

In Step Two of the regression, which included all seven illness perceptions, greater endorsement of illness identity, $\beta=-.21, p=.011$, and consequences, $\beta=-.26, p=.003$, accounted for an additional $13 \%$ of variance in fatigue. The total model, with all variables included, accounted for $60 \%$ of the variance in fatigue, $R^{2}=.60, F(9,159)=11.24, p<.001$.

Table 10

Summary of Linear Regression Analysis for Variables Predicting Fatigue Severity

\begin{tabular}{|c|c|c|c|c|c|c|}
\hline \multirow[b]{2}{*}{ Variable } & \multicolumn{3}{|c|}{ Model 1} & \multicolumn{3}{|c|}{ Model 2} \\
\hline & $B$ & S.E $B$ & $\beta$ & $B$ & S.E $B$ & $\beta$ \\
\hline Age & .10 & .08 & .10 & .06 & .08 & .06 \\
\hline Employment & 3.75 & 1.85 & $.15^{*}$ & 3.03 & 1.74 & .13 \\
\hline Pain severity & -1.95 & .46 & $-.32 * * *$ & -1.65 & .43 & $-.27 * * *$ \\
\hline Nausea & -3.99 & .95 & $-.32 * * *$ & -3.02 & .91 & $-.24 * *$ \\
\hline Sleep dissatisfaction & -.78 & .69 & -.09 & -.25 & .64 & -.03 \\
\hline Anxiety & -.22 & .06 & $-.27 * *$ & -.21 & .06 & $-.25 * *$ \\
\hline Personal control & & & & -.16 & .18 & -.07 \\
\hline Treatment control & & & & -.18 & .26 & -.06 \\
\hline Illness identity & & & & -.70 & .27 & $-.21 *$ \\
\hline Chronicity & & & & .19 & .14 & .12 \\
\hline Cyclicality & & & & -.07 & .24 & -.02 \\
\hline Consequences & & & & -.62 & .21 & $-.26 * *$ \\
\hline Illness coherence & & & & -.27 & .19 & -.10 \\
\hline$R^{2}$ & .47 & & & .60 & & \\
\hline$F$ & $15.46 * * *$ & & & $11.24 * * *$ & & \\
\hline$\Delta R^{2}$ & & & & .13 & & \\
\hline$\Delta F$ & & & & $4.52 * * *$ & & \\
\hline
\end{tabular}

Note: $B=$ unstandardized beta weight, S.E. $B=$ standard error of the unstandardized beta values, $\beta=$ standardized beta weight. $* p<.05, * * p<.01, * * * p<.001$. 


\section{Hypothesis 3. The indirect effect of positive and negative coping strategies on the}

relationship between each of the seven illness perceptions and fatigue severity.

Results from the seven separate indirect effect analyses indicated there was not a single significant indirect effect through negative coping on the relationship between each of the illness perceptions and fatigue severity. Both personal and treatment controllability, on the other hand, were found to have a negative indirect effect on fatigue severity, through positive coping. The following section will detail the relationship between each illness perception and fatigue severity using positive and negative coping strategies as mediators. Refer to Table 11 for a complete breakdown of each mediation analysis.

Table 11

Bootstrapping Analyses Examining the Indirect Effect of Positive and Negative Coping Strategies on the Relationship Between Illness Perceptions and Fatigue Severity

\begin{tabular}{lrrrr}
\hline \multicolumn{1}{c}{ Variable } & $\beta$ & \multicolumn{1}{c}{$S E$} & $t$ & $p$-value \\
\hline Personal Controllability & & & & \\
\hline Total effect of predictor on outcome (Path C) & -.10 & .12 & -.83 & .405 \\
Effect of predictor on mediators (Paths A) & & & & \\
$\quad$ Treatment Control $\rightarrow$ Positive Coping & .04 & .01 & 5.61 & $<.001$ \\
$\quad$ Treatment Control $\rightarrow$ Negative Coping & -.003 & .01 & -.57 & .572 \\
Effect of mediators on outcome (Paths B) & & & & \\
Positive Coping $\rightarrow$ Fatigue & -1.75 & .96 & -1.83 & .068 \\
$\quad$ Negative Coping $\rightarrow$ Fatigue & .40 & 1.55 & .26 & .799 \\
Direct effect of predictor on outcome (Path C') & -.02 & .12 & -.16 & .875 \\
\hline Treatment Controllability & & & & \\
\hline Total effect of predictor on outcome (Path C) & -.31 & .16 & -1.90 & .059 \\
Effect of predictor on mediators (Paths A) & & & & \\
Illness Coherence $\rightarrow$ Positive Coping & .06 & .01 & 5.35 & $<.001$ \\
Illness Coherence $\rightarrow$ Negative Coping & -.002 & .01 & -.25 & .804 \\
Effect of mediators on outcome (Paths B) & & & & \\
$\quad$ Positive Coping $\rightarrow$ Fatigue & -1.70 & .97 & -1.75 & .081 \\
$\quad$ Negative Coping $\rightarrow$ Fatigue & .27 & 1.61 & .17 & .865 \\
Direct effect of predictor on outcome (Path C') & -.21 & .17 & -1.19 & .236 \\
\hline
\end{tabular}


Table 11 Continued

\begin{tabular}{|c|c|c|c|c|}
\hline Variable & $\beta$ & $S E$ & $t$ & p-value \\
\hline \multicolumn{5}{|l|}{ Illness Identity } \\
\hline Total effect of predictor on outcome (Path C) & -.88 & .21 & -4.14 & $<.001$ \\
\hline \multicolumn{5}{|l|}{ Effect of predictor on mediators (Paths A) } \\
\hline Consequences $\rightarrow$ Positive Coping & .03 & .02 & 1.84 & .068 \\
\hline Consequences $\rightarrow$ Negative Coping & -.003 & .01 & -.35 & .728 \\
\hline \multicolumn{5}{|l|}{ Effect of mediators on outcome (Paths B) } \\
\hline Positive Coping $\rightarrow$ Fatigue & -.55 & 1.07 & -.51 & 609 \\
\hline Negative Coping $\rightarrow$ Fatigue & .99 & 1.74 & .57 & .572 \\
\hline Direct effect of predictor on outcome (Path C') & -.86 & .22 & -3.99 & $<.001$ \\
\hline \multicolumn{5}{|l|}{ Chronicity } \\
\hline Total effect of predictor on outcome (Path C) & -.07 & .08 & -.84 & .402 \\
\hline \multicolumn{5}{|l|}{ Effect of predictor on mediators (Paths A) } \\
\hline Timeline Cyclical $\rightarrow$ Positive Coping & -.01 & .01 & -1.94 & .054 \\
\hline Timeline Cyclical $\rightarrow$ Negative Coping & -.01 & .004 & -1.78 & .076 \\
\hline \multicolumn{5}{|l|}{ Effect of mediators on outcome (Paths B) } \\
\hline Positive Coping $\rightarrow$ Fatigue & -1.60 & .94 & -1.70 & .091 \\
\hline Negative Coping $\rightarrow$ Fatigue & .84 & 1.57 & .53 & .595 \\
\hline Direct effect of predictor on outcome (Path C') & -.08 & .08 & -.98 & .327 \\
\hline \multicolumn{5}{|l|}{ Cyclicality } \\
\hline Total effect of predictor on outcome (Path C) & -.48 & .17 & -2.85 & .005 \\
\hline \multicolumn{5}{|l|}{ Effect of predictor on mediators (Paths A) } \\
\hline Timeline Chronic $\rightarrow$ Positive Coping & .003 & .01 & .27 & .786 \\
\hline Timeline Chronic $\rightarrow$ Negative Coping & .01 & .01 & 1.42 & .156 \\
\hline \multicolumn{5}{|l|}{ Effect of mediators on outcome (Paths B) } \\
\hline Positive Coping $\rightarrow$ Fatigue & -1.79 & .89 & -2.01 & .045 \\
\hline Negative Coping $\rightarrow$ Fatigue & .75 & 1.54 & .49 & .624 \\
\hline Direct effect of predictor on outcome (Path C') & -.48 & .17 & -2.86 & .005 \\
\hline \multicolumn{5}{|l|}{ Consequences } \\
\hline Total effect of predictor on outcome (Path C) & -.49 & .12 & -4.00 & $<.001$ \\
\hline \multicolumn{5}{|l|}{ Effect of predictor on mediators (Paths A) } \\
\hline Personal Control $\rightarrow$ Positive Coping & .03 & .01 & 2.94 & .004 \\
\hline Personal Control $\rightarrow$ Negative Coping & .003 & .01 & .65 & .516 \\
\hline \multicolumn{5}{|l|}{ Effect of mediators on outcome (Paths B) } \\
\hline Positive Coping $\rightarrow$ Fatigue & -1.16 & .89 & -1.30 & .196 \\
\hline Negative Coping $\rightarrow$ Fatigue & .56 & 1.53 & .37 & .712 \\
\hline Direct effect of predictor on outcome (Path C') & -.46 & .13 & -3.70 & $<.001$ \\
\hline
\end{tabular}


Table 11 Continued

\begin{tabular}{|c|c|c|c|c|}
\hline Variable & $\beta$ & $S E$ & $t$ & p-value \\
\hline \multicolumn{5}{|l|}{ Illness Coherence } \\
\hline Total effect of predictor on outcome (Path C) & -.03 & .15 & -.18 & .856 \\
\hline \multicolumn{5}{|l|}{ Effect of predictor on mediators (Paths A) } \\
\hline Illness Coherence $\rightarrow$ Positive Coping & .001 & .01 & .07 & .946 \\
\hline Illness Coherence $\rightarrow$ Negative Coping & -.02 & .01 & -3.94 & $<.001$ \\
\hline \multicolumn{5}{|l|}{ Effect of mediators on outcome (Paths B) } \\
\hline Positive Coping $\rightarrow$ Fatigue & -1.45 & 1.01 & -1.44 & .152 \\
\hline Negative Coping $\rightarrow$ Fatigue & 1.64 & 1.78 & .92 & .357 \\
\hline Direct effect of predictor on outcome (Path C') & .01 & .15 & .09 & .932 \\
\hline Indirect Effects & Estimate & $S E$ & LL 95\%CI & UL $95 \% \mathrm{Cl}$ \\
\hline \multicolumn{5}{|l|}{ Personal Controllability } \\
\hline Positive Coping & -.08 & .04 & -.176 & -.003 \\
\hline Negative Coping & -.001 & .01 & -.029 & .011 \\
\hline \multicolumn{5}{|l|}{ Treatment Controllability } \\
\hline Positive Coping & -.10 & .06 & -.238 & -.013 \\
\hline Negative Coping & .001 & .01 & -.036 & .019 \\
\hline \multicolumn{5}{|l|}{ Illness Identity } \\
\hline Positive Coping & -.02 & .04 & -.117 & .031 \\
\hline Negative Coping & -.003 & .02 & -.079 & .021 \\
\hline \multicolumn{5}{|l|}{ Chronicity } \\
\hline Positive Coping & .02 & .02 & .000 & .064 \\
\hline Negative Coping & -.01 & .01 & -.039 & .013 \\
\hline \multicolumn{5}{|l|}{ Cyclicality } \\
\hline Positive Coping & -.01 & .02 & -.065 & .039 \\
\hline Negative Coping & .01 & .02 & -.016 & .068 \\
\hline \multicolumn{5}{|l|}{ Consequences } \\
\hline Positive Coping & -.03 & .02 & -.096 & .002 \\
\hline Negative Coping & .002 & .01 & -.009 & .034 \\
\hline \multicolumn{5}{|l|}{ Illness Coherence } \\
\hline Positive Coping & -.001 & .02 & -.042 & .030 \\
\hline Negative Coping & -.04 & .05 & -.142 & .044 \\
\hline
\end{tabular}

Note. SE: standard error; LL: lower limit; UL: upper limit; CI: confidence interval.

Personal controllability. Greater endorsement of the perception of personal control over the cancer experience and associated symptoms was not significantly associated with greater fatigue severity when examining the relationship on its own, $\beta=-.10, S E=.12, p=.405$. When examining the relationship with both positive and negative coping strategies included in the 
model as mediators, there was a significant indirect effect of personal controllability on fatigue, through positive coping, $\beta=-.08, S E=.04,95 \% \mathrm{Bca} C \mathrm{CI}[-.176,-.003]$, but not through negative coping, $\beta=-.001, S E=.01,95 \% \mathrm{Bca} C \mathrm{CI}[-.029, .011]$, holding all other variables constant. Upon examining the individual pathways, greater personal controllability was significantly associated with greater positive, $\beta=.04, S E=.01, p<.001$, but not negative, $\beta=-.003, S E=.01, p=.572$, coping strategies. However, positive, $\beta=-1.75, S E=.96, p=.068$, and negative coping strategies, $\beta=.40, S E=1.55, p=.799$, were both non-significantly associated with fatigue severity. Furthermore, after including both mediators in the model, the direct effect of personal controllability on fatigue severity was still non-significant, $\beta=-.02, S E=.12, p=.875$. In summary, greater sense of personal controllability was associated with greater selection of positive coping strategies, which in turn was associated with greater fatigue severity; an unexpected finding. However, the index of mediation, $\beta=-.04, S E=.02,95 \%$ Bca CI [-.093, -.002], which represents the standardized indirect effect, is very small. Specifically, the indirect effect of greater endorsement of personal controllability on fatigue, through greater positive coping, accounted for .04 of a standard deviation increase in fatigue. In total, $43 \%$ of the variance in fatigue severity was accounted for by the model, $R^{2}=.43, F(7,243)=26.44, p<.001$, with the majority being explained by the covariates included in the model. ${ }^{1}$ The results of the mediation analysis are displayed in Figure 3.

Treatment controllability. Greater endorsement of treatment controllability (i.e., the perception that medical interventions can help to treat or manage one's cancer experience and

${ }^{1}$ A hierarchical linear regression including all seven illness perceptions, as well as positive and negative coping as predictors, revealed that the positive and negative coping explained less than $1 \%$ of variance in fatigue severity. 
associated symptoms) was not significantly associated with fatigue severity when examining the relationship on its own, $\beta=-.31, S E=.16, p=.059$. However, when examining the relationship with both positive and negative coping strategies included in the model as mediators, treatment

a. Total effect

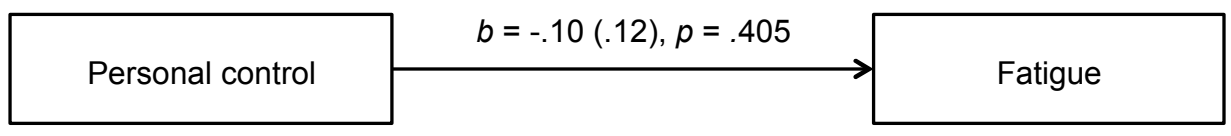

b. Direct \& indirect effects

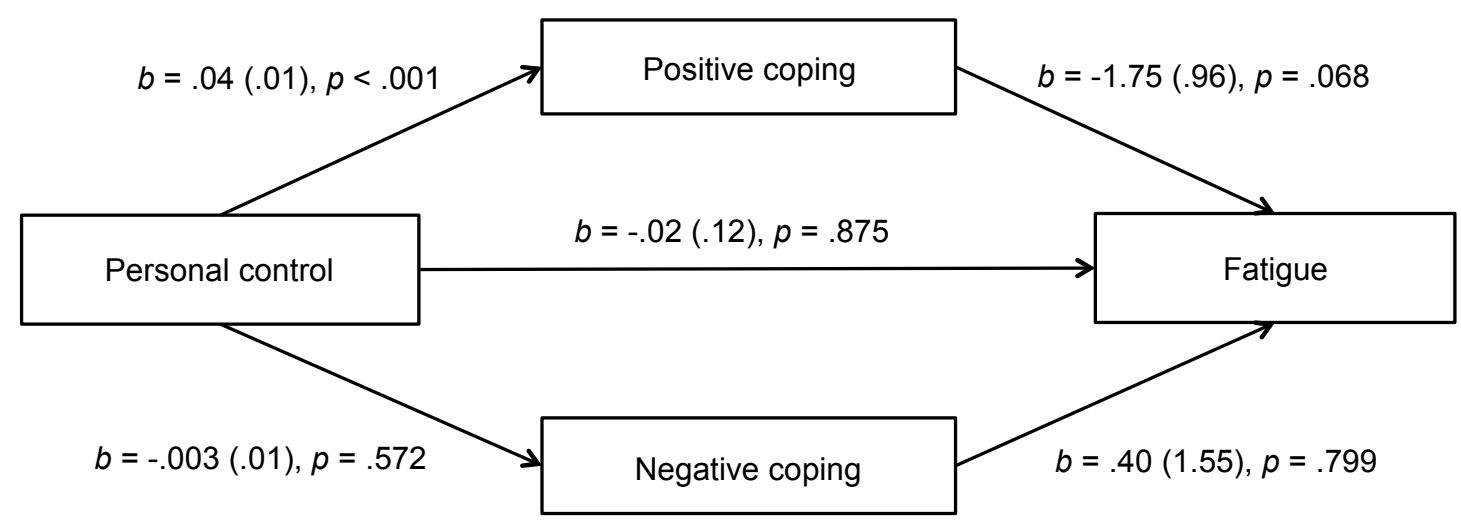

Figure 3. Model examining the relationship between personal control and fatigue severity, with positive and negative coping strategies included in the model as mediators. $b=$ unstandardized coefficient, followed by standard error of the unstandardized coefficient, then p-value.

controllability had a significant indirect effect on fatigue through positive coping, $\beta=-.10, S E=$ $.06,95 \%$ Bca CI [-.236, -.013], but not negative coping, $\beta=.001, S E=.01,95 \%$ Bca CI [-.036, .019], holding all other variables constant. Upon examining the individual pathways, greater 
treatment controllability was significantly associated with greater selection of positive coping strategies, $\beta=.06, S E=.01, p<.001$. However, it was not associated with selection of negative coping strategies, $\beta=-.002, S E=.01, p=.804$. In addition, neither negative coping strategies, $\beta$ $=.27, S E=1.61, p=.865$, or positive coping strategies, $\beta=-1.70, S E=.97, p=.081$, were significantly associated with fatigue severity. Furthermore, after accounting for both mediators in the model, the direct effect of the perception of treatment controllability on fatigue severity remained non-significant, $\beta=-.21, S E=.17, p=.236$. Ultimately, it appears that greater sense of treatment controllability was associated with greater fatigue when greater selection of positive coping strategies was included in the model as a mediator, which is an unexpected finding. However, once again, when one notes the index of mediation, $\beta=-.04, S E=.02,95 \% \mathrm{Bca} \mathrm{CI}$ [-.093, -.004], it is apparent this indirect effect is very small. Specifically, the indirect effect of greater endorsement of treatment controllability on fatigue, through greater use of positive coping, accounted for .04 of a standard deviation increase in fatigue. In total, $46 \%$ of the variance in fatigue severity was accounted for by the model, $R^{2}=.46, F(7,218)=26.65, p<$ .001 , with the majority being explained by the covariates included in the model. ${ }^{1}$ The results of the mediation analysis are displayed in Figure 4.

Illness identity. Greater endorsement of illness identity (greater number of symptoms attributed to cancer diagnosis) was significantly associated with fatigue severity when examining the relationship on its own, $\beta=-.88, S E=.21, p<.001$. However, when examining the relationship with both positive and negative coping strategies included in the model as mediators, Illness identity did not have an indirect effect on fatigue through either positive or negative coping, holding all other variables constant. Furthermore, after accounting for both mediators in the model, the direct effect of the perception of treatment controllability on fatigue severity 
remained significant, $\beta=-.86, S E=.22, p<.001$. In summary, greater endorsement of illness identity was associated with greater fatigue severity, but this relationship was not indirectly affected by either positive or negative coping strategies. In total, $52 \%$ of the variance in fatigue severity was accounted for by the model, $R^{2}=.52, F(7,155)=24.06, p<.001$.

a. Total effect

\begin{tabular}{|c|c|c|c|}
\hline Treatment control & $b=-.31(.16), p=.059$ & Fatigue \\
\cline { 2 - 4 } & &
\end{tabular}

b. Direct \& indirect effects

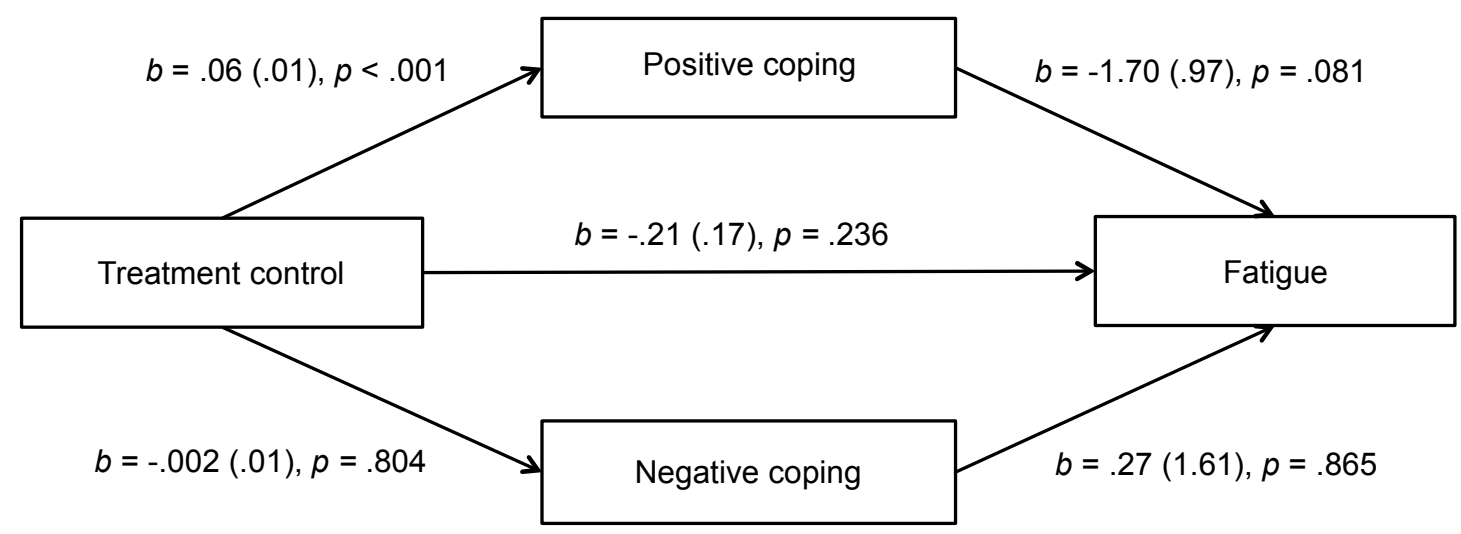

Figure 4. Model examining the relationship between personal control and fatigue, with positive and negative coping strategies included as mediators. $b=$ unstandardized coefficient, followed by standard error of the unstandardized coefficient in brackets, followed by p-value.

Chronicity. When examining the relationship between chronicity and fatigue severity, with positive and negative coping included as mediators in the model, neither the total, direct, or indirect effects were significant. In total, $47 \%$ of the variance in fatigue severity was accounted 
for by the model, $R^{2}=.47, F(7,222)=28.41, p<.001$, indicating the covariates included in the model accounted for a large amount of variance in fatigue. ${ }^{1}$

Cyclicality. Greater endorsement of cyclicality was significantly associated with greater fatigue severity when examining the relationship on its own, $\beta=-.48, S E=.17, p=.005$. However, when examining the relationship with both positive and negative coping strategies included in the model, cyclicality did not have an indirect effect on fatigue through either positive or negative coping, holding all other variables constant. Furthermore, after accounting for both mediators in the model, the direct effect of the perception of treatment cyclicality on fatigue severity remained significant, $\beta=-.48, S E=.17, p=.005$. In summary, greater endorsement of cyclicality was associated with greater fatigue severity, but this relationship was not indirectly affected by either positive or negative coping strategies. In total, $45 \%$ of the variance in fatigue severity was accounted for by the model, $R^{2}=.45, F(7,242)=28.01, p<.001$.

Consequences. Greater endorsement of consequences associated with the cancer diagnosis was significantly associated with fatigue severity when examining the relationship on its own, $\beta=-.49, S E=.12, p<.001$. However, consequences did not have an indirect effect on fatigue through positive or negative coping, holding all other variables constant. Furthermore, after accounting for both mediators in the model, the direct effect of the perception of consequences on fatigue severity remained significant, $\beta=-.46, S E=.13, p<.001$. To summarize, greater endorsement of consequences was associated with greater fatigue severity, but this relationship was not indirectly affected by either positive or negative coping strategies. In total, $46 \%$ of the variance in fatigue severity was accounted for by the model, $R^{2}=.46$, $F(7,242)=29.82, p<.001$ 
Illness coherence. When examining the relationship between illness coherence and fatigue severity, including positive and negative coping as mediators in the model, neither the total, direct, or indirect effects were significant. In total, $44 \%$ of the variance in fatigue severity was accounted for by the model, $R^{2}=.44, F(7,190)=21.21, p<.001$, indicating the covariates included in the model accounted for a large amount of variance in fatigue. ${ }^{1}$ 


\section{Discussion}

This study examined the relationship between specific patient factors - medical, demographic, symptom severity, perceptions related to the cancer experience, and coping strategies - and how these variables were associated with fatigue severity in ovarian cancer patients. First, of the demographic, medical, and symptom severity variables examined, younger age, being unemployed, and experiencing greater pain, anxiety, nausea, and sleep dissatisfaction were all significantly associated with worse fatigue. Second, Leventhal's CSM of illness perceptions was used as a framework to examine the relationship of patients' perceptions of cancer with fatigue severity, using positive and negative coping strategies as mediators. Results revealed that of the seven illness perceptions examined, only greater endorsement of illness identity and consequences associated with the cancer experience were significantly associated with more fatigue severity. Finally, the indirect effects through positive and negative coping strategies on the relationship between each illness perception and fatigue severity were examined. Interestingly, only greater positive coping was found to have a significant indirect effect on the relationship between personal and treatment control and fatigue.

\section{Sample Description}

In terms of demographic variables, the participants in this current study, while not representative of the general population, were similar to the average breakdown of participants that typically participate in cancer studies (de Jong et al., 2004; Hoffman et al., 2009; Kornblith et al., 1995). Specifically, the vast majority were Caucasian, over the age of 50, married or in a long-term relationship, highly educated, and had an average annual household income at or above $\$ 40,000$. The women in the present study appeared representative of the typical ovarian cancer population. Approximately $69 \%$ of the sample was diagnosed with late stage (III or IV) 
ovarian cancer, which is consistent with population-based data (Anderson \& Hacker, 2008; Visintin et al., 2008). Approximately half of the women were currently undergoing treatment at the time of this study. Moreover, in line with the high rate of recurrence for ovarian cancer, more than $1 / 3$ of participants were currently receiving treatment due to recurrence of disease. All analyses were broken down to determine if fatigue severity was impacted by medical treatments, as previous research has noted increased fatigue during chemotherapy or radiation therapy (Blesch et al., 1991; Danaher et al., 2006; Hacker \& Ferrans, 2003; Jacobsen et al., 1999). However, patients currently undergoing treatment did not endorse significantly greater fatigue. Sixty-five percent of the present sample endorsed clinically significant fatigue, as denoted by a score of 38 or less on the FACIT-F (Cella et al., 2005). As a reminder, lower scores on the FACIT-F indicate worse fatigue and fatigue-related impairment. The mean score in our sample was 35.81. Interestingly, participants endorsed low to moderate pain severity, which is in contrast to previous research with other cancer populations, which tend to show moderate to high levels of pain (Anderson \& Hacker, 2008; Cella et al., 2003). Participants reported moderate levels on both the anxiety and sleep dissatisfaction measures, which is consistent with previous studies on cancer patients (Cella et al., 2003; Portenoy et al., 1994; Roscoe et al., 2007; Stone et al., 2001). Finally, the present sample reported low levels of nausea, which is slightly lower than previous research on cancer patients (Jereczek-Fossa et al., 2002). Importantly, pain, anxiety, sleep dissatisfaction, and nausea were not significantly different between patients currently undergoing cancer treatments and those who were not $(p>.05)$, which is inconsistent with previous studies (Cella et al., 2003; Miaskowski \& Lee, 1999; Sun et al., 2005).

Upon examining the seven illness perceptions, participants felt that they understood their cancer experience and associated symptoms, believed they had a high amount of control over 
their symptoms, trusted available medical interventions (e.g., chemotherapy or surgery) to treat their cancer, considered their cancer to be a long-term or chronic condition, and experienced a number of negative consequences associated with their cancer diagnosis. In addition, participants reported a moderate degree of illness identity, attributing 6 out of a possible 14 physical symptoms to their cancer diagnosis, and moderate endorsement that their cancer is a cyclical problem (e.g., will recur), with a mean rating of 11.24 out of a total of 20. Similar rates of endorsement have also been demonstrated in patients with vasculitis (Grayson et al., 2013), diabetes mellitus (Searle, Norman, Thompson, \& Vedhara, 2007), hypertension (Ross, Walker, \& MacLeod, 2004), osteoarthritis (Bijsterbosch et al., 2009), and systemic sclerosis (Richards et al., 2003). The findings indicate a general trend for patients with chronic medical conditions, including cancer patients, to only moderately endorse illness identity and cyclicality, with higher overall endorsement of chronicity, consequences, personal and treatment control, and illness coherence.

On first glance, it may seem counterintuitive that patients tended to endorse positive illness perceptions (e.g., high endorsement of both personal control over their cancer experience, with concordant high endorsement of negative perceived consequences). However, these illness perceptions are tapping into distinct domains, and thus represent unique facets of each patient's cancer experience that are perceived as independent parts. For example, one patient may endorse a high degree of control over their cancer experience and report few consequences associated with their experience, while another patient may endorse a high degree of personal control while also reporting a large number of negative consequences associated with their cancer. Importantly, these illness perceptions provide information as to the general understanding and 
outlook patients have concerning their cancer diagnosis, offering insight into a number of distinct facets that patients use to make sense of their diagnosis.

On a final descriptive note, patients reported moderate to high use of positive coping strategies, and only moderate use of negative coping strategies. This moderate to high rate of endorsement of positive coping strategies is in line with previous research examining fatigue outcomes in chronic fatigue syndrome (Heijmans, 1998) and cancer patients (Hoffman et al., 2009). In addition, Heijmans (1998) also reported only moderate use of negative coping strategies, analogous to our current findings.

\section{Summary of Main Findings}

Hypothesis 1. Demographic, medical factors, and types of symptoms associated with

fatigue. Analyses examining the relationship between demographic, medical variables, and types of symptoms with fatigue both confirmed and failed to confirm previous findings within general or ovarian cancer populations. These findings are discussed below.

Demographic variables associated with fatigue. In line with previous research, younger individuals endorsed significantly greater fatigue severity (Can et al., 2004; de Jong et al., 2005; Geinitz et al., 2004; Donovan et al., 2014; Shun et al., 2005; Wratten et al., 2004). This negative relationship between age and fatigue may be due to younger patients experiencing greater noticeable changes in cognitive and physical energy levels once CRF manifests, compared to older adults who may already be experiencing less cognitive and physical energy prior to the manifestation of their CRF due to reductions in energy inherent to the aging process. In addition, three previous studies found younger (vs. older) patients to be less effective in maintaining a positive outlook, in regulating their mood, and in employing positive coping strategies (e.g., seeking medical aid to manage treatment-related side effects; Carlson et al., 2004; Merluzzi \& 
Martinez Sanchez, 1997; Wenzel et al., 1999) all of which may result in greater fatigue. Next, individuals who were unemployed also endorsed greater fatigue severity (Can et al., 2004; Danette Hann et al., 1999; Treharne et al., 2008). This association appears logical when one examines unemployment as a consequence of fatigue. Specifically, individuals who suffer from significant fatigue may be unable to maintain employment. Indeed, prior research has found CRF to hinder cancer patients from maintaining or resuming employment (Hofman et al., 2007).

Medical variables and symptoms associated with fatigue. In line with prior research, greater pain, anxiety, nausea and sleep dissatisfaction severity were all significantly associated with greater fatigue in our sample. A number of studies have demonstrated a positive relationship between pain and fatigue in cancer patients (Badr et al., 2006; Bower et al., 2000; Given et al., 2001; Jacobsen et al., 1999). Importantly, ovarian cancer patients are at greater risk, compared to other cancer populations, for experiencing pain and pain management problems due to a myriad of reasons, including post-cytoreductive surgical pain, IP catheter pain (due to insertion, dislodgment or infection), and abdominal pain (cramping and distension due to catheter insertion and site-specific chemotherapy). Like pain, nausea also increases in a linear fashion with both higher doses and combined use of IV and IP chemotherapy (Armstrong et al., 2006; Rothenberg et al., 2003). Moreover, while heightened anxiety has been previously correlated with increased fatigue within general cancer populations (Bower et al., 2006; Holzner et al., 2003; Tchekmedyian, Kallich, McDermott, Fayers, \& Erder, 2003); to date, only one study has found increased anxiety in ovarian cancer patients who met criteria for significant fatigue, compared to those who did not (Holzner et al., 2003). Building on prior research, this study is the first to demonstrate significant relationships between greater pain, nausea, and anxiety with fatigue severity in ovarian cancer patients. 
Finally, past research shows that sleep disturbances are common among cancer patients (Derogatis et al., 1979; Stiefel et al., 1990), and have been correlated with greater CRF severity and duration before, during, and immediately after cancer treatment (Anderson et al., 2003; Berger \& Higginbotham, 2000; Danaher et al., 2006; Given, Given, Azzouz, \& Stommel, 2001; Lee, 2001), and in long-term cancer survivors (Bower et al., 2000; Clevenger et al., 2012). While this current study found an association between sleep dissatisfaction and fatigue, in line with two prior studies that noted a significant association between greater sleep disruption and fatigue in ovarian cancer patients (Clevenger et al., 2012; Sandadi et al., 2011), additional research is necessary to elucidate the specific underlying factors contributing to this relationship. For example, the posited causal factors implicated in the induction of sleep disturbances, accounting partially or wholly for the relationship between sleep dissatisfaction and fatigue, appear to be different at each point in the cancer experience. On one hand, precipitating factors (e.g., prior to beginning treatment), include anxiety associated with the cancer diagnosis and upcoming treatment, and the type and stage of cancer (Davidson, MacLean, Brundage, \& Schulze, 2002; Roscoe et al., 2007). On the other hand, during the treatment phase, the effects of anti-cancer therapies and associated side effects (e.g., nausea, vomiting, pain) are implicated in sleep disturbances (Berger, 1997; Berger \& Higginbotham, 2000; Clevenger et al., 2012). In addition, patients' natural compensatory behaviours in response to sleep dissatisfaction (e.g., attempts to extend sleep time by napping) can lead to a discrepancy in the patients' natural sleep cycle, resulting in more severe and prolonged sleep disturbance, as well as increased fatigue (AncoliIsrael et al., 2001; Quesnel, Savard, Simard, Ivers, \& Morin, 2003; Savard, Simard, Ivers, \& Morin, 2005). 
Demographic variables not associated with fatigue. This study failed to find a significant association between fatigue severity and the following demographic variables: Ethnicity, relationship status, having one or more children, level of education, and annual income. However, to date, four studies examining fatigue in cancer patients have explored the relationship between ethnicity and fatigue (Carlson et al., 2004; Danette Hann et al., 1999; Jacobsen et al., 2004; Shun et al., 2005). Although the review by Prue et al., (2006) noted that fatigue did not differ among ethnic groups, another study by Carlson et al., (2004) examining CRF within a sample of cancer patients in the United States $(N=3095)$ found significantly greater fatigue in minority populations (e.g., Black, Asian, and Hispanic patients) compared to patients of European descent. A failure to find an association between ethnicity and fatigue in this current study may be due to the lack of sufficient ethnic representation, which was overwhelmingly Caucasian $(n=214)$, with the number of patients reporting other ethnicities, including Asian $(n=35)$, Black $(n=12)$, and Hispanic $(n=5)$ being quite low. It is possible that a lack of sufficient sample size for the other ethnic groups may mask potential differences between groups. In addition, while three previous studies have noted an association between lower income and increased fatigue (Can et al., 2004; Hann et al., 1999; Jacobsen et al., 2004), one study failed to find an association (Hann et al., 1997). However, once again, the current sample did not include many individuals in lower income brackets, as $56 \%$ of participants reported having an annual income of $\$ 40,000$ dollars or more per year. Upon examining the association of fatigue with relationship status, the literature is once again inconsistent, with one study reporting greater fatigue in individuals who were not in a long-term relationship (So et al., 2003), and four studies failing to find an association (Can et al., 2004; Haghighat et al., 2003; Hann et al., 1999; Jacobsen et al., 2004; Respini et al., 2003). In addition, while one study has 
noted a positive association between having children and greater fatigue (Dhruva et al., 2010), one other study failed to find an association (de Jong et al., 2004). These same inconsistencies in findings can be seen with education level as well, with a number of studies failing to find an association (Can et al., 2004; Haghighat et al., 2003; Hann et al., 1999; Respini et al., 2003; Smets et al., 1998), and two finding noting lower education level was associated with worse fatigue (Jacobsen et al., 2004; Shun et al., 2005).

Ultimately, the extant literature shows a significant amount of discrepant findings when examining the association of various demographic variables with fatigue in cancer patients. This current study adds to this literature by providing evidence that ethnicity, relationship status, having one or more children, level of education, and annual income are not associated with fatigue in ovarian cancer patients.

Medical variables not associated with fatigue. In line with prior research, the following medical variables failed to demonstrate a significant correlation with fatigue: Time since diagnosis, stage of cancer, whether the patient was currently undergoing treatment, and type of treatment. Although findings vary, the majority of studies have failed to find an association between fatigue and time since diagnosis (Andrykowski et al., 1998; Bartsch, Weis, \& Moser, 2003; Hann et al., 1997; Hann et al., 1998; Knobel et al., 2000; Okuyama et al., 2001), and tumour stage (Andrykowski et al., 1998; Hann et al., 1997; Hann et al., 1998; Knobel et al., 2000; Loge et al., 2000; Okuyama et al., 2000, 2001). However, the findings are particularly equivocal when assessing the relationship between fatigue and whether patients are currently undergoing treatment, and the strength or combination of treatment. A number of studies have reported no relationship between these treatment-related factors (Blesch et al., 1991; Danaher et al., 2006; Escobar et al., 2004; Hacker \& Ferrans, 2003; Hussain et al., 2003; Jaaback, et al., 
2016; Jacobsen et al., 1999; Markman et al., 2003; Rothenberg et al., 2003), and a number of studies have demonstrated increased fatigue during and immediately after chemotherapy or radiation therapy (Ahlberg, Ekman, \& Gaston-Johansson, 2005b; Carlsson et al., 2000; Lutgendorf et al., 2000; Stone et al., 2001), and when combined or more intense (e.g., increased dose) treatment regimes were utilized (Armstrong et al., 2006; Rothenberg et al., 2003).

Overall, this study provides evidence that the following patient factors are significantly associated with fatigue in ovarian cancer patients: Age, employment status, pain, anxiety, nausea, and sleep dissatisfaction. This information adds to a growing literature on factors implicated in fatigue outcomes in cancer patients. It also provides novel insight into patient factors correlated with fatigue in ovarian cancer patients-a sub-population of the general cancer population that appears to have been largely ignored to date when examining CRF outcomes. This information may help healthcare providers to understand patient characteristics that may predict who is at increased risk for cancer-related fatigue in ovarian cancer.

\section{Hypothesis 2. The association of illness perceptions with fatigue severity.}

Interestingly, when evaluating bivariate correlations, greater endorsement of illness identity, chronicity, cyclicality, and consequences were each associated with greater fatigue severity, while lower endorsement of personal and treatment control, and lower illness coherence were each associated with significantly less fatigue. However, when simultaneously examining these seven illness perceptions in a hierarchical linear regression (controlling for age, employment status, pain, anxiety, nausea, and sleep dissatisfaction), only greater illness identity and consequences were significantly associated with fatigue severity. These results may be best explained by the addition of the covariates in the regression model, which explained $47 \%$ of the variance in fatigue. Only an additional $13 \%$ of variance in fatigue was explained when the seven 
illness perceptions were included in the model, with illness identity and consequences appearing to explain the additional variance.

Interestingly, these findings are in line with results found in two studies examining the relationship of illness perceptions to fatigue outcomes in a sample of patients with chronic fatigue syndrome (CFS; Edwards et al., 2001; Heijmans, 1998). Both studies found that when examining all seven illness perceptions together in a hierarchical regression model, only greater endorsement of illness identity and negative consequences were associated with greater fatigue severity, accounting for $14 \%$ (Edwards et al., 2001) and 17\% (Heijmans, 1998) of the variance in fatigue. This commonality in findings may indicate that the relationship between these two illness perceptions and fatigue outcomes is similar across different types of chronic medical illnesses.

However, these results are also inconsistent with prior research in other medical populations. For example, one study of patients with vasculitis (Grayson et al., 2013) found all of the seven illness perceptions, excluding chronicity, to be significantly associated with fatigue, accounting for $18 \%$ of its variance. In addition, two separate studies examining the relationship between fatigue and perceived self-efficacy to manage symptoms (analogous to the illness perception of personal controllability) in MS (Trojan et al., 2007) and in a group of patients with mixed types of cancer (Hoffman et al., 2009), found this illness perception to predict less fatigue. Finally, another study by Ahlberg et al. (2005a) reported a significant negative association between sense of coherence and fatigue in a sample of uterine cancer patients. However, these aforementioned three studies did not employ Leventhal's full CSM when examining the association of illness perceptions on fatigue outcomes. Thus, it is difficult to ascertain whether these associations would remain if all of the illness perceptions were included in the model, 
where the shared variance between the variables would be parsed out and have allowed for the unique variance for each illness perception to be assessed in relation to fatigue.

Although the illness perceptions of illness identity and consequences were found in this study and two others (Edwards et al., 2001; Heijmans, 1998) to be related to fatigue severity, it is possible that the CSM does not provide the best framework for understanding these relationships. It may be that illness perceptions may be representing the extent of cancer-related symptomology. For example, the symptoms and consequences associated with CRF (e.g., pain, nausea, and sleep disturbances, loss of energy and ability to complete day-to-day tasks) are well established within the literature (Andrykowski et al., 2010; Bower et al., 2012; Brown et al., 2008; Horneber et al., 2012; Prue et al., 2006; Weis, 2011). Indeed, when examining the association between illness identity and fatigue in this present sample, the consistency of symptom attributions becomes apparent when one examines the 14 individual symptoms that comprise this scale. The following five symptoms were attributed by more than $55 \%$ of respondents to their cancer experience: Pain, loss of strength, sleep difficulties, fatigue, and nausea; while upset stomach was attributed by $50 \%$ of respondents to their cancer experience. Not only are these highly endorsed illness identity items highly correlated with fatigue in our own sample, but prior research has repeatedly found an association between pain, lack of strength, sleep difficulties, nausea, and fatigue in cancer patients (Ahlberg et al., 2005b; Badr et al., 2006; Berger \& Higginbotham, 2000; Bower et al., 2000; Derogatis et al., 1979; Given et al., 2001; Jacobsen et al., 1999; Knobf, 1986). Notably, the remainder of the illness identity items had very low endorsement: Stiff joints, sore throat, breathlessness, weight loss, sore eyes, wheeziness, headaches, and dizziness. Ultimately, the relationship between higher endorsement 
of illness identity and fatigue may be best explained by patient symptom severity, which may be driving worse fatigue.

Next, upon examining the relationship between the illness perception of perceived consequences and fatigue, this association may be best understood by considering the possibility that fatigue is a negative consequence associated with the cancer experience. Indeed, fatigue is often described in the literature as the most significant negative consequence associated with the cancer experience (Bower et al., 2005; Cella et al., 2003). Fatigue results in a host of negative outcomes including inability to maintain employment, incapacity to complete day-to-day tasks, and loss of quality of life due to reduced energy to maintain relationships, engage in daily routines, or participate in valued life activates such as hobbies, leisure activities, or other social engagements that provide value to ones life (Andrykowski et al., 2010; Berger, 1997; Bower et al., 2012; Brown et al., 2008; Horneber et al., 2012; Prue et al., 2006; Weis, 2011). Ultimately, this relationship may best be explained by reversing the causal order; greater fatigue may in fact be driving greater endorsement of negative consequences associated with the cancer experience. Given that these data are cross-sectional, this is an important consideration.

Why were the remaining illness perceptions were not associated with fatigue severity? One possible explanation may relate to the wording of the questions. The remaining illness perceptions (personal and treatment control, cyclicality and chronicity, and coherence) address the patients' perceptions related to their cancer experience, not related to their fatigue experience. For example, one of the "personal controllability" questions asks the respondent whether they agree that "the course of my illness depends on me." Presumably the respondent when answering this question is responding to their general cancer experience, and not fatigue in particular. Potentially the results from this study could be quite informative if the questionnaire 
was re-designed to ascertain patient perceptions relating specifically to their fatigue, instead of their cancer experience in general. Ultimately, the illness perceptions are capturing patients' perceptions of their general cancer experience, which precludes our ability to assess the relationship between illness perceptions specific to fatigue and fatigue severity or fatigue-related outcomes.

\section{Aim 3. The indirect effect of positive and negative coping strategies on the relationship between each of the seven illness perceptions and fatigue.}

The results of the indirect effects analyses partially confirmed hypothesis three: Greater endorsement of the illness perceptions of both personal control and treatment control were indirectly associated with greater fatigue, when positive coping was included in the model as a mediator, albeit only to a small degree. As both of the indirect effects through positive coping are negative in value, this indicates that greater endorsement of both personal and treatment control are associated with worse fatigue, and that this association is carried through greater selection of positive coping strategies.

Why do personal and treatment control indirect effect fatigue through positive coping? This may be due to the nature of what positive coping strategies entail. Positive coping strategies are comprised of problem-focused or approach-based (e.g., changing or modifying stressors associated with the cancer experience), emotional or instrumental support-seeking, and reappraisal-based strategies (e.g., self-reflection, examination and alteration of emotional responses to the cancer experience; Dempster, Howell, \& McCorry, 2015; Hagger \& Orbell, 2003). Thus, it may be that patients who are experiencing worse fatigue, and also endorse a greater sense of personal or treatment control, believe that they, and their medical team, can manage their cancer and associated symptoms - all of which could manifest as increased use of 
positive coping strategies, such as seeking out medical assistance, attempting to reappraise their symptoms (e.g., see their fatigued state in a new light) or seeking social or emotional support. If this hypothesis is correct, then fatigue may be driving greater use of positive coping strategies in individuals who endorse a high sense of personal and treatment controllability. Indeed, Hagger and Orbell (2003) found that cancer patients that perceived their illness/disease to be treatable (e.g., surgery, chemotherapy, physiotherapy), and who believe their own personal behaviours/actions can impact their illness and related health outcomes (e.g., greater perceptions of personal or treatment controllability) were significantly positively correlated with cognitive reappraisal based, problem-focused, and social/emotional support seeking forms of coping behaviours. To explore this possibility, we examined reversing the mediation model within our current data set, so that fatigue was the independent variable, personal and treatment controllability were the outcome variables, and positive coping was the mediator. The indirect effects through positive coping were maintained, indicating a reversal of order could potentially account for the significant indirect effect. Explained causally, patients experiencing greater fatigue who endorse greater treatment and personal control tend to use more positive coping strategies in an attempt to manage or deal with their fatigue.

An alternate explanation may be that individuals who endorse a high sense of personal or treatment control, who engage in positive coping strategies, may experience increased fatigue due to burnout or exhaustion. In line with this hypothesis, a literature review by Arndt et al. (2014) found that cancer patients (e.g., breast and lung) who exerted more regulatory behaviors (e.g., attempting to reframe their experience, regulate emotions, or problem solve symptom management), in an attempt to manage negative outcomes associated with their cancer treatment, reported greater endorsement of fatigue and cognitive problems (e.g., issues of concentration, 
working memory capacity, and mental fogginess; Kaplan \& Berman, 2010). The authors posited that greater use of self-regulatory behaviours to manage distress associated with cancer or treatment-related side effects may ultimately result in depletion of mental resources, which negatively impact patients' ability to self-regulate or cope with other negative cancer-related outcomes, such as fatigue. Indeed, Arendt et al. (2014) posited that depletion of mental resources may ultimately manifest as fatigue in cancer patients. Another study conducted by Lebel, Rosberger, Edgar, \& Devins, (2008) provides further support for this hypothesis. Lebel and colleagues (2008) found that greater use of problem-solving coping strategies in breast cancer survivors at 3-months post diagnosis predicted worse cancer-related distress at 6-years post diagnosis. They hypothesized that attempting to produce positive outcomes early on in the cancer diagnosis may ultimately be detrimental over time, if the anticipated positive outcomes the problem-solving coping strategies were expected to produce fail to manifest. This alternative explanation fits nicely with the indirect effects found through positive coping on the relationship between personal and treatment control and fatigue. In line with Arendt et al.'s (2014) and Lebel et al.'s (2008) findings, patients who are attempting to exert a greater number of self-regulatory behaviours to manage cancer-related symptoms (e.g., pain, nausea, distress or anxiety) may ultimately exhaust their mental resources and lose faith in the utility of positive coping, both of which may result in increased fatigue.

A final explanation for these results may be that regardless of the indirect effects found, illness perceptions are not in fact directly associated with fatigue. Two possible explanations appear reasonable. As stated previously, the questions designed to capture each of the illness perceptions are worded to capture the general cancer experience, and not fatigue in particular. Moreover, while Leventhal's CSM has shown promise in revealing associations between illness 
perceptions with other psychosocial outcomes, including depression, anxiety, and quality of life; fatigue may be a distinct cancer-related outcome unaffected by the patient's perceptions related to their general cancer experience. Indeed, the high level of variance accounted for in fatigue severity by demographic and medical variables provides evidence that these factors exert strong influence on fatigue outcomes, while patient perceptions fail to account for much variance.

Ultimately, while an indirect effect through positive coping was found when examining the relationship between personal control and treatment control with fatigue, these two indirect effects were very small, making these two associations difficult to interpret within the context of the current theoretical model. A number of potential alternative explanations are more parsimonious, including the possibility that the relationship between these two illness perceptions and fatigue is in fact causally reversed (e.g., patients with greater fatigue who endorse more personal or treatment control will use more positive coping strategies in an attempt to manage their fatigue), or that patients high in self-efficacy, which would be manifested in the use of more positive coping strategies, may experience burn-out from their attempts to manage their cancer symptoms, which could ultimately result in greater fatigue.

\section{Limitations}

The present findings must be considered in light of several limitations. First, there are limitations regarding the generalizability of the sample. The vast majority of the sample (77\%) was Caucasian, was highly educated, and reported high annual incomes. However, this lack of proportional representation of ethnic groups, education levels, and income brackets is a common occurrence in public health research (Yancey, Ortega, \& Kumanyika, 2006), making the present sample consistent with the majority of studies assessing CRF outcomes. 
A second limitation involves the cross-sectional nature of the study. All analyses were conducted using a single time point, limiting causal inferences. Although illness perceptions are posited to predict fatigue severity, it is possible that fatigue is in fact driving illness perceptions. For example, greater fatigue may precede and then drive greater endorsement of negative consequences associated with the cancer experience. Indeed, prior research using longitudinal designs has found that greater fatigue during and after cancer treatment is associated with worse psychosocial (e.g., anxiety and depression) and quality of life outcomes after cessation of treatment (Bower et al., 2005; Fagundas et al., 2011). Ultimately, a longitudinal study may have allowed for inferences into the dynamic nature of these variables, and to understand how changes in the proposed predictor variables affect changes in fatigue severity and maintenance over time.

A third limitation is the quality of the measures. Only a single item was used to assess sleep dissatisfaction and nausea, resulting in a dearth of information on the severity, quality (e.g., type of sleep problem, or extent of nausea), or consistency of these two symptoms. For example, the single item that measured sleep dissatisfaction could be capturing sleep disturbance due to environmental issues (e.g., noisy environment or disruptive bed partner), a circadian rhythm disorder, nightmares, sleep apnea, narcolepsy, shift work, or parasomnias. While some of these may be relevant to understanding the relationship between sleep disturbances and fatigue within the context of cancer (e.g., circadian rhythm disruption has been associated with ongoing fatigue in cancer survivors; Clevenger et al., 2012), other unmeasured factors prevent our ability to determine what is driving the link between sleep dissatisfaction and fatigue. In addition, as mentioned previously, the measure of illness perceptions assessed general cancer-related illness perceptions, failing to capture patients' specific perceptions of their fatigue experience. In line with this limitation, the coping questionnaire merely assessed for general coping strategies, 
instead of fatigue-specific coping. This lack of specificity may inhibit our ability to detect the direct association between fatigue-specific illness perception, coping strategies, and fatigue severity. Finally, despite using a questionnaire that was designed to capture CRF, it lacked specificity in ascertaining the impact fatigue has on patients' daily life, or the level of distress the patient experiences in response to their fatigue. A more tailored questionnaire, which captures and specifies the physical (e.g., reduced energy to perform tasks) and mental (e.g., inability to concentrate, poor memory retention) domains of fatigue, as well as fatigue-related distress (e.g., social, emotional, psychological, cognitive, and physiological) would be beneficial in elucidating whether fatigue-related impairment and distress are differentially associated with demographic or medical variables, or patient perceptions of their cancer experience. In addition, a daily fatigue diary would be beneficial in capturing the quality, consistency, and level of disruptions associated with fatigue. For example, at what point during the day is cognitive and physical fatigue worse (e.g., morning or evening), does it come in cycles where a certain number of days are better or worse, and how are fatigue-related impairment and distress differentially impacting daily activities?

Fourth, as this study was conducted using a data set originally collected for another purpose, a measure assessing depression was not available to include in the model. As depression has been found to be significantly correlated with fatigue in a number of previous studies (Andrykowski et al., 2010; Brown, McMillan, \& Milroy, 2005; Dimeo et al., 2004; GastonJohansson et al., 1999; Haghighat et al., 2003; Hann et al., 1997; Loge, Abrahamsen, Ekeberg, \& Kaasa, 2000; Okuyama et al., 2000; Smets et al., 1998; Stone et al., 2001), this may have accounted for a significant amount of unexplained variance in fatigue. 
Finally, while this present study does include information on patient medical history, the nuances of the dosage and treatment combination were lacking. For example, the level of radiation or chemotherapy dosage is unknown, as well as whether the patients received IV or IP chemotherapy, or a combination of both. In addition, infections due to catheter insertion are unknown. These factors are of relevance as prior research has demonstrated that both stronger dosage and combined IV and IP chemotherapy, as well as infections at the IP catheter insertion site, are associated with greater treatment related side-effects (e.g., pain, abdominal distress, sleep disturbance), and can impact fatigue outcomes, including the onset, maintenance and severity of fatigue (Armstrong et al., 2006; Jaaback et al., 2016; Rothenberg et al., 2003; Sura et al., 2006).

\section{Clinical Implications}

The results of this present study provide support for two demographic variables correlated with fatigue in ovarian cancer patients: Age and employment status. In addition, a number of symptoms were revealed to be significantly associated with fatigue severity as well, including pain, sleep dissatisfaction, nausea, and anxiety severity. In contrast, the utility of assessing patient illness perceptions and coping strategies to identify individuals at greater risk for fatigue appears to be less promising.

However, these results provide evidence that similar variables associated with fatigue in the general cancer population also appear to extend to ovarian cancer patients as well. This provides clinicians with valuable insight into which factors may predict or predispose ovarian cancer patients to experiencing greater CRF. Although there is currently a lack of consensus within the medical community concerning the optimal method or frequency for screening for CRF (Mitchell, 2010), due to the high rate of incidence, it is recommended that patients be 
assessed for CRF at regular intervals throughout the various stages of the cancer experience (e.g., diagnosis, treatment, immediately post-treatment, long-term follow-up). It is also recommended that specific etiological factors (e.g., cancer treatment type, infection, pain, etc.) be taken into account when assessing for risk of CRF in patients (Berger et al., 2015; Mitchell, 2010). By providing a checklist of specific patient-related factors associated with increased fatigue severity in ovarian cancer patients, clinicians may be able to quickly assess for patient level of risk for experiencing fatigue, and employ specific strategies to help reduce fatigue severity, such as pharmaceutical or psychosocial interventions designed to reduce anxiety, pain, nausea, or sleep dissatisfaction.

If this idea is correct, the clinical implications for managing fatigue are clearmanagement of fatigue should focus on cancer and treatment-related side effects, such as pain, nausea, and perceived sleep quality, as well as psychological variables including patient anxiety, instead of focusing on the patient's perceptions of their cancer experience.

\section{Future Directions}

The results ultimately failed to provide support for applying Leventhal's CSM to understanding fatigue outcomes in ovarian cancer patients. However, as previously discussed, the measures used to capture illness perceptions and coping strategies did not assess these domains specific to the context of fatigue, or fatigue-related outcomes, potentially masking associations that may exist. Future research, employing modified questionnaires designed to assess illness perceptions and coping strategies specific to fatigue, distress related to fatigue, as well as fatigue-related outcomes (e.g., disruption in daily life due to fatigue) would be beneficial in parsing out whether patients' perceptions and coping strategies specific to their fatigue experience are associated with fatigue in ovarian cancer patients. In addition, a more nuanced 
fatigue questionnaire, with a combined daily fatigue diary, would be beneficial in identifying the differences in cognitive and physical fatigue manifestations, as well as distress related to fatigue, and whether fatigue severity and disruption to daily life is variable across days, weeks, or months. Indeed, prior research has found a significant association between use of positive coping strategies and reduced fatigue-related distress, which is in opposition to the results found in this present study (Reuille, 2002). This indicates that while the experience of fatigue itself may not be impacted by coping strategies, the distress associated with fatigue may be impacted by selection of positive coping strategies. Although use of positive coping strategies may not impact objective fatigue outcomes, the act of acceptance-based strategies, or seeking social or emotional support may improve distress associated with the fatigue experience. Indeed, prior longitudinal research found use of positive coping strategies to predict less cancer-related distress and fatigue in breast cancer survivors at three-months and one year after the initial baseline assessment (Stanton et al., 2002). Finally, a longitudinal design, using multiple data collection points at 3- 6and 12-month intervals would allow for a better understanding of how fatigue is impacted by demographic, medical, and perceptions of fatigue and fatigue-related consequences across time, and how specific dynamic cancer-related factors (e.g., recurrence of disease or resuming another course of treatment) impact fatigue severity over time.

Additionally, employing an alternate model to assess the association of psychosocial variables with fatigue may provide novel insight into CRF outcomes in ovarian cancer patients. While Leventhal's CSM appeared promising as a tool to understanding potentially modifiable patient-related factors (illness perceptions and coping strategies) associated with fatigue, the data indicate that the way one understands or perceives and copes with their cancer experience does not appear to be associated with fatigue severity. An alternative model that may provide novel 
insight into the fatigue outcomes is Self-Regulation Theory (SRT), which proposes that providing patients with specific information related to their illness or symptoms facilitates adaptive or positive coping, allowing patients to navigate and manage stressful or negative outcomes associated with their disease status (Johnson, 1999; Johnson, Fieler, Wlasowicz, Mitchell, \& Jones, 1997). Applying SRT to fatigue in cancer populations, the model posits that in order for patients to effectively cope with CRF, they must have an understanding of what it is, characteristic symptoms of fatigue, how fatigue typically manifests during the course of treatment, and management strategies for dealing with fatigue. In line with this model, one previous study which assessed pre-surgical expectation of post-surgery fatigue in colorectal cancer patients, found that those who expected less fatigue reported greater fatigue and fatiguerelated disruption to their daily life two months post-surgery (Paddison et al., 2009). The authors posited that unrealistically low expectations of fatigue might predispose patients to experience greater fatigue-related distress, due to a lack of appropriate preparation or expectation, ultimately resulting in greater perceived fatigue-related consequences. In comparison, the patients who expected greater fatigue and fatigue-related consequences reported lower fatigue and fatiguerelated consequences post-treatment, which the authors attributed to more realistic expectations and preparation prior to beginning their treatment. Ultimately the authors suggested that if patients are adequately prepared for the fatigue experience with accurate information about what to expect in terms of symptoms and disruption to daily life, prior to beginning cancer treatment, this will serve to reduce distress related to fatigue, thereby enabling patients' to cope adaptively. 


\section{References}

Ahlberg, K., Ekman, T., \& Gaston-Johansson, F. (2005a). Fatigue, psychological distress, coping resources, and functional status during radiotherapy for uterine cancer. Oncology Nursing Forum, 32(3), 633-640. http://doi. 10.1188/05.ONF.633-640

Ahlberg, K., Ekman, T., \& Gaston-Johansson, F. (2005b). The experience of fatigue, other symptoms and global quality of life during radiotherapy for uterine cancer. International Journal of Nursing Studies, 42(4), 377-386. http://doi.org/10.1016/j.ijnurstu.2004.07.008

Ahlberg, K., Wallgren, A., \& Gaston-johansson, F. (2004). Fatigue, psychological distress, coping and quality of life in patients with uterine cancer. Journal of Advanced Nursing, 45(2), 205-213. http://doi. 10.1046/j.1365-2648.2003.02882.x

Almadrones, L. (2007). Evidence-based research for intraperitoneal chemotherapy in epithelial ovarian cancer. Clinical Journal of Oncology Nursing, 11(2), 211-216. http://doi.org/10.1188/07.CJON.211-216

Ancoli-Israel, S., Liu, L., Marler, M. R., Parker, B. A., Jones, V., Sadler, G. R., ... Fiorentino, L. (2006). Fatigue, sleep, and circadian rhythms prior to chemotherapy for breast cancer.

Supportive Care in Cancer, 14(3), 201-9. http://doi.org/10.1007/s00520-005-0861-0

Ancoli-Israel, S., Moore, P. J., \& Jones, V. (2001). The relationship between fatigue and sleep in cancer patients: A review. European Journal of Cancer Care, 10(4), 245-255. http://doi.org/10.1046/j.1365-2354.2001.00263.x

Ancoli-Israel, S., Rissling, M., Neikrug, A., Trofimenko, V., Natarajan, L., Parker, B. a, ... Liu, L. (2012, June). Light treatment prevents fatigue in women undergoing chemotherapy for breast cancer. Supportive Care in Cancer, 20(6), 1211-1219. http://doi.org/10.1007/s00520$011-1203-\mathrm{z}$ 
Andersen, B. L., Woods, X. A., \& Copeland, L. J. (1997). Sexual self-schema and sexual morbidity among gynecologic cancer survivors. Journal of Consulting and Clinical Psychology, 65(2), 211-220. http://doi.org/10.1007/s11103-011-9767-z.Plastid

Anderson, K. O., Getto, C. J., Mendoza, T. R., Palmer, S. N., Wang, X. S., Reyes-Gibby, C. C., \& Cleeland, C. S. (2003). Fatigue and sleep disturbance in patients with cancer, patients with clinical depression, and community-dwelling adults. Journal of Pain and Symptom Management, 25(4), 307-318. http://doi.org/10.1016/S0885-3924(02)00682-6

Anderson, N., \& Hacker, E. (2008). Fatigue in women receiving intraperitoneal chemotherapy for ovarian cancer: A review of contributing factors. Clinical Journal of Oncology Nursing, 12(3), 445-454. http://doi.org/10.1188/08.CJON.445-454

Andrykowski, M. A., Curran, S. L., \& Lightner, R. (1998). Off-treatment fatigue in breast cancer survivors: A controlled comparison. Journal of Behavioral Medicine, 21(1), 1-18. https://doi-org.ezproxy.lib.ryerson.ca/10.1023/A:1018700303959

Andrykowski, M., Donovan, K., Laronga, C., \& Jacobsen, P. B. (2010). Prevalence, predictors, and characteristics of off-treatment fatigue in breast cancer survivors. Cancer, 116(24), 5740-8. http://doi.org/10.1002/cncr.25294

Appels, A., \& Mulder, P. (1989). Fatigue and heart disease: The association between "vital exhaustion" and past, present and future coronary heart disease. Journal of Psychosomatic Research, 33(6), 727-738. http://doi.org/10.1016/0022-3999(89)90088-3

Armstrong, D. K., Bundy, B., Wenzel, L., Huang, H. Q., Baergen, R., Lele, S., .. Burger, R. a. (2006). Intraperitoneal cisplatin and paclitaxel in ovarian cancer. The New England Journal of Medicine, 354(1), 34-43. http://doi.org/10.1056/NEJMoa052985

Arndt, J., Das, E., Schagen, S. B., Reid-Arndt, S. A., Cameron, L. D., \& Ahles, T. A. (2014). 
Broadening the cancer and cognition landscape: The role of self-regulatory challenges. Psycho-Oncology, 23(1), 1-8. http://doi.org/10.1002/pon.3351

Badr, H., Basen-Engquist, K., Taylor, C., \& De Moor, C. (2006). Mood states associated with transitory physical symptoms among breast and ovarian cancer survivors. Journal of Behavioral Medicine, 29(5), 461-475. http://doi.org/10.1007/s10865-006-9052-9

Balsamo, M., Romanelli, R., Innamorati, M., Ciccarese, G., Carlucci, L., \& Saggino, A. (2013). The State-Trait Anxiety Inventory: Shadows and lights on its construct validity. Journal of Psychopathology and Behavioral Assessment, 35(4), 475-486.

http://doi.org/10.1007/s10862-013-9354-5

Bardwell, W., \& Ancoli-Israel, S. (2008). Breast cancer and fatigue. Sleep Medicine Clinics, 3(1), 61-71. http://doi.org/10.1016/j.jsmc.2007.10.011

Barsevick, A., Frost, M., Zwinderman, A., Hall, P., \& Halyard, M. (2010). I'm so tired: Biological and genetic mechanisms of cancer-related fatigue. Quality of Life Research, 19(10), 1419-1427. http://doi.org/10.1007/s11136-010-9757-7

Barsevick, A., Irwin, M., Hinds, P., Miller, A., Berger, A., Jacobsen, P., ... Cella, D. (2013). Recommendations for high-priority research on cancer-related fatigue in children and adults. Journal of the National Cancer Institute, 105(19), 1432-40. http://doi.org/10.1093/jnci/djt242

Bartsch, H. H., Weis, J., \& Moser, M. T. (2003). Cancer-related fatigue in patients attending oncological rehabilitation programs: Prevalence, patterns and predictors. Onkologie, 26, 5157. http://doi.org/10.1159/000069864

Basen-Engquist, K., Bodurka-Bevers, D., Fitzgerald, M. A., Webster, K., Cella, D., Hu, S., \& Gershenson, D. M. (2001). Reliability and validity of the Functional Assessment of Cancer 
Therapy-Ovarian. Journal of Clinical Oncology, 19(6), 1809-1817.

Bellizzi, K. M., \& Blank, T. O. (2006). Predicting posttraumatic growth in breast cancer survivors. Health Psychology, 25(1), 47-56. http://doi.org/10.1037/0278-6133.25.1.47

Berger, A. M. (1997). Patterns of fatigue and activity and rest during adjuvant breast cancer chemotherapy. Oncology Nursing Forum, 25(1), 51-62.

http://www.ncbi.nlm.nih.gov/pubmed/9460773

Berger, A. M. (1998). Patterns of fatigue and activity and rest during adjuvant breast cancer chemotherapy. Oncology Nursing Forum, 25(1), 51-62. Retrieved from http://www.ncbi.nlm.nih.gov/pubmed/9460773

Berger, A. M., \& Farr, L. (1999). The influence of daytime inactivity and nighttime restlessness on cancer-related fatigue. Oncology Nursing Forum, 26(10), 1663-71. http://www.ncbi.nlm.nih.gov/pubmed/10573683

Berger, A. M., \& Higginbotham, P. (2000). Correlates of fatigue during and following adjuvant breast cancer chemotherapy: A pilot study. Oncology Nursing Forum, 27(9), 1443-8. http://www.ncbi.nlm.nih.gov/pubmed/11058976

Berger, A. M., Mooney, K., Alvarez-perez, A., Breitbart, W. S., Carpenter, K. M., Cella, D., ... Smith, C. (2015). Cancer-related fatigue: Clinical practice guidelines in oncology. Journal of National Comprehensive Cancer Network, 13(8), 1012-1039. http://doi.10.6004/jncen.2003.0029

Bijsterbosch, J., Scharloo, M., Visser, A. W., Watt, I., Meulenbelt, I., Huizinga, T. W. J., ... Kloppenburg, M. (2009). Illness perceptions in patients with osteoarthritis: Change over time and association with disability. Arthritis Care and Research, 61(8), 1054-1061. http://doi.org/10.1002/art.24674 
Blesch, K. S., Paice, J. A., Wickham, R., Harte, N., Schnoor, D. K., Purl, S., ... Coveny, S. B. (1991). Correlates of fatigue in people with breast or lung cancer. Oncology Nursing Forum, 18(1), 81-7. http://www.ncbi.nlm.nih.gov/pubmed/2003120

Bodurka-Bevers, D., Basen-Engquist, K., Carmack, C. L., Fitzgerald, M., Wolf, J. K., De Moor, C., \& Gershenson, D. M. (2000). Depression, anxiety, and quality of life in patients with epithelial ovarian cancer. Gynecologic Oncology, 78, 302-308.

http://doi.org/10.1006/gyno.2000.5908

Borenstein, M. (2000). Power and Precision. Retrieved from http://www.poweranalysis.com/about_biostat.htm

Bower, J. E., Ganz, P. A., Desmond, K. A., Bernaards, C., Rowland, J. H., Meyerowitz, B. E., \& Belin, T. R. (2006). Fatigue in long-term breast carcinoma survivors: A longitudinal investigation. Cancer, 106(4), 751-758. http://doi.org/10.1002/cncr.21671

Bower, J. E., Ganz, P. A., Desmond, K. A., Rowland, J. H., Meyerowitz, B. E., \& Belin, T. R. (2000). Fatigue in breast cancer survivors: Occurrence, correlates, and impact on quality of life. Journal of Clinical Oncology, 18(4), 743-53.

http://www.ncbi.nlm.nih.gov/pubmed/10673515

Bower, J. E., Ganz, P. a., Dickerson, S. S., Petersen, L., Aziz, N., \& Fahey, J. L. (2005). Diurnal cortisol rhythm and fatigue in breast cancer survivors. Psychoneuroendocrinology, 30(1), 92-100. http://doi. 10.1016/j.psyneuen.2004.06.003

Bower, J. E., Ganz, P. a, \& Aziz, N. (2005). Altered cortisol response to psychologic stress in breast cancer survivors with persistent fatigue. Psychosomatic Medicine, 67(2), 277-80. http://doi.org/10.1097/01.psy.0000155666.55034.c6

Bower, J. E., Ganz, P. a, Irwin, M. R., Arevalo, J. M. G., \& Cole, S. W. (2011). Fatigue and gene 
expression in human leukocytes: Increased NF- $\mathrm{KB}$ and decreased glucocorticoid signaling in breast cancer survivors with persistent fatigue. Brain, Behavior, and Immunity, 25(1), 147-50. http://doi.org/10.1016/j.bbi.2010.09.010

Bower, J. E., Lamkin, D. M., \& Manuscript, A. (2012). Inflammation and cancer-related fatigue: Mechanisms, contributing factors, and treatment implications. Brain, Behavior, and Immunity, 30(0), S48-S57. http://doi.org/10.1016/j.bbi.2012.06.011

Broeckel, J. A., Jacobsen, P. B., Horton, J., Balducci, L., \& Lyman, G. H. (1998). Characteristics and correlates of fatigue after adjuvant chemotherapy for breast cancer. Journal of Clinical Oncology, 16(5), 1689-96. http://doi.org/10.1200/JCO.1998.16.5.1689

Brown, D. J. F., McMillan, D. C., \& Milroy, R. (2005). The correlation between fatigue, physical function, the systemic inflammatory response, and psychological distress in patients with advanced lung cancer. Cancer, 103(2), 377-382. http://doi.org/10.1002/cncr.20777

Brown, L. F., \& Kroenke, K. (2009). Cancer-related fatigue and its associations with depression and anxiety: A systematic review. Psychosomatics, 50(5), 440-447. http://doi.org/10.1176/appi.psy.50.5.440

Brown, S., Barsevick, A. M., Newhall, T., \& Manuscript, A. (2008). Management of cancerrelated fatigue. Clinical Journal of Oncology Nursing, 12(5 Suppl), 21-25. http://doi.org/10.1188/08.CJON.S2.21-25

Bültmann, U., Kant, I. J., Schröer, C. A. P., \& Kasl, S. V. (2002). The relationship between psychosocial work characteristics and fatigue and psychological distress. International Archives of Occupational and Environmental Health, 75(4), 259-266.

http://doi.org/10.1007/s00420-001-0294-0

Butt, Z., Lai, J. S., Rao, D., Heinemann, A. W., Bill, A., \& Cella, D. (2013). Measurement of 
fatigue in cancer, stroke, and HIV using the Functional Assessment of Chronic Illness Therapy - Fatigue (FACIT-F) scale. Journal of Psychosomatic Research, 74(1), 64-68. http://doi.org/10.1016/j.jpsychores.2012.10.011

Can, G., Durna, Z., \& Aydiner, A. (2004). Assessment of fatigue in and care needs of Turkish women with breast cancer. Cancer Nursing, 27(2), 153-61. http://www.ncbi.nlm.nih.gov/pubmed/15253173

Canadian Cancer Society's Advisory Committee on Cancer Statistics. (2017). Ovarian Cancer Statistics. Toronto. Retrieved from http://www.cancer.ca/en/cancer-information/cancertype/ovarian/statistics/?region $=$ on

Carlson, L. E., Angen, M., Cullum, J., Goodey, E., Koopmans, J., Lamont, L., ... Bultz, B. D. (2004). High levels of untreated distress and fatigue in cancer patients. British Journal of Cancer, 90(12), 2297-2304. http://doi.org/10.1038/sj.bjc.6601887

Carlsson, M., Strang, P., \& Bjurström, C. (2000). Treatment modality affects long-term quality of life in gynaecological cancer. Anticancer Research, 20(1B), 563-568. http://www.ncbi.nlm.nih.gov/pubmed/10769726

Carver, C. (1997). You want to measure coping but your protocol's too long: Consider the Brief COPE. International Journal of Behavioral Medicine, 4(1), 92-100.

Carver, C. S., Scheier, M. F., \& Weintraub, J. K. (1989). Assessing coping strategies: A theoretically based approach. Journal of Personality and Social Psychology, 56(2), 267283. http://doi.org/10.1037/0022-3514.56.2.267

Cattell, R. (1966). The scree test for the number of factors. Multivariate Behavioral Research, 1(2), 245-276. http://doi.org/10.1207/s15327906mbr0102_10

Cella, D., Paul, D., Yount, S., Winn, R., Chang, C., Banik, D., \& Weeks, J. (2003). What are the 
most important symptom targets when treating advanced cancer? A survey of providers in the National Comprehensive Cancer Network (NCCN). Cancer Investigation, 21(4), 526535. http://doi.org/10.1081/CNV-120022366

Cella, D., Yount, S., Sorensen, M., Chartash, E., Sengupta, N., \& Grober, J. (2005). Validation of the Functional Assessment of Chronic Illness Therapy Fatigue Scale relative to other instrumentation in patients with rheumatoid arthritis. The Journal of Rheumatology, 32(5), $811-819$.

Chen, S.-L., Tsai, J. C., \& Lee, W. L. (2008). Psychometric validation of the Chinese version of the Illness Perception Questionnaire-Revised for patients with hypertension. Journal of Advanced Nursing, 64(5), 524-534. http://doi.org/10.1111/j.1365-2648.2008.04808.x

Cleeland, C., \& Ryan, C. (1991). The Brief Pain Inventory User Guide. Pain Research Group. Retrieved from http://www.mdanderson.org/education-and-research/departments-programsand-labs/departments-and-divisions/symptom-research/symptom-assessmenttools/BPI_UserGuide.pdf

Cleeland, C. S., \& Ryan, K. M. (1994). Pain assessment: Global use of the Brief Pain Inventory. Annals of the Academy of Medicine, Singapore, 23(2), 129-138.

Clevenger, L., Schrepf, A., Christensen, D., DeGeest, K., Bender, D., Ahmed, A., ... Lutgendorf, S. K. (2012). Sleep disturbance, cytokines, and fatigue in women with ovarian cancer. Brain, Behavior, and Immunity, 26(7), 1037-44. http://doi.org/10.1016/j.bbi.2012.04.003

Comrey, A., \& Lee, H. (1992). A first course in factor analysis (2nd ed.). Hillsdale, NJ: Lawrence Erlbaum Associates.

Costanzo, E. S., Lutgendorf, S. K., Bradley, S. L., Rose, S. L., \& Anderson, B. (2005). Cancer attributions, distress, and health practices among gynecologic cancer survivors. 
Psychosomatic Medicine, 67(6), 972-980. http://doi. 10.1097/01.psy.0000188402.95398.c0

Costanzo, E. S., Lutgendorf, S. K., Rothrock, N. E., \& Anderson, B. (2006). Coping and quality of life among women extensively treated for gynecologic cancer. Psycho-Oncology, 15(2), 132-142. http://doi.org/10.1002/pon.930

Danaher, E. H., Ferrans, C., Verlen, E., Ravandi, F., van Besien, K., Gelms, J., \& Dieterle, N. (2006). Fatigue and physical activity in patients undergoing hematopoietic stem cell transplant. Oncology Nursing Forum, 33(3), 614-624. http://doi.org/10.1188/06.ONF.614624

Davidson, J. R., MacLean, A. W., Brundage, M. D., \& Schulze, K. (2002). Sleep disturbance in cancer patients. Social Science \& Medicine, 54, 1309-21. http://doi.org/10.1016/S02779536(01)00043-0

de Jong, N., Candel, M., Schouten, H. C., Abu-Saad, H. H., \& Courtens, M. (2004). Prevalence and course of fatigue in breast cancer patients receiving adjuvant chemotherapy. Annals of Oncology, 15(6), 896-905. http://doi.org/10.1093/annonc/mdh229

de Jong, N., Candel, M., Schouten, H., Abu-Saad, H., \& Courtens, A. (2005). Course of mental fatigue and motivation in breast cancer patients receiving adjuvant chemotherapy. Annals of Oncology, 16(January), 372-382. http://doi.org/10.1093/annonc/mdi095

Dempster, M., Howell, D., \& McCorry, N. K. (2015). Illness perceptions and coping in physical health conditions: A meta-analysis. Journal of Psychosomatic Research, 79(6), 506-513. http://doi.org/10.1016/j.jpsychores.2015.10.006

Derogatis, L. R., Feldstein, M., Morrow, G., Schmale, A., Schmitt, M., Gates, C., ... Adler, L. M. (1979). A survey of psychotropic drug prescriptions in an oncology population. Cancer, 44, 1919-1929. 
Dhruva, A., Dodd, M., Paul, S., Cooper, B., Lee, K., West, C., ... Miaskowski, C. (2010).

Trajectories of fatigue in patients with breast cancer before, during, and after radiation therapy. Cancer Nursing, 33(3), 201-212.

http://doi.org/10.1097/NCC.0b013e3181c75f2a.Trajectories

Dimeo, F., Schmittel, A., Fietz, T., Schwartz, S., Köhler, P., Böning, D., \& Thiel, E. (2004).

Physical performance, depression, immune status and fatigue in patients with hematological malignancies after treatment. Annals of Oncology, 15(8), 1237-42.

http://doi.org/10.1093/annonc/mdh314

Donovan, H. S., Hartenbach, E. M., \& Method, M. W. (2005). Patient-provider communication and perceived control for women experiencing multiple symptoms associated with ovarian cancer. Gynecologic Oncology, 99(2), 404-411. http://doi.org/10.1016/j.ygyno.2005.06.062

Donovan, K., Kristen, A., Jacobsen, P., Andrykowski, M., Winters, E., Balducci, L., ... McGrath, P. (2004). Course of fatigue in women receiving chemotherapy and/or radiotherapy for early stage breast cancer. Journal of Pain and Symptom Management, 28(4), 373-380. http://doi. 10.1016/j.jpainsymman.2004.01.012

Dukes Holland, K., \& Holahan, C. K. (2003). The relation of social support and coping to positive adaptation to breast cancer. Psychology \& Health, 18(1), 15-29. http://doi.org/10.1080/0887044031000080656

Edwards, R., Suresh, R., Lynch, S., Clarkson, P., \& Stanley, P. (2001). Illness perceptions and mood in chronic fatigue syndrome. Journal of Psychosomatic Research, 50(2), 65-68. http://doi.org/10.1016/S0022-3999(00)00204-X

Eismann, E. A., Lush, E., \& Sephton, S. E. (2010). Circadian effects in cancer-relevant psychoneuroendocrine and immune pathways. Psychoneuroendocrinology, 35(7), 963-76. 
http://doi.org/10.1016/j.psyneuen.2009.12.011

Escobar, P. F., Markman, M., Rose, P., Zanotti, K., Webster, K., \& Belinson, J. (2004). Phase 2 trial of carboplatin, paclitaxel, and irinotecan in ovarian, fallopian tube, and primary peritoneal cancers. Gynecologic Oncology, 92, 192-196. http://doi.org/10.1016/j.ygyno.2003.10.003

Evans, D., \& Norman, P. (2009). Illness representations, coping and psychological adjustment to Parkinson's disease. Psychology \& Health, 24(10), 1181-1196. http://doi.org/10.1080/08870440802398188

Fagundas, C. P., Murray, D. M., Hwang, B. S., Gouin, J.-P., Thayer, J. F., Sollers, J. J., ... Kiecolt-Glaser, J. K. (2011). Sympathetic and parasympathetic activity in cancer-related fatigue: More evidence for a physiological substrate in cancer survivors. Psychoneuroendocrinology, 36(8), 1137-1147. http://doi.org/10.1016/j.psyneuen.2011.02.005

Field, A. (2009). Discovering statistics using SPSS (3rd ed.). Los Angeles, CA: SAGE Publications.

Gaston-Johansson, F., Fall-dickson, J. M., Bakos, A. B., \& Kennedy, M. J. (1999). Fatigue, pain, and depression in pre-autotransplant breast cancer patients. Cancer Practice, 7(5), 240-248. http://doi. 10.1046/j.1523-5394.1999.75008.x

Geinitz, H., Zimmermann, F. B., Thamm, R., Keller, M., Busch, R., \& Molls, M. (2004). Fatigue in patients with adjuvant radiation therapy for breast cancer: Long-term follow-up. Journal of Cancer Research and Clinical Oncology, 130(6), 327-333.

http://doi.org/10.1007/s00432-003-0540-9

Geoff, B., Mandel, L., Melancon, C., \& Muntz, H. (2004). Frequency of symptoms of ovarian 
cancer in women presenting to primary care clinics. The Journal of the American Medical Association, 291(22), 2705-2712. http://doi. 10.1001/jama.291.22.2705

Giannousi, Z., Manaras, I., Georgoulias, V., \& Samonis, G. (2010). Illness perceptions in Greek patients with cancer: A validation of the Revised-Illness Perception Questionnaire. PsychoOncology, 19(1), 85-92. http://doi.org/10.1002/pon.1538

Given, B., Given, C., Azzouz, F., \& Stommel, M. (2001). Physical functioning of elderly cancer patients prior to diagnosis and following initial treatment. Nursing Research, 50(4), 222-32. http://doi.org/10.1097/00006199-200107000-00006

Goff, B. A., Mandel, L. S., Melancon, C. H., \& Muntz, H. G. (2004). Frequency of symptoms of ovarian cancer in women presenting to primary care clinics. Journal of the American Medical Association, 291(22), 2705-2712. http://doi.org/10.1001/jama.291.22.2705

Grande, G., Arnott, J., Brundle, C., \& Pilling, M. (2014). Predicting cancer patients' participation in support groups: A longitudinal study. Patient Education and Counseling, 96(2), 229-236. http://doi.org/10.1016/j.pec.2014.05.003

Gray, S. E. (2007). Illness representations in young people with chronic fatigue syndrome. Psychology \& Health, 22(2), 159-174. http://doi.org/10.1080/14768320600774595

Grayson, P. C., Amudala, N. A., McAlear, C. A., Leduc, R. L., Shereff, D., Richesson, R., ... Merkel, P. A. (2013). Illness perceptions and fatigue in systemic vasculitis. Arthritis Care and Research, 65(11), 1835-1843. http://doi.org/10.1002/acr.22069

Hack, T. F., \& Degner, L. F. (2004). Coping responses following breast cancer diagnosis predict psychological adjustment three years later. Psychooncology, 13(1057-9249), 235-247. http://doi.org/10.1002/pon.739

Hacker, E. D., \& Ferrans, C. E. (2003). Quality of life immediately after peripheral blood stem 
cell transplantation. Cancer Nursing, 26(4), 312-322. http://doi.org/00002820-20030800000010

Hagger, M. S., \& Orbell, S. (2003). A meta-analytic review of the common-sense model of illness representations. Psychology \& Health, 18(2), 141-184. http://doi.org/10.1080/088704403100081321

Hagger, M. S., \& Orbell, S. (2005). A confirmatory factor analysis of the revised Illness Perception Questionnaire (IPQ-R) in a cervical screening context. Psychology \& Health, 20(2), 161-173. http://doi.org/10.1080/0887044042000334724

Haghighat, S., Akbari, M. E., Holakouei, K., Rahimi, A., \& Montazeri, A. (2003). Factors predicting fatigue in breast cancer patients. Supportive Care in Cancer, 11(8), 533-538. http://doi.org/10.1007/s00520-003-0473-5

Hann, D., Garovoy, N., Finkelstein, B., Jacobsen, P. B., Azzarello, L. M., \& Fields, K. (1999). Fatigue and quality of life in breast cancer patients undergoing autologous stem cell transplantation: A longitudinal comparative study. Journal of Pain and Symptom Management, 17(5), 311-319. http://doi.org/10.1016/S0885-3924(99)00007-X

Hann, D., Jacobsen, P., Martin, S., Azzarello, L., \& Greenberg, H. (1998). Fatigue and quality of life following radiotherapy for breast cancer: A comparative study. Journal of Clinical Psychology in Medical Settings, 5(1), 19-33. http://doi. 10.1023/A:1026249702250

Hann, D., Jacobsen, P., Martin, S., Kronish, L., Azzarello, L., \& Fields, K. (1997). Fatigue in women treated with bone marrow transplantation for breast cancer: A comparison with women with no history of cancer. Supportive Care in Cancer, 5(1), 44-52. http://doi.10.1007/BF01681961

Harcourt, D., Rumsey, N., \& AMbler, N. (1999). Same-day diagnosis of symptomatic breast 
problems: psychological impact and coping strategies. Psychology, Health \& Medicine, 4(1), 57-71. http://doi.10.1080/135485099106405

Hayes, A. F. (2012). PROCESS: A versatile computational tool for observed variable mediation, moderation, and conditional process modeling [White paper]. Retrieved from http://www.afhayes.com/ public/process2012.pdf

Heijmans, M. J. W. M. (1998). Coping and adaptive outcome in chronic fatigue syndrome. Journal of Psychosomatic Research, 45(1), 39-51. http://doi.org/10.1016/S00223999(97)00265-1

Hoffman, A. J., von Eye, A., Gift, A. G., Given, B., Given, C. W., \& Rothert, M. (2009). Testing a theoretical model of perceived self-efficacy for cancer-related fatigue self-management and optimal physical functional status. Nursing Research, 58(1), 32-41. http://doi.org/10.1097/NNR.0b013e3181903d7b

Hofman, M., Ryan, J. L., Figueroa-Moseley, C. D., Jean-Pierre, P., \& Morrow, G. R. (2007). Cancer-related fatigue: the scale of the problem. The Oncologist, 12(1), 4-10. http://doi.org/10.1634/theoncologist.12-S1-4

Holzner, B., Kemmler, G., Meraner, V., Maislinger, A., Kopp, M., Bodner, T., ... SpernerUnterweger, B. (2003). Fatigue in ovarian carcinoma patients: A neglected issue? Cancer, 97(6), 1564-1572. http://doi.org/10.1002/cncr.11253

Horneber, M., Fischer, I., Dimeo, F., Rüffer, J. U., \& Weis, J. (2012). Cancer-related fatigue: Epidemiology, pathogenesis, diagnosis, and treatment. Deutsches Ärzteblatt International, 109(9), 161-71. http://doi.org/10.3238/arztebl.2012.0161

Howlader N, Noone A, Krapcho M, Miller D, Bishop K, Kosary C, ... Cronin K. (2017). Cancer Statistics Review, 1975-2014 - SEER Statistics. Bethesda, MD. Retrieved from 
https://seer.cancer.gov/csr/1975_2014/

Hrushesky, W. J. M., Grutsch, J., Wood, P., Yang, X., Oh, E.-Y., Ansell, C., ... Braun, D. (2009). Circadian clock manipulation for cancer prevention and control and the relief of cancer symptoms. Integrative Cancer Therapies, 8(4), 387-97. http://doi.org/10.1177/1534735409352086

Hussain, M. M., Kotz, H., Minasian, L., Premkumar, A., Sarosy, G., Reed, E., ... Kohn, E. C. (2003). Phase II trial of carboxyamidotriazole in patients with relapsed epithelial ovarian cancer. Journal of Clinical Oncology, 21(23), 4356-63. http://doi.org/10.1200/JCO.2003.04.136

Ishida, A., Mutoh, T., Ueyama, T., Bando, H., Masubuchi, S., Nakahara, D., ... Okamura, H. (2005). Light activates the adrenal gland: Timing of gene expression and glucocorticoid release. Cell Metabolism, 2(5), 297-307. http://doi.org/10.1016/j.cmet.2005.09.009

Jaaback, K., Johnson, N., \& Lawrie, T. (2016). Intraperitoneal chemotherapy for the initial management of primary epithelial ovarian cancer. The Cochrane Database of Systematic Reviews, 1, 1469-493X. http://doi.org/10.1002/14651858.CD005340.pub3

Jacobsen, P. B., Andrykowski, M., \& Thors, C. L. (2004). Relationship of catastrophizing to fatigue among women receiving treatment for breast cancer. Journal of Consulting and Clinical Psychology, 72(2), 355-361. http://doi.org/10.1037/0022-006X.72.2.355

Jacobsen, P. B., Hann, D. M., Azzarello, L. M., Horton, J., Balducci, L., \& Lyman, G. H. (1999). Fatigue in women receiving adjuvant chemotherapy for breast cancer. Journal of Pain and Symptom Management, 18(4), 233-242. http://doi.org/10.1016/S0885-3924(99)00082-2 Jereczek-Fossa, B. A., Marsiglia, H. R., \& Orecchia, R. (2002). Radiotherapy-related fatigue. Critical Reviews in Oncology/Hematology, 41(3), 317-325. http://doi.org/10.1016/S1040- 
8428(01)00143-3

Johnson, J. E. (1999). Self-regulation theory and coping with physical illness. Research in Nursing \& Health, 22, 435-448. http://doi.org/10.1002/(SICI)1098240X(199912)22:6<435::AID-NUR2>3.0.CO;2-Q

Johnson, J. E., Fieler, V. K., Wlasowicz, G. S., Mitchell, M. L., \& Jones, L. S. (1997). The effects of nursing care guided by self-regulation theory on coping with radiation therapy. Oncology Nursing Forum, 24(6), 1041-50. http://www.ncbi.nlm.nih.gov/pubmed/9243588

Kaplan, S., \& Berman, M. G. (2010). Directed attention as a common resource for executive functioning and self-regulation. Perspectives on Psychological Science, 5(1), 43-57. http://doi.org/10.1177/1745691609356784

Knibb, R. C., \& Horton, S. L. (2008). Can illness perceptions and coping predict psychological distress amongst allergy sufferers? British Journal of Health Psychology, 13(1), 103-19. http://doi.org/10.1348/135910706X173278

Knight, R. G., Waalmanning, H. J., \& Spears, G. F. (1983). Some norms and reliability data for the State Trait Anxiety Inventory and the Zung Self-Rating Depression Scale. British Journal of Clinical Psychology, 22(4), 245-249. http://doi. 10.1111/j.20448260.1983.tb00610.x

Knobel, H., Loge, J. H., Nordøy, T., Kolstad, A. L., Espevik, T., Kvaløy, S., \& Kaasa, S. (2000). High level of fatigue in lymphoma patients treated with high dose therapy. Journal of Pain and Symptom Management, 19(6), 446-56. http://doi. 10.1016/S0885-3924(00)00144-5

Knobf, M. T. (1986). Physical and psychologic distress associated with adjuvant chemotherapy in women with breast cancer. Journal of Clinical Oncology, 4(5), 678-84. http://doi.org/10.1200/JCO.1986.4.5.678 
Kornblith, A. B., Thaler, H. T., Wong, G., Vlamis, V., Lepore, J. M., Loseth, D. B., ... Portenoy, R. K. (1995). Quality of life of women with ovarian cancer. Gynecologic Oncology, 59(2), 231-242. http://doi.org/S0090825885700145

Lebel, S., Rosberger, Z., Edgar, L., \& Devins, G. M. (2008). Predicting stress-related problems in long-term breast cancer survivors. Journal of Psychosomatic Research, 65(6), 513-523. http://doi.org/10.1016/j.jpsychores.2008.07.018

Lee., K. (2001). Sleep and fatigue. Annual Review of Nursing Research, 19(1), 249-273.

Leventhal, H., Leventhal, E. A., \& Contrada, R. J. (1998). Self-regulation, health and behavior: A perceptual-cognitive approach. Psychology of Health, 13, 717-733. http://doi.org/10.1080/08870449808407425

Leventhal, H., Meyer, D., \& Nerenz, D. (1980). The common sense representation of illness danger. Contributions to Medical Psychology, 2, 7-30.

Loge, J. H., Abrahamsen, A. F., Ekeberg, O., \& Kaasa, S. (2000). Fatigue and psychiatric morbidity among Hodgkin's disease survivors. Journal of Pain and Symptom Management, 19(2), 91-99. http://doi.org/10.1016/S0885-3924(99)00148-7

Lutgendorf, S. K., Anderson, B., Rothrock, N., Buller, R. E., Sood, A. K., \& Sorosky, J. I. (2000). Quality of life and mood in women receiving extensive chemotherapy for gynecologic cancer. Cancer, 89(6), 1402-1411. http://doi. 10.1002/1097-

0142(20000915)89:6<1402::AID-CNCR26>3.0.CO;2-H

Lutgendorf, S. K., Anderson, B., Ullrich, P., Johnsen, E. L., Buller, R. E., Sood, A. K., ...

Ritchie, J. (2002). Quality of life and mood in women with gynecologic cancer: A one year prospective study. Cancer, 94(1), 131-140. http://doi.org/10.1002/cncr.10155

Markman, M., Rowinsky, E., Hakes, T., Reichman, B., Jones, W., Lewis, J. L., ... Phillips, M. 
(1992). Phase I trial of intraperitoneal taxol: A Gynecoloic Oncology Group study. Journal of Clinical Oncology, 10(9), 1485-91. http://doi.org/10.1200/JCO.1992.10.9.1485

Markman, M., Zanotti, K., Webster, K., Peterson, G., Kulp, B., \& Belinson, J. (2003). Phase 2 trial of single agent docetaxel in platinum and paclitaxel-refractory ovarian cancer, fallopian tube cancer, and primary carcinoma of the peritoneum. Gynecologic Oncology, 91(3), 573576. http://doi.org/10.1016/j.ygyno.2003.08.001

McCaul, K. D., Sandgren, A. K., King, B., O’Donnell, S., Branstetter, A., \& Foreman, G. (1999). Coping and adjustment to breast cancer. Psycho-Oncology, 8(3), 230-236. http://doi.org/10.1002/(SICI)1099-1611(199905/06)8:3<230::AID-PON374>3.0.CO;2-\#

Merluzzi, T. V, \& Martinez Sanchez, M. a. (1997). Assessment of self-efficacy and coping with cancer: Development and validation of the cancer behavior inventory. Health Psychology, 16(2), 163-70. http://doi.org/http://dx.doi.org/10.1037/0278-6133.16.2.163

Miaskowski, C., \& Lee, K. A. (1999). Pain, fatigue, and sleep disturbances in oncology outpatients receiving radiation therapy for bone metastasis: A pilot study. Journal of Pain and Symptom Management, 17(5), 320-332. http://doi.org/10.1016/S0885-3924(99)00008-1

Millar, K., Purushotham, A. D., McLatchie, E., George, W. D., \& Murray, G. D. (2005). A 1year prospective study of individual variation in distress, and illness perceptions, after treatment for breast cancer. Journal of Psychosomatic Research, 58(4), 335-342. http://doi.org/10.1016/j.jpsychores.2004.10.005

Miller, A. H., Ancoli-Israel, S., Bower, J. E., Capuron, L., \& Irwin, M. R. (2008). Neuroendocrine-immune mechanisms of behavioral comorbidities in patients with cancer. Journal of Clinical Oncology, 26(6), 971-982. http://doi. 10.1200/JCO.2007.10.7805 Minton, O., Alexander, S., \& Stone, P. C. (2012). Identification of factors associated with cancer 
related fatigue syndrome in disease-free breast cancer patients after completing primary treatment. Breast Cancer Research and Treatment, 136(2), 513-20.

http://doi.org/10.1007/s10549-012-2284-1

Mitchell, S. A. (2010). Cancer-related fatigue: State of the science. Physical Medicine and Rehabilitation Clinics of North America, 2(5), 364-383.

http://doi.org/10.1016/j.pmrj.2010.03.024

Moss-Morris, R., Weinman, J., Petrie, K., Horne, R., Cameron, L., \& Buick, D. (2002). The Revised Illness Perception Questionnaire (IPQ-R). Psychology \& Health, 17(1), 1-16. http://doi.org/10.1080/08870440290001494

Neikrug, A. B., Rissling, M., Trofimenko, V., Liu, L., Natarajan, L., Lawton, S., ... AncoliIsrael, S. (2012). Bright light therapy protects women from circadian rhythm desynchronization during chemotherapy for breast cancer. Behavioral Sleep Medicine, 10(3), 202-16. http://doi.org/10.1080/15402002.2011.634940

Okuyama, T., Akechi, T., Kugaya, A., Okamura, H., Imoto, S., Nakano, T., ... Uchitomi, Y. (2000). Factors correlated with fatigue in disease-free breast cancer patients: Application of the Cancer Fatigue Scale. Supportive Care in Cancer, 8(3), 215-222. http://doi.org/10.1007/s005209900114

Okuyama, T., Tanaka, K., Akechi, T., Kugaya, A., Okamura, H., Nishiwaki, Y., ... Uchitomi, Y. (2001). Fatigue in ambulatory patients with advanced lung cancer: Prevalence, correlated factors, and screening. Journal of Pain and Symptom Management, 22(1), 554-564. http://doi.org/10.1016/S0885-3924(01)00305-0

Osowiecki, D., \& Compas, B. (1998). Psychological adjustment to cancer: Control beliefs and coping in adult cancer patients. Cognitive Therapy and Research, 22(5), 483-499. 
http://doi.10.1023/A:1018725716620

Otte, J., \& Carpenter, J. (2009). Theories, models, and frameworks related to sleep-wake disturbances in the context of cancer. Cancer Nursing, 32(2), 90-104.

Paddison, J. S., Booth, R. J., Cameron, L. D., Robinson, E., Frizelle, F. A., \& Hill, A. G. (2009). Fatigue after colorectal surgery and its relationship to patient expectations. Journal of Surgical Research, 151(1), 145-152. http://doi.org/10.1016/j.jss.2008.01.030

Payne, J. (2002). The trajectory of fatigue in adult patients with breast and ovarian cancer receiving chemotherapy. Oncology Nursing Forum, 29(9), 1334-1340. http://doi.10.1188/02.ONF.1334-1340

Piper, B., \& Cella, D. (2010). Cancer-related fatigue: Definitions and clinical subtypes. Journal of the National Comprehensive Cancer Network, 8(8), 958-966. http://doi. 10.6004/jnccn.2010.0070

Portenoy, R. K., Thaler, H. T., Kornblith, A. B., McCarthy Lepore, J., Friedlander-Klar, H., Coyle, N., ... Scher, H. (1994). Symptom prevalence, characteristics and distress in a cancer population. Quality of Life Research, 3(3), 183-189. http://doi.org/10.1007/BF00435383

Preacher, K. J., \& Kelley, K. (2011). Effect size measures for mediation models: Quantitative strategies for communicating indirect effects. Psychological Methods, 16(2), 93-115. http://doi.org/10.1037/a0022658

Prue, G., Rankin, J., Allen, J., Gracey, J., \& Cramp, F. (2006). Cancer-related fatigue: A critical appraisal. European Journal of Cancer, 42(7), 846-63. http://doi.org/10.1016/j.ejca.2005.11.026

Quesnel, C., Savard, J., Simard, S., Ivers, H., \& Morin, C. M. (2003). Efficacy of cognitivebehavioral therapy for insomnia in women treated for nonmetastatic breast cancer. Journal 
of Consulting and Clinical Psychology, 71(1), 189-200. http://doi.org/10.1037/0022006X.71.1.189

Redeker, N. S., Lev, E. L., \& Ruggiero, J. (2000). Insomnia, fatigue, anxiety, depression, and quality of life of cancer patients undergoing chemotherapy. School of Inquiry Nursing Practice Journal, 14, 286-290.

Respini, D., Jacobsen, P. B., Thors, C., Tralongo, P., \& Balducci, L. (2003). The prevalence and correlates of fatigue in older cancer patients. Critical Reviews in Oncology/Hematology, 47(3), 273-279. http://doi.org/10.1016/S1040-8428(02)00176-2

Reuille, K. M. (2002). Using self-regulation theory to develop an intervention for cancer-related fatigue. Clinical Nurse Specialist, 16(6), 311-312. http://doi.org/00002800-20021100000015

Richards, H., Herrick, A., Griffin, K., Gwilliam, P., Loukes, J., \& Fortune, G. (2003). Systemic sclerosis: Patients' perceptions of their condition. Arthritis and Rheumatism, 49(5), 689-96. http://doi.org/10.1002/art.11385

Rizou, I., De Gucht, V., Papavasiliou, A., \& Maes, S. (2016). The contribution of illness perceptions to fatigue and sleep problems in youngsters with epilepsy. European Journal of Paediatric Neurology, 20(1), 93-99. http://doi.org/10.1016/j.ejpn.2015.10.001

Roscoe, J. A., Morrow, G. R., Hickok, J. T., Bushunow, P., Matteson, S., Rakita, D., \& Andrews, P. L. R. (2002). Temporal interrelationships among fatigue, circadian rhythm and depression in breast cancer patients undergoing chemotherapy treatment. Supportive Care in Cancer, 10(4), 329-336. http://doi.org/10.1007/s00520-001-0317-0

Roscoe, J., Kaufman, M., Matteson-Rusby, S., Palesh, O., Ryan, J., Kohli, S., ... Morrow, G. (2007). Cancer-Related Fatigue and Sleep Disorders. The Oncologist, 12(1), 35-42. 
http://doi.org/10.1634/theon-cologist.12-S1-35

Ross, S., Walker, A., \& MacLeod, M. J. (2004). Patient compliance in hypertension: Role of illness perceptions and treatment beliefs. Journal of Human Hypertension, 18(9), 607-613. http://doi.org/10.1038/sj.jhh.1001721

Rothenberg, M., Liu, P., Braly, P., Wilczynski, S., Hannigan, E., Wadler, S., ... Alberts, D. (2003). Combined intraperitoneal and intravenous chemotherapy for women with optimally debulked ovarian cancer: Results from an intergroup phase II trial. Journal of Clinical Oncology, 21(7), 1313-1319. http://doi.org/10.1200/JCO.2003.07.031

Rutter, C. L., \& Rutter, D. R. (2002). Illness representation, coping and outcome in irritable bowel syndrome. British Journal of Health Psychology, 7(4), 377-391. http://doi.org/10.1348/135910702320645372

Ryan, J. L., Carroll, J. K., Ryan, E. P., Mustian, K. M., Fiscella, K., \& Morrow, G. R. (2007). Mechanisms of cancer-related fatigue. The Oncologist, 12(1), 22-34. http://doi.org/10.1634/theoncologist.12-S1-22

Saligan, L. N., \& Kim, H. S. (2012). A systematic review of the association between immunogenomic markers and cancer-related fatigue. Brain, Behavior, and Immunity, 26(6), 830-848. http://doi.org/10.1016/j.bbi.2012.05.004

Sandadi, S., Frasure, H. E., Broderick, M. J., Waggoner, S. E., Miller, J. A., \& von Gruenigen, V. E. (2011). The effect of sleep disturbance on quality of life in women with ovarian cancer. Gynecologic Oncology, 123(2), 351-355. http://doi.org/10.1016/j.ygyno.2011.07.028

Savard, J., Simard, S., Ivers, H., \& Morin, C. M. (2005). Randomized study on the efficacy of cognitive-behavioral therapy for insomnia secondary to breast cancer, part II: Immunologic 
effects. Journal of Clinical Oncology, 23(25), 6097-6106.

http://doi.org/10.1200/JCO.2005.12.513

Scharloo, M., Baatenburg De Jong, R. J., Langeveld, T., Van Velzen-Verkaik, E., Doorn-Op Den

Akker, M. M., \& Kaptein, A. A. (2005). Quality of life and illness perceptions in patients with recently diagnosed head and neck cancer. Head \& Neck, 27(10), 857-863. http://doi.org/10.1002/hed.20251

Searle, A., Norman, P., Thompson, R., \& Vedhara, K. (2007). Illness representations among patients with type 2 diabetes and their partners: Relationships with self-management behaviors. Journal of Psychosomatic Research, 63(2), 175-184.

http://doi.org/10.1016/j.jpsychores.2007.02.006

Seo, Y., Oh, H., \& Seo, W. (2010). Causal relationships among factors associated with cancerrelated fatigue. European Journal of Oncology Nursing, 14(5), 380-6. http://doi.org/10.1016/j.ejon.2009.09.008

Sephton, S., \& Spiegel, D. (2003). Circadian disruption in cancer: A neuroendocrine-immune pathway from stress to disease? Brain, Behavior, and Immunity, 17(5), 321-328. http://doi.org/10.1016/S0889-1591(03)00078-3

Servaes, P., Verhagen, S., \& Bleijenberg, G. (2002). Determinants of chronic fatigue in diseasefree breast cancer patients: A cross-sectional study. Annals of Oncology, 13(4), 589-598. http://doi.org/10.1093/annonc/mdf082

Shun, S., Lai, Y., Jing, T., Jeng, C., Lee, F., Hu, L., \& Cheng, S. (2005). Fatigue patterns and correlates in male liver cancer patients receiving transcatheter hepatic arterial chemoembolization. Supportive Care in Cancer, 13(5), 311-7. http://doi.org/10.1007/s00520-004-0740-0 
Smets, E. M., Garssen, B., Bonke, B., \& de Haes, J. C. (1995). The Multi-Dimensional Fatigue Inventory (MFI): Psychometric qualities of an instrument to assess fatigue. Journal of Psychosomatic Research, 39(5), 315-325. http://doi. 10.1016/0022-3999(94)00125-O

Smets, E. M., Visser, M. R., Willems-Groot, F., Garssen, B., Oldenburger, F., van Tienhoven, G., \& de Haes, J. C. (1998). Fatigue and radiotherapy: Experience in patients undergoing treatment. British Journal of Cancer, 78(7), 899-906.

So, W. K. W., Dodgson, J., \& Tai, J. W. M. (2003). Fatigue and quality of life among Chinese patients with hematologic malignancy after bone marrow transplantation. Cancer Nursing, 26(3), 211-219. http://doi.org/10.1097/00002820-200306000-00006

Son, G. H., Chung, S., \& Kim, K. (2011). The adrenal peripheral clock: Glucocorticoid and the circadian timing system. Frontiers in Neuroendocrinology, 32(4), 451-65. http://doi.org/10.1016/j.yfrne.2011.07.003

Spielberger, C. (1983). Manual for the State-Trait Anxiety Inventory (Form Y). Palo Alto, CA: Consulting Psychologists Press.

Stanton, A. L., Danoff-burg, S., \& Huggins, M. E. (2002). The first year after breast cancer diagnosis: Hope and coping strategies as predictors of adjustment. Psycho-Oncology, 11(2), 93-102. http://doi.org/10.1002/pon.574

Stevens, J. (2009). Applied multivariate statistics for the social sciences (5th ed.). New York, NY; Routledge.

Stewart, D. E., Duff, S., Wong, F., Melancon, C., \& Cheung, A. M. (2001). The views of ovarian cancer survivors on its cause, prevention, and recurrence. Medscape Women's Health, 6(5), 5-5. http://www.ncbi.nlm.nih.gov/pubmed/11698927

Stiefel, F. C., Kornblith, A., \& Holland, J. C. (1990). Changes in the prescription patterns of 
psychotropic drugs for cancer patients during a 10-year period. Cancer, 65, 1048-1053. http://doi. 10.1002/1097-0142(19900215)65:4<1048::AID-CNCR2820650434>3.0.CO;2-N

Stone, P., Hardy, J., Huddart, R., A’Hern, R., \& Richards, M. (2000). Fatigue in patients with prostate cancer receiving hormone therapy. European Journal of Cancer, 36(9), 1134-1141. http://doi.org/10.1016/S0959-8049(00)00084-8

Stone, P., Richards, M., A'Hern, R., \& Hardy, J. (2001). Fatigue in patients with cancers of the breast or prostate undergoing radical radiotherapy. Journal of Pain and Symptom Management, 22(6), 1007-15. http://doi.org/Doi 10.1016/S0885-3924(01)00361-X

Sun, C. C., Bodurka, D. C., Weaver, C. B., Rasu, R., Wolf, J. K., Bevers, M. W., ... Rubenstein, E. B. (2005). Rankings and symptom assessments of side effects from chemotherapy: Insights from experienced patients with ovarian cancer. Supportive Care in Cancer, 13(4), 219-227. http://doi.org/10.1007/s00520-004-0710-6

Sura, W., Murphy, S., \& Gonzales, I. (2006). Level of fatigue in women receiving dose-dense versus standard chemotherapy for breast cancer: A pilot study. Oncology Nursing Forum, 33(5), 1015-1021. http://doi.org/10.1188/06.ONF.1015-1021

Tchekmedyian, N. S., Kallich, J., McDermott, A., Fayers, P., \& Erder, M. H. (2003). The relationship between psychologic distress and cancer-related fatigue. Cancer, 98(1), 198203. http://doi.org/10.1002/cncr.11463

Thompson, D. S., \& Shear, M. K. (1998). Psychiatric disorders and gynecological oncology: A review of the literature. General Hospital Psychiatry, 20(4), 241-247. http://doi.org/10.1016/S0163-8343(98)00030-9

Treharne, G. J., Lyons, a C., Hale, E. D., Goodchild, C. E., Booth, D. a, \& Kitas, G. D. (2008). Predictors of fatigue over 1 year among people with rheumatoid arthritis. Psychology, 
Health \& Medicine, 13(4), 494-504. http://doi.org/10.1080/13548500701796931

Trojan, D., Arnold, D., Collet, J.P., Shapiro, S., Bar-Or, A., Robinson, A., ... Da Costa, D. (2007). Fatigue in multiple sclerosis: Association with disease-related, behavioural and psychosocial factors. Multiple Sclerosis, 13(8), 985-995. http://doi.org/10.1177/1352458507077175

Van Elderen, T., Maes, S., Dusseldorp, E., van Elderen, T., Maes, S., \& Dusseldorp, E. (1999). Coping with coronary heart disease: A longitudinal study. Journal of Psychosomatic Research., 47(2), 175-183. http://doi. 10.1016/S0022-3999(99)00024-0

Visser, M. R., \& Smets, E. M. (1998). Fatigue, depression and quality of life in cancer patients: How are they related? Supportive Care in Cancer, 6(2), 101-8. http://doi.org/10.1007/s005200050142

Webster, K., Cella, D., \& Yost, K. (2003). The Functional Assessment of Chronic Illness Therapy (FACIT) measurement system: Properties, applications, and interpretation. Health and Quality of Life Outcomes, 1(1), 79. http://doi.org/10.1186/1477-7525-1-79

Weis, J. (2011). Cancer-related fatigue: Prevalence, assessment and treatment strategies. Expert Review of Pharmacoeconomics \& Outcomes Research, 11(4), 441-446. http://doi.org/doi:10.1586/erp.11.44

Wenzel, L. B., Fairclough, D. L., Brady, M. J., Cella, D., Garrett, K. M., Kluhsman, B. C., ... Marcus, A. C. (1999). Age-related differences in the quality of life of breast carcinoma patients after treatment. Cancer, 86(9), 1768-1774. http://doi.org/10.1002/(SICI)10970142(19991101)86:9<1768::AID-CNCR19>3.0.CO;2-O

Wratten, C., Kilmurray, J., Nash, S., Seldon, M., Hamilton, C. S., O’Brien, P. C., \& Denham, J. W. (2004). Fatigue during breast radiotherapy and its relationship to biological factors. 
International Journal of Radiation Oncology Biology Physics, 59(1), 160-167. http://doi.org/10.1016/j.ijrobp.2003.10.008

Yancey, A. K., Ortega, A. N., \& Kumanyika, S. K. (2006). Effective recruitment and retention of minority research participants. Annual Review of Public Health, 27(1), 1-28.

http://doi.org/10.1146/annurev.publhealth.27.021405.102113 